Yue-Xi Liu ${ }^{1,2}$, Bing-Yin Wang ${ }^{1,2}$, Jun-Jie Weng ${ }^{1}$, Dan $\mathrm{Yu}^{1}$, Sandra Richter ${ }^{3}$,

Thomas Kick ${ }^{3}$, Clemens Naumann ${ }^{3}$, Marina Braun-Unkhoff ${ }^{3}$, Zhen-Yu Tian ${ }^{1,2, *}$

\title{
A wide-range experimental and modeling study of oxidation and combustion of n-propylbenzene
}

Combustion and Flame, Volume 191, May 2018, pages 53-65

$<$ final revised text author version $>$

The original publication is available at www.elsevier.com

https://doi.org/10.1016/j.combustflame.2017.12.029

(C) <year $>$. This manuscript version is made available under the CC-BY-NC-ND

4.0 license http://creativecommons.org/licenses/by-nc-nd/4.0/ 


\section{A wide-range experimental and modeling study of oxidation and combustion of n-propylbenzene}

Yue-Xi Liu ${ }^{1,2}$, Bing-Yin Wang ${ }^{1,2}$, Jun-Jie Weng ${ }^{1}$, Dan $\mathrm{Yu}^{1}$, Sandra Richter ${ }^{3}$, Thomas Kick ${ }^{3}$, Clemens Naumann $^{3}$, Marina Braun-Unkhoff ${ }^{3}$, Zhen-Yu Tian $^{1,2, *}$

${ }^{1}$ Institute of Engineering Thermophysics, Chinese Academy of Sciences, Beisihuanxi 11, Beijing 100190, China

${ }^{2}$ University of Chinese Academy of Sciences, 19A Yuquan Rd., Beijing 100049, China

${ }^{3}$ Institute of Combustion Technology, German Aerospace Center (DLR), 70569 Stuttgart, Germany 
Abstract: The oxidation of n-propylbenzene (NPB) was studied in a jet-stirred reactor (JSR) equipped with online GC and GC-MS for temperatures ranging between 700-1100 K, at $\varphi=0.4-2.0$. In addition, laminar flame speeds were measured at $p=1,3$ and 6 bar at a preheat temperature of $T=473 \mathrm{~K}$, and ignition delay times in a shock tube device behind reflected shock waves, for stoichiometric mixtures at around $p=16$ bar. Mole fraction profiles of 25 intermediates including six species, namely 1-propenylbenzene, 2-propenylbenzene, $\alpha$ methylstyrene, naphthalene, indene, and benzofuran were observed additionally. With $\varphi$ increasing, NPB consumption shifts to higher temperatures, and the reaction temperature zone becomes broader. Based on the experimental measurements and on new calculations of the rate constants for the $\mathrm{H}$-abstractions from NPB with $\mathrm{OH}$, an updated kinetic model involving 292 species and 1919 reactions was developed with a reasonable agreement with the measured species profiles, flame speed values, and ignition delay times. Rate of production analysis reveals that NPB consumption is generally governed by $\mathrm{C}-\mathrm{H}$ bond cleavage to form

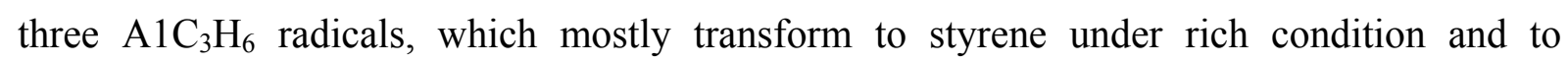
benzaldehyde under lean condition. Compared to the aromatics formed in the oxidation of two other aromatic C9 fuels, 1,3,5-trimethylbenzene and 1,2,4-trimethylbenzene, NPB exhibits to be the most reactive fuel with the least aldehyde intermediates. Moreover, the present model gives a reasonable agreement with the literature-reported ignition delay times and JSR data. These results can improve the understanding of the oxidation and combustion of NPB as a surrogate fuel constituent for kerosene and diesel.

Keywords: n-Propylbenzene; Jet-stirred reactor; Oxidation; Combustion; Modeling; Laminar flame speed; Ignition delay times; Soot precursor. 


\section{Introduction}

In the past decades, the aviation industry experienced a rapid growth in both civilian and military areas. More and more attention has been paid to the combustion studies of aviation fuels, as the energy source of aircrafts, with respect to high efficiency and low pollutant emissions. Zheng et al. [1] identified the molecular class compositions of RP-3 aviation kerosene by gas chromatography-mass spectrometer (GC-MS) analysis as alkanes (53.0\%), naphthenes (37.7\%), aromatics (4.6\%), and other minor species. Compositions of Jet-A POSF 4658 identified by Widegren et al. [2] applying GC-MS were alkanes (68.2\%), aromatics (25.5\%), naphthalenes (3.0\%) and cycloalkanes (3.3\%). Therefore, alkanes, cycloalkanes, and aromatics are the major components of all the aviation fuels certified today [3-5]. Due to the hundreds of components in aviation fuels, surrogate fuels have been commonly used to study the combustion of aviation fuels and make the modeling feasible.

NPB has been considered as an important component of surrogate model fuels in kerosene studies: NPB can yield more light hydrocarbons (e.g. methane, ethylene, and propene) and aromatics compared to other 1-ring aromatics, such as toluene, ethylbenzene, and xylene, with the advantage of a chemistry less complicated compared to the oxidation of butylbenzene resulting in much more isomers than NPB. For example, Dagaut et al. [6] used $74 \%$ n-decane and $26 \%$ NPB as surrogate model fuel of kerosene. For these reasons, it is worth investigating the oxidation of NPB in order to better understand the underlying mechanism process in NPB combustion.

The focus of most previous studies on NPB was put on species profiles, burning velocities (flame), and ignition (shock tube). In 2005, Johnston et al. [7] studied the laminar burning velocities of NPB in a stainless steel vessel at $450 \mathrm{~K}$ and $304 \mathrm{kPa}$ for equivalence ratios of 0.8 to 1.4 . The study of NPB laminar flame speeds with both experiments and model was reported by Hui et al. [8, 9] ( $\varphi=0.7-1.4,400$ and $450 \mathrm{~K}, p=1 \mathrm{~atm})$; they also considered the influence of temperature and pressure $(\varphi=0.7-1.3,350-470 \mathrm{~K} ; p=1-3 \mathrm{~atm})$. In recent 
years, Ji et al. [10] and Mehl et al. [11] studied the laminar flame speed of NPB at atmospheric pressure, in a wide range of equivalence ratios. Studies of ignition delay times of NPB were first reported by Roubaud et al. [12] (600-900 K, $\varphi=1.0,24.7 \mathrm{~atm})$, and later on by Darcy et al. [13-15] ( $\varphi=0.29-1.92,1$ to 50 atm, 800-1600 K). Gudiyella et al. [16, 17] applied the shock tube technique to study mole fraction profiles by using standard GCtechniques during NPB oxidation and pyrolysis $(\varphi=0.5-1.9,838-1678 \mathrm{~K}, 25$ and $50 \mathrm{~atm})$. Anderson et al. [18] reported on mole fraction profiles obtained by mass spectrometer when studying a non-premixed laminar flame of NPB doped with methane. Wang et al. [19] discussed the mole fraction profiles of reactants, intermediates and products measured in a fuel-rich $(\varphi=1.79)$ premixed low-pressure laminar flame of NPB by using synchrotron VUV photoionization mass spectrometry [20, 21].

The oxidation data of mole fraction profiles of NPB are quite limited. Dagaut et al. [22] studied the oxidation of NPB in a JSR within 900-1250 K, 1 atm, and at variable equivalence ratios $(0.5 \leq \varphi \leq 1.5)$. Mole fractions of 23 species were measured with GC. They proposed a comprehensive model to reproduce the experimental data. However, many aromatic species (soot precursors) were not measured. Thus, an investigation of the oxidation of NPB is desirable to reveal the reaction pathways and, moreover, to improve the NPB reaction model. This work aims to identify and quantify intermediates and products of NPB oxidation as well as to measure its burning velocities and ignition delay times. Based on the experimental data set, the second goal is to develop a comprehensive reaction model involving the aromatic species newly detected in the present work. Rate of production (ROP) and sensitivity analyses were performed to identify the consumption pathways of NPB and the key reactions. Furthermore, the comparison of the oxidation of three C9 isomers, namely 1,3,5trimethylbenzene (135TMB), 1,2,4-trimethylbenzene (124TMB) and NPB, was presented to reveal the differences among the major intermediates and consumption pathways. The updated mechanism will improve the understanding of the combustion characteristics of 
diesel and jet fuels, in particular with respect to the formation of soot precursors and aldehydes, pollutants being of pivotal role for local air quality.

\section{Experiments}

\subsection{Oxidation}

The experiments were carried out in a home-made JSR. The details of the setup and procedure can be found in our recent work [23, 24], and only a brief description is given here. The JSR was equipped with online GC (7890B, Agilent) and GC-MS (7890B-5977A, Agilent) for gas analysis. The inlet concentration of NPB is $1.0 \%$ and the equivalence ratios $(\varphi)$ are from 0.4 over 1.0 to 2.0, as shown in Table S1 in the Supplemental Material (SM). Compared to the previously reported JSR work by Dagaut et al. [22] $(0.1 \%$ NPB, $\varphi=0.5-$ 1.5), a higher concentration of NPB and a wider range of equivalence ratios were used in the present work in order to produce observable higher concentrations of intermediates. An estimate of the heat release is added in Section 1 of SM.

The flow rates of $\mathrm{O}_{2}$ and $\mathrm{Ar}$ were regulated by MKS mass-flow controllers. The fuel was injected into a vaporization tank by a high-pressure infusion pump (FL2200, Fuli), then vaporized at $473 \mathrm{~K}$ and carried out by $450 \mathrm{sccm}$ gas flow of Ar. All the tubes were kept at 473 $\mathrm{K}$ by heating belts before entering JSR to minimize temperature gradients and after JSR to avoid condensation. The temperature range was $700-1100 \mathrm{~K}$ in the present work. The temperature ramp was $25 \mathrm{~K}$ between the data points. The temperature of JSR was controlled by a heating controller (HT60, Horst). The reaction temperature was measured by a K-type thermocouple located at the center of the sphere.

The GC and GC-MS techniques were used to quantify and qualify the products and intermediates. TCD was used to analyze $\mathrm{H}_{2}, \mathrm{CO}, \mathrm{CO}_{2}$ and $\mathrm{CH}_{4}$. The quantification of light hydrocarbons and aromatics was performed by FID with chromatographic columns of $\mathrm{Al}_{2} \mathrm{O}_{3}$ $\mathrm{KCl}$ and HP-INNOWax, respectively. The calibration was carried out by injecting known 
amounts of the standard gases. The newly detected intermediates without standard gas (e.g. $\mathrm{A} 1 \mathrm{C}_{3} \mathrm{H}_{5}$ ) were quantified by using the effective carbon number method. The detection threshold of GC was about $0.1 \mathrm{ppm}$ for FID and $10.0 \mathrm{ppm}$ for TCD. The estimated uncertainty was about $\pm 5 \%$ for major species and $\pm 15 \%$ for intermediates. The experimental conditions and detailed analysis of methods are given in Section 2 in SM, followed by the original measured data (Table S2-S7) in Section 3.

\subsection{Laminar burning velocity}

Values of the laminar burning velocity $\left(S_{\mathrm{u}}\right)$ were determined at a preheat temperature of $T=473 \mathrm{~K}$, at pressures of 1,3 , and 6 bar within a wide range of $\varphi$ by applying the cone angle method $[25,26]$. According to Fig. $1, S_{\mathrm{u}}$ is calculated from the cone angle $\alpha$ of the flame and the velocity $\left(v_{\mathrm{u}}\right)$ of the unburned gas: $S_{\mathrm{u}}=v_{\mathrm{u}} \cdot \sin \alpha$. For the determination of the cone angle, premixed conical-shaped flames have been stabilized above a flame holder by the use of a coflow, either air for rich flames $(\varphi \geq 1.0)$ or a mixture of $5 \% \mathrm{CH}_{4}, 5 \% \mathrm{H}_{2}$ and $90 \% \mathrm{~N}_{2}$ for lean flames $(\varphi \leq 1.0)$. The used burner has been described in previous studies [27-30]. The fuel was first vaporized at temperatures between $473 \mathrm{~K}$ and $560 \mathrm{~K}$ (depending on pressure), then mixed with a preheated $\mathrm{N}_{2}$-stream (Linde, $99.999 \%$ ), and adjusted to the setting temperature of $473 \mathrm{~K}$. Finally, $\mathrm{O}_{2}$ (Linde, $99.95 \%$ ) was added so that the ratio between $\mathrm{N}_{2}$ and $\mathrm{O}_{2}$ matches their amounts in air $\left(\mathrm{N}_{2}: \mathrm{O}_{2}=79: 21\right)$. The liquid flow rate of NPB was controlled by a HPLC-pump (LC-20AD, Shimadzu) and the gas flows of $\mathrm{N}_{2}$ and $\mathrm{O}_{2}$ by mass flow controllers (F-111B, Bronkhorst). The cone angle detection was performed by recording pictures with a CCD-camera (Imager Intense, LaVision). 


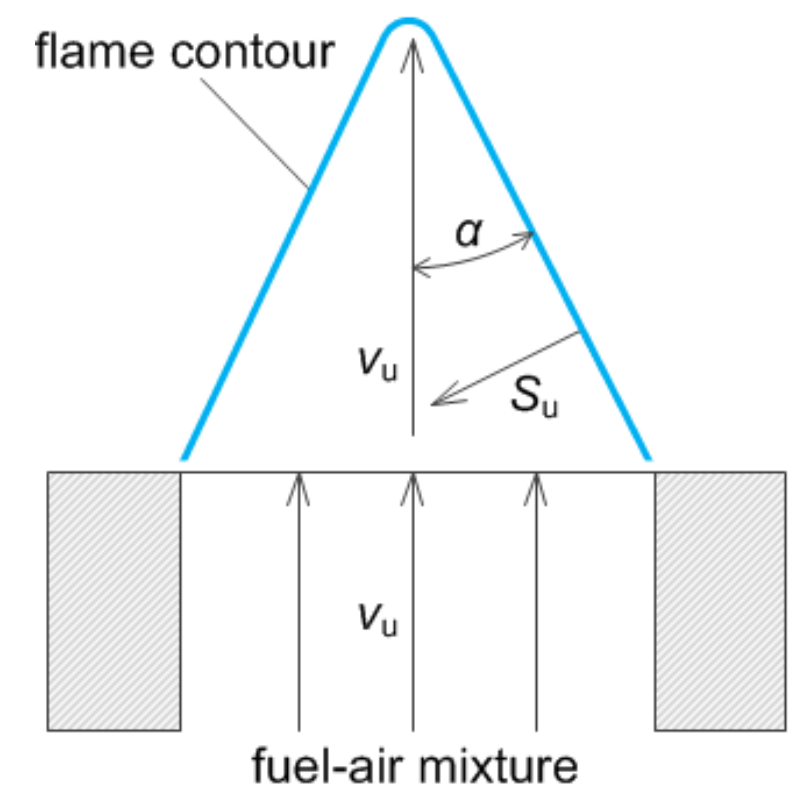

Fig. 1 Determination of the laminar burning velocity $\left(S_{\mathrm{u}}\right)$ using the cone angle method $(\alpha-$ cone angle, $v_{\mathrm{u}}$ - velocity of the unburned gas)

\subsection{Ignition delay time}

Ignition delay times have been measured in a high pressure shock tube with an internal diameter of $46 \mathrm{~mm}$, a driver section of about $10 \mathrm{~m}$ and a driven section of $3.25 \mathrm{~m}$ in length [31]. The driven section was heated to $433 \mathrm{~K}$. He/Ar mixtures were used to achieve tailored interface conditions. The gas mixtures were prepared for each experiment by injecting the liquid NPB with a syringe. Preheated $\mathrm{N}_{2}$ and synthetic air $\left(80 \% \mathrm{~N}_{2}, 20 \% \mathrm{O}_{2}\right)$ were added thereafter to adjusting $\varphi$ and the selected dilution of 1:2. After stirring the ingredients for 10 min, the NPB-air- $\mathrm{N}_{2}$ mixture was filled into the shock tube. The incident shock speed was measured over three $30 \mathrm{~mm}$ intervals using four piezo-electric pressure transducers. The temperature and pressure behind the reflected shock wave were computed from the measured incident shock speed and the attenuation using a one-dimensional shock model.

The ignition was observed by measuring pressure profiles with piezo-electric gauges coated with a thin layer of RTV116 high temperature silicone rubber located at a distance of 1 $\mathrm{cm}$ away from the end plate. In addition, the $\mathrm{CH}^{*}$-emission at $431 \mathrm{~nm}$, at the same position and through the end flange as well, was selected by a narrow band pass filters (FWHM $=5$ $\mathrm{nm}$ ) and measured with a photo-multiplier in combination with a logarithmic amplifier. All 
ignition delay time values as measured within the present work were determined by measuring the time difference between the initiation of the system by the reflected shock wave at the end plate and the occurrence of the maximum of the $\mathrm{CH}^{*}$-signal at the side on measurement port $1 \mathrm{~cm}$ away from the end plate taking the blast wave propagation into account.

The experimental setup allows measurements of ignition delay times up to $10 \mathrm{~ms}$ depending on temperature. Post-shock compression effects mainly due to the interaction of incident gas with the attenuated reflected shock wave introduce a time dependent pressure increase $p=p(\mathrm{t})$ with a maximum compression of $p_{5} / p_{5}(\mathrm{t}=0) \approx 1.2$ at about $10 \mathrm{~ms}$; this results in a temperature increase $T=T(\mathrm{t})$ and thus, in an acceleration of the reactive system towards ignition.

\section{Modeling}

The oxidation experiments were simulated using the PSR code in the CHEMKIN-II software [32], while SENKIN code was used to predict ignition delay times. According to the experimental definition of ignition delay time provided in section 2.3 , the occurrence of the maximum $\mathrm{CH}$ concentration was used to derive ignition delay time from modeling. The complete mechanism composed of 292 species and 1919 reactions is available in SM. The reactions related to NPB and its derived species are listed in Table S8 (see SM). Simulations of the laminar flame speed were performed with the open-source software Cantera [33] using the free flame model and by considering the multi-component diffusion model and thermodiffusion. Thermochemical and transport data were based on [34-36]. Mesh points were refined to achieve equal solution tolerance; the refine criteria "slope" and "curve" were set to 0.2 leading to about 120 mesh points. The reaction mechanism developed was coupled with our recent mechanism which has been developed for the oxidation of acetylene [23]. 
As Dagaut et al. had established a detailed mechanism for oxidation of NPB [22], and with their mechanism yielding a general agreement between the predicted and measured data of NPB in this work (TW), their sub-mechanism was employed in the present work. The thermochemical data of most species derived from NPB were obtained from Wang et al. [19]. The sensitivity analysis of Dagaut's model under the experimental conditions of the present work revealed that the $\mathrm{H}$-abstractions from $\mathrm{NPB}$ with $\mathrm{OH}$ were the most sensitive fuel consumption reactions, with their rate constants estimated previously. Hence, these reactions need to be re-visited, to get more precise rate constant. In this work, ab initio calculation was performed at the CBS-QB3 level [37] implemented in Gaussian 09 and then the CHEMRATE software was used to calculate the rate coefficient "k" of R1802 (NPB + OH $=$ $\mathrm{A}_{1} \mathrm{CH}_{2} \mathrm{CH}_{2} \mathrm{CH}_{2}+\mathrm{H}_{2} \mathrm{O}$ ). The calculated results and the comparisons among the current work and previous data are shown in Figs. S4-S6.

According to Dagaut's mechanism [22], the initiations of NPB (see Table S8) give rise to three $\mathrm{C}_{9} \mathrm{H}_{11}$ radicals, which then decompose directly to benzyl, toluene, styrene or benzaldehyde, respectively. The $\mathrm{H}$-abstraction reactions $\left(\mathrm{NPB}+\mathrm{R} / \mathrm{O} / \mathrm{OH} / \mathrm{HO}_{2}=\mathrm{A}_{1} \mathrm{C}_{3} \mathrm{H}_{6}+\right.$ $\mathrm{RH} / \mathrm{OH} / \mathrm{H}_{2} \mathrm{O} / \mathrm{H}_{2} \mathrm{O}_{2}$ ) were assumed to be the major consumption pathway of NPB since the activation energy barriers of the unimolecular reactions are much larger than those of the $\mathrm{H}$ abstraction reactions in their model. It is reasonable to believe that $\mathrm{A}_{1} \mathrm{C}_{3} \mathrm{H}_{6}$ radicals will generate allyl benzenes $\left(\mathrm{A}_{1} \mathrm{C}_{3} \mathrm{H}_{5}\right)$ through $\mathrm{H}$-abstraction, which had not been considered in Dagaut's model. In 2013, Wang et al. [19] considered the destruction mechanism from

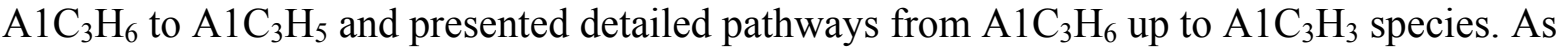
this model exhibits a general agreement with the profiles of allyl benzenes measured in the

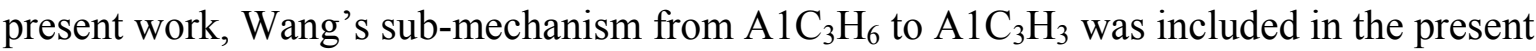
model.

The $\mathrm{H}$-abstraction reaction rate coefficients with $\mathrm{O}_{2}$ were estimated from the mechanism of propane. As there are several new studies updated $\mathrm{H}$-abstraction reaction rate coefficients 
of propane, the coefficients in present work were also been changed [30, 38, 39]. As heavy aromatic species such as indene and bibenzyl have been detected, the production pathways should be considered in the present work. Reactions of indene (R595, R596, R597, R601, and R1906) are taken from the model proposed by Tian et al. as they predicted the mole fraction of indene well in their study [40]. Especially, R1906 shows the relationship between indene and propenylbenzene. The bibenzyl reaction (R864) is from the mechanism developed by Dagaut et al. [22] to replace the previous one which was estimated. The species names and their corresponding structures are shown in Table S9 (see SM).

\section{Results and discussion}

By using GC and GC-MS, 24 intermediates and products including light hydrocarbons, oxygenated and aromatic species were detected and quantified. Compared to the early study [22], naphthalene, benzofuran, indene, and three allyl benzenes $\left(\mathrm{A}_{1} \mathrm{C}_{3} \mathrm{H}_{5}\right)$ were additionally observed in the oxidation of NPB. To study the combustion characteristics of NPB, laminar burning velocities and ignition delay times were also measured. A detailed kinetic model was established to better understand NPB oxidation using a wide range of further validation, and compared with Dagaut's and Wang's models on the simulation of major species. The measured shock tube data by Darcy et al. [14] and the oxidation experimental data by Dagaut et al. [22] were compared with the predictions obtained by the present model. Furthermore, the comparison between the oxidation results of NPB isomers, 1,3,5-trimethylbenzene (135TMB) [41] and 1,2,4-trimethylbenzene (124TMB) [24] were performed, in order to find a suitable fuel with higher energy density (enthalpy of combustion at $273 \mathrm{~K}:-5264.48 \mathrm{~kJ} / \mathrm{mol}$ ) and lower pollutant emissions which can be potentially applied as a surrogate fuel component of kerosene.

\subsection{Major species}


Figure 2 displays the mole fraction profiles of $\mathrm{NPB}, \mathrm{CO}, \mathrm{CO}_{2}$ and $\mathrm{H}_{2}$. In general, the current model captures the conversion of NPB and the generation of the three major products well. The equivalence ratio has a strong effect on the onset temperature and the reaction zone. At $\varphi$ $=2.0, \mathrm{NPB}$ starts to be oxidized at $800 \mathrm{~K}$, and the complete consumption was achieved at temperatures higher than $1000 \mathrm{~K}$. The onset temperature is shifted downwards to $775 \mathrm{~K}$, and the reaction zone is shortened (by about $25 \mathrm{~K}$ ) at $\varphi=1.0$. These values change to $750 \mathrm{~K}$ and $50 \mathrm{~K}$ at $\varphi=0.4$. Compared to the results of Dagaut et al. $(0.1 \% \mathrm{NPB})$ [22], the onset temperatures of NPB in this work are shifted slightly to lower temperature. CO exhibits peakshaped profiles at the lean and stoichiometric conditions, while it is a major product at $\varphi=$ 2.0. The present model reproduces the mole fraction profiles of $\mathrm{CO}$ well except an overprediction under lean condition, which is mainly caused by the overprediction of $\mathrm{CH}_{3}$ as the major precursor of $\mathrm{CO}$. According to rate-of-production (ROP) analysis, most of the $\mathrm{CH}_{3}$ is formed from the decomposition of $\mathrm{A}_{1} \mathrm{CHCH}_{2} \mathrm{CH}_{3}$ radicals yielding styrene followed by decomposition to A1CO and methyl. These pathways generate large amounts of methyl radical and increase the rate of the production of $\mathrm{CO} . \mathrm{CO}_{2}$ is another major product with satisfactory prediction for the three equivalence ratios conditions. The final production of $\mathrm{CO}_{2}$ is increased as $\varphi$ decreased as more oxygen was involved and more $\mathrm{CO}$ oxidized to $\mathrm{CO}_{2} . \mathrm{H}_{2}$ was mainly detected in rich conditions and rarely observed at $\varphi=1.0$ and 0.4 , respectively. In addition, comparisons among the current and previous simulated data on major species were performed and shown in Section 7 (see SM). In summary, the present model gives reasonable predictions on the major species at all the investigated conditions. 

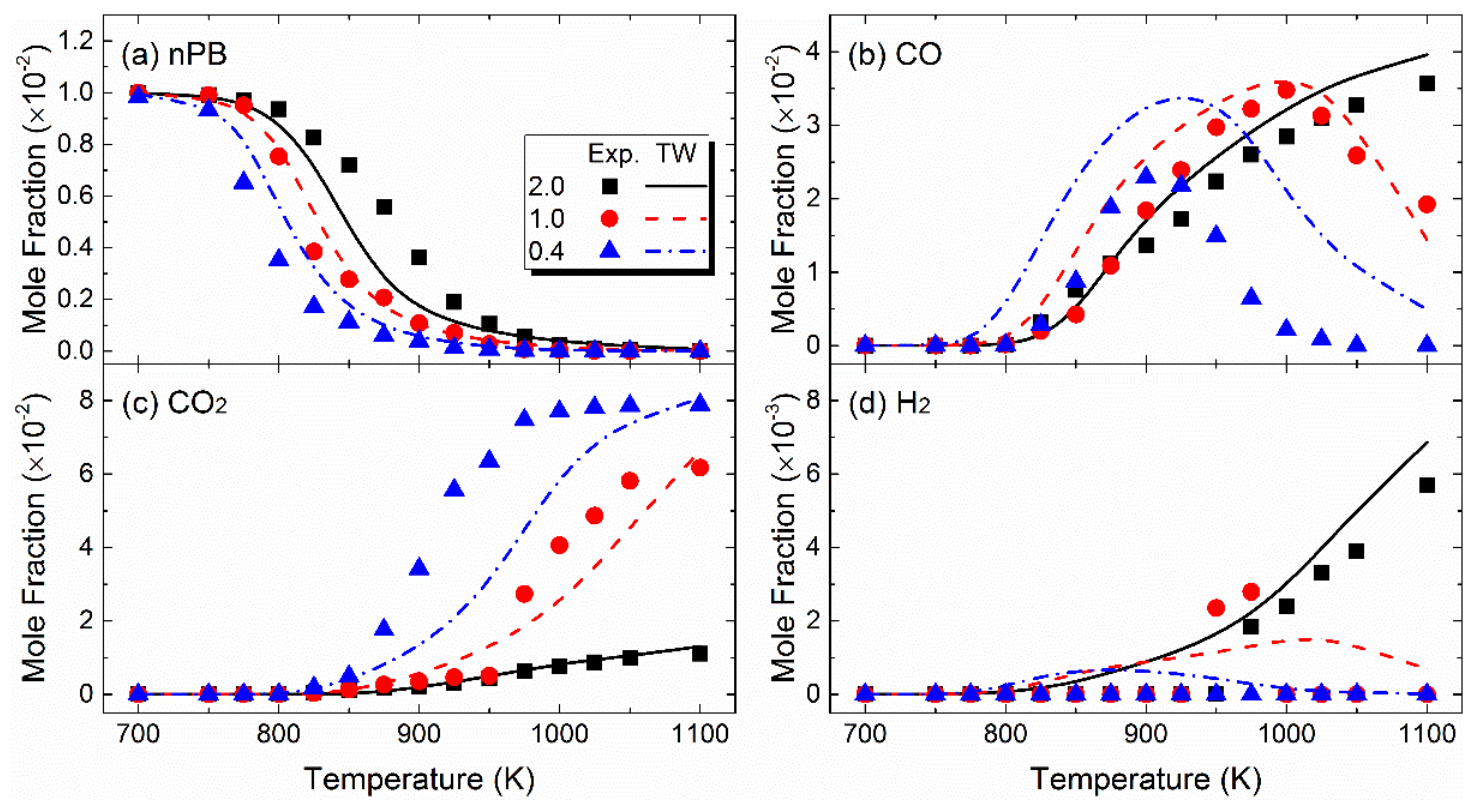

Fig. 2 Comparison between the measured (symbols) and modeling results (curves) of NPB (a), $\mathrm{CO}$ (b), $\mathrm{CO}_{2}$ (c) and $\mathrm{H}_{2}$ (d) using the reaction model of the present work (TW): Experimental data $-\varphi=2.0$-square, 1.0-circle and 0.4-triangle; modeling results - 2.0-solid, 1.0-dash and 0.4-dash dotted.

\subsection{Intermediates}

In the current work, 21 intermediates were detected and the mole fraction profiles are presented in Figs. 3-5. Figure 3 depicts the experimental and modeling results of the light hydrocarbons whose peak values and temperatures decrease from rich to lean condition. In general, the simulated results have good agreements with experimental measurements, especially on tendencies, peak temperatures, and peak values. $\mathrm{CH}_{4}$ and $\mathrm{C}_{2} \mathrm{H}_{4}$ have very good predictions under three equivalence ratios. Their concentrations decrease when the equivalence ratio is reduced. The predicted profiles of $\mathrm{C}_{2} \mathrm{H}_{2}$ match the measured data within the uncertainty at $\varphi=1.0$ and 0.4 , while the current model tends to underpredict the values at $\varphi=2.0$. According to the ROP analysis, phenoxy radical (A1CO) is the major precursor of $\mathrm{C}_{2} \mathrm{H}_{2}$ and appeared in almost all the formation channels of $\mathrm{C}_{2} \mathrm{H}_{2}$; therefore, its low concentration in rich condition led to the underprediction of acetylene. The ROP analysis shows that $\mathrm{C}_{2} \mathrm{H}_{6}$ was mostly produced by the combination of methyl radicals: $\mathrm{CH}_{3}+\mathrm{CH}_{3}$ $(+\mathrm{M})=\mathrm{C}_{2} \mathrm{H}_{6}(+\mathrm{M}) . \mathrm{C}_{2} \mathrm{H}_{6}$ was commonly overpredicted by the large concentration of $\mathrm{CH}_{3}$. 
Propene $\left(\mathrm{C}_{3} \mathrm{H}_{6}\right)$ was underpredicted and mainly produced by the substitution reaction:

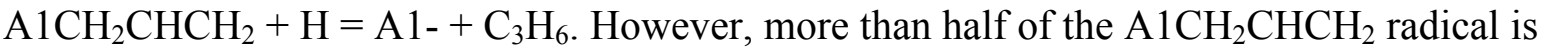
consumed by $\mathrm{H}$-abstraction and thus, yielding benzaldehyde. Less than about one fifth of the radical reacted with $\mathrm{H}$-atom through the substitution reaction mentioned above, which favored the underprediction of $\mathrm{C}_{3} \mathrm{H}_{6} .1,3-$-Cyclopentadiene (CPD) was also detected in the present work, and its peak value decreased as the equivalence ratio decreased. CPD is also produced from the phenoxy radical, and converted to $\mathrm{C}_{5} \mathrm{H}_{5}$ and further on, converted to benzene or decomposed to $\mathrm{C}_{1}-\mathrm{C}_{4}$ species (e.g. $\mathrm{HO}_{2}+\mathrm{C}_{5} \mathrm{H}_{5}=\mathrm{CH}_{4}+\mathrm{CO}_{2}+\mathrm{C}_{3} \mathrm{H}_{2}$ ). In general, the simulated results have good agreements with the experimental data.

Figure 4 depicts the mole fraction profiles of the oxygenated intermediates including $\mathrm{CH}_{3} \mathrm{CHO}, \mathrm{C}_{3} \mathrm{H}_{4} \mathrm{O}$, phenol, benzaldehyde, benzofuran, and formaldehyde. These species are strongly influenced by the inlet concentration of $\mathrm{O}_{2}$ : their peak values increased while the peak temperatures decreased when more $\mathrm{O}_{2}$ was introduced. $\mathrm{CH}_{3} \mathrm{CHO}$ was overpredicted and $\mathrm{C}_{3} \mathrm{H}_{4} \mathrm{O}$ was underpredicted, but the peak temperatures were predicted well. The ROP analysis reveals that $\mathrm{C}_{2} \mathrm{H}_{6}$, which was overpredicted by the current model, is a key precursor of $\mathrm{CH}_{3} \mathrm{CHO}$ leading to its overprediction, too. $\mathrm{C}_{3} \mathrm{H}_{4} \mathrm{O}$ was produced mainly through the following pathways: $\mathrm{C}_{3} \mathrm{H}_{6}(51.48 \%$ in rich condition and 

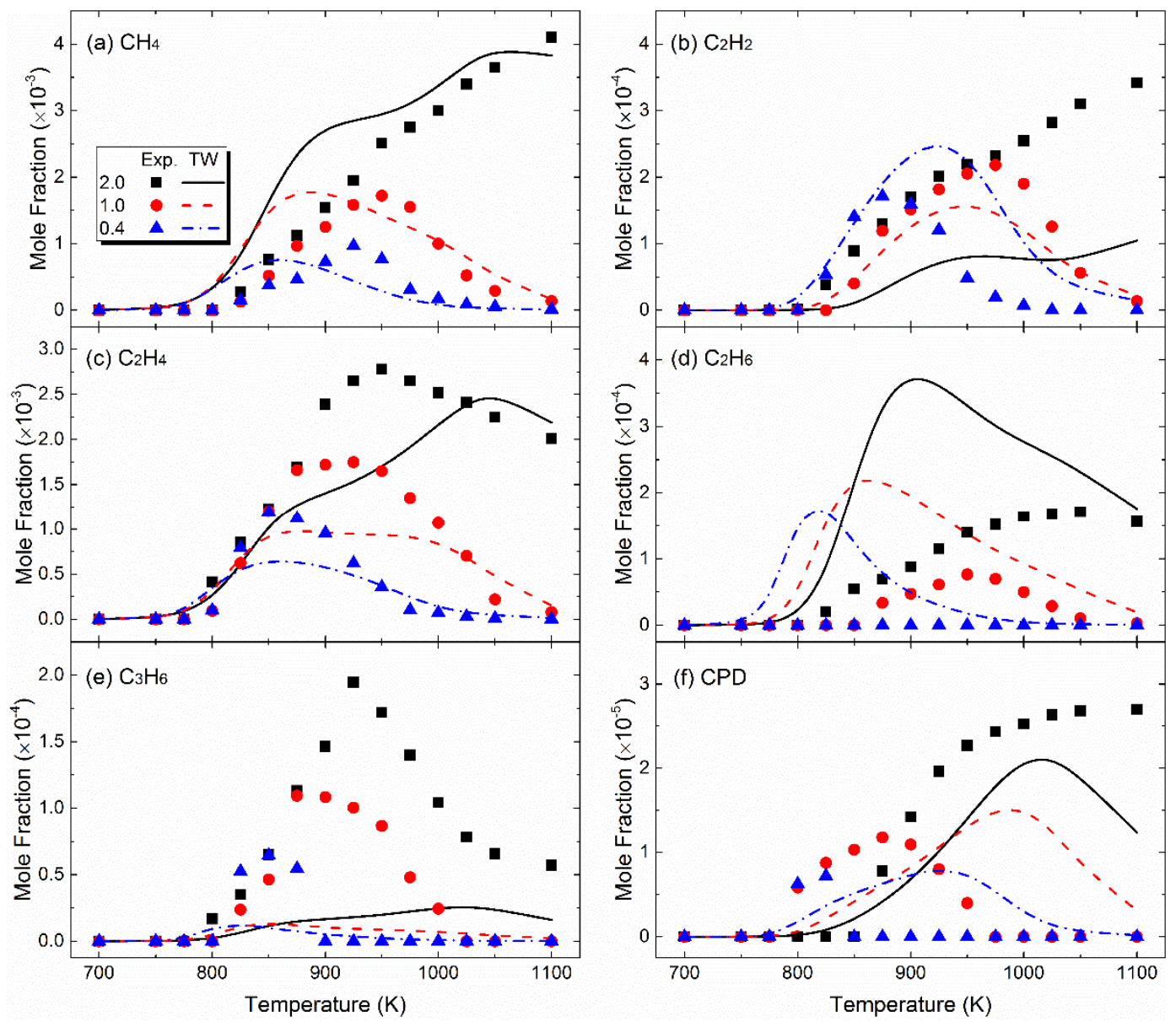

Fig. 3 Comparison between the measured (symbols) and modeling results (curves) of $\mathrm{CH}_{4}(\mathrm{a})$, $\mathrm{C}_{2} \mathrm{H}_{2}$ (b), $\mathrm{C}_{2} \mathrm{H}_{4}$ (c), $\mathrm{C}_{2} \mathrm{H}_{6}$ (d), $\mathrm{C}_{3} \mathrm{H}_{6}$ (e) and CPD (f) using the reaction model of the present work (TW): Experimental data $-\varphi=2.0$-square, 1.0-circle, and 0.4-triangle; modeling results - 2.0-solid, 1.0-dash and 0.4-dash dotted. 

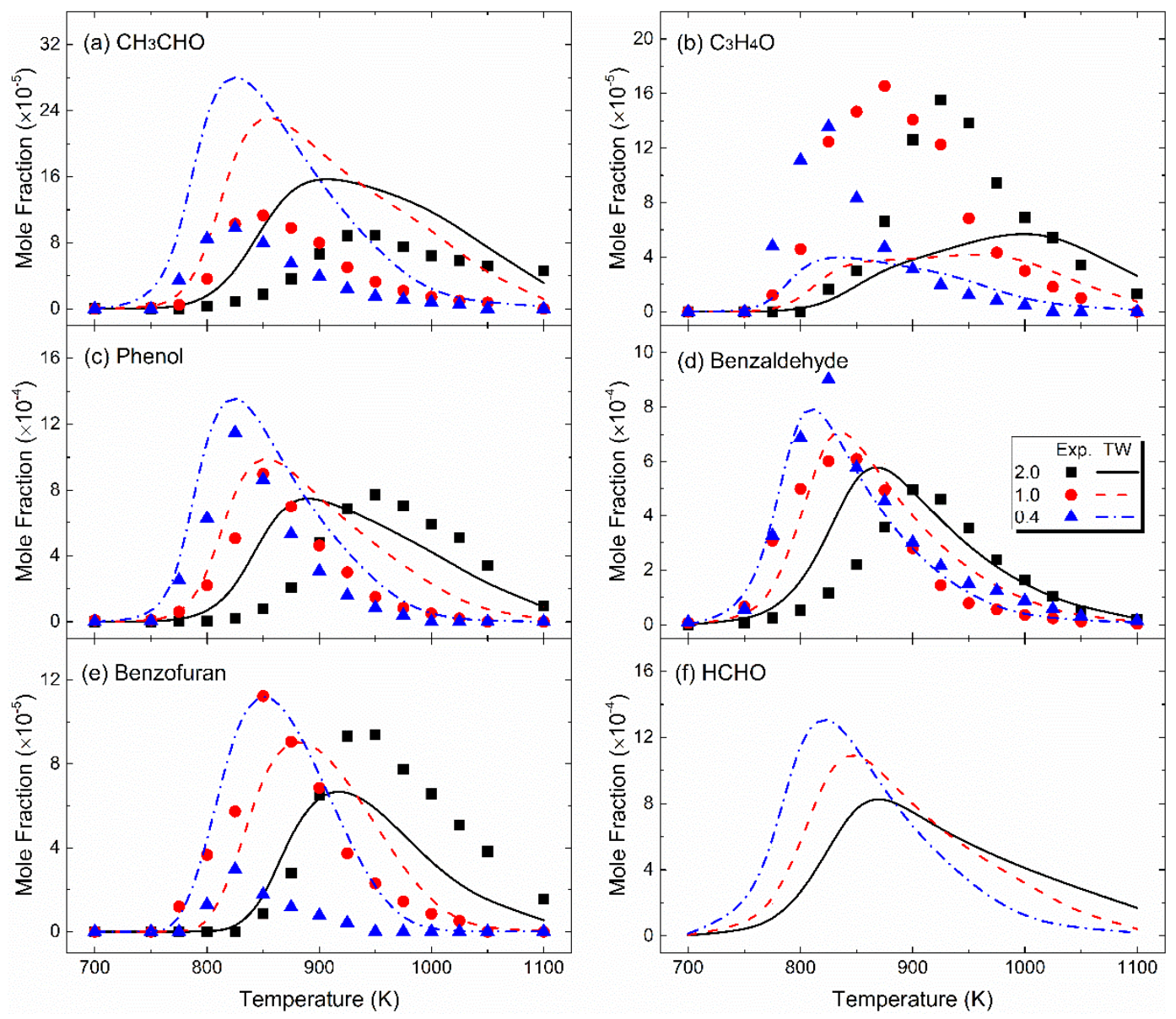

Fig. 4 Comparison between the measured (symbols) and modeling results (curves) of $\mathrm{CH}_{3} \mathrm{CHO}(\mathrm{a}), \mathrm{C}_{3} \mathrm{H}_{4} \mathrm{O}$ (b), phenol (c), benzaldehyde (d), benzofuran (e) and formaldehyde (f) using the reaction model of the present work (TW): Experimental data $-\varphi=2.0$-square, 1.0 circle, and 0.4-triangle; modeling results - 2.0-solid, 1.0-dash and 0.4-dash dotted.

$46.54 \%$ in lean condition, respectively) or $\mathrm{A}_{1} \mathrm{C}_{3} \mathrm{H}_{6}(27.6 \%$ in rich condition and $34.39 \%$ in lean condition, respectively) $\rightarrow \mathrm{aC}_{3} \mathrm{H}_{5} \rightarrow \mathrm{C}_{3} \mathrm{H}_{5} \mathrm{O} \rightarrow \mathrm{C}_{3} \mathrm{H}_{4} \mathrm{O}$; the lower curves in Fig. 4 (b) result by the underprediction of $\mathrm{C}_{3} \mathrm{H}_{6}$. The two oxygenated aromatics, phenol and benzaldehyde, show good agreements between the experimental and simulated results. Their peak values are 800 and $600 \mathrm{ppm}$, respectively, at $875 \mathrm{~K}$ at $\varphi=2.0$ and became higher when the equivalence ratio declined. Under rich condition, the peak value of phenol is slightly larger than that of benzaldehyde and twice as large under lean condition. The ROP analysis indicated that $34.8 \%$ benzaldehyde is transformed to phenol through the reaction sequence: $\mathrm{A} 1 \mathrm{CHO} \rightarrow \mathrm{A} 1 \mathrm{CO} \rightarrow \mathrm{A} 1-\rightarrow \mathrm{A} 1 \mathrm{O} \rightarrow \mathrm{A} 1 \mathrm{OH}$ in rich condition and $60.3 \%$ at $\varphi=0.4$ respectively. Benzofuran is another oxygenated aromatics being one of the newly observed 
species in the oxidation of NPB, with the biggest concentration of $70 \mathrm{ppm}$ at $925 \mathrm{~K}$ in rich condition. It is mainly formed by the combination of $\mathrm{A} 1 \mathrm{O}$ and $\mathrm{C}_{2} \mathrm{H}_{2}$ and can be regarded as a product of benzaldehyde. In addition, HCHO is an important intermediate in the oxidation process. The chromatographic peak of $\mathrm{HCHO}$ cannot be distinguished from other intermediates' peaks observed in the present work, as caused by the limitation of the chromatographic column. Figure 4 (f) shows the simulated results of HCHO. Similar to the other oxidized intermediates discussed above, $\mathrm{HCHO}$ generates more and consumes faster under lean conditions. According to ROP analysis, $\mathrm{HCHO}$ consumes to $\mathrm{HCO}$ in all conditions through the same pathways. At lean conditions, $\mathrm{HCHO}$ is mostly generated via the $\mathrm{H}-$ abstraction of $\mathrm{CH} 3 \mathrm{O}$. The main formation pathway will change to: $\mathrm{CH}_{3}+\mathrm{O}_{2}=\mathrm{HCHO}+\mathrm{OH}$ at rich conditions, due to the much less generation of $\mathrm{CH}_{3} \mathrm{O}$.

Figure 5 displays the measured and predicted profiles of aromatic species. In general, both the peaks and the tendencies predicted with the present model exhibit good agreements with experimental results. Most peak values decreased as $\varphi$ increased, besides those of three allyl benzenes. The peaks appear in the temperature range of about $850 \mathrm{~K}$ to $900 \mathrm{~K}$ for $\varphi=$ 2.0, while benzene's peak appear at $T=1050 \mathrm{~K}$. Benzene and styrene are believed to be the main aromatic intermediates in this experiment as their peak values are nearly ten times larger than those of toluene and ethylbenzene. Benzene was formed by two main pathways: NPB $\rightarrow$

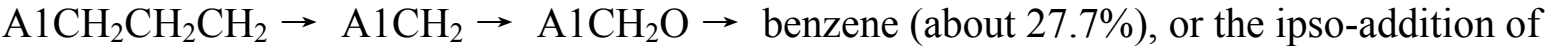
$\mathrm{NPB}$ by $\mathrm{H}$-atom (about $55.2 \%$ ). $\mathrm{A}_{1 \mathrm{CH}_{2}}$ (benzyl) is the key precursor of toluene and ethylbenzene, but most of this radical is transformed to $\mathrm{A}_{1} \mathrm{CH}_{2} \mathrm{O}$. The formation of benzene consuming more $\mathrm{A}_{1 \mathrm{CH}}$ radicals than the other 

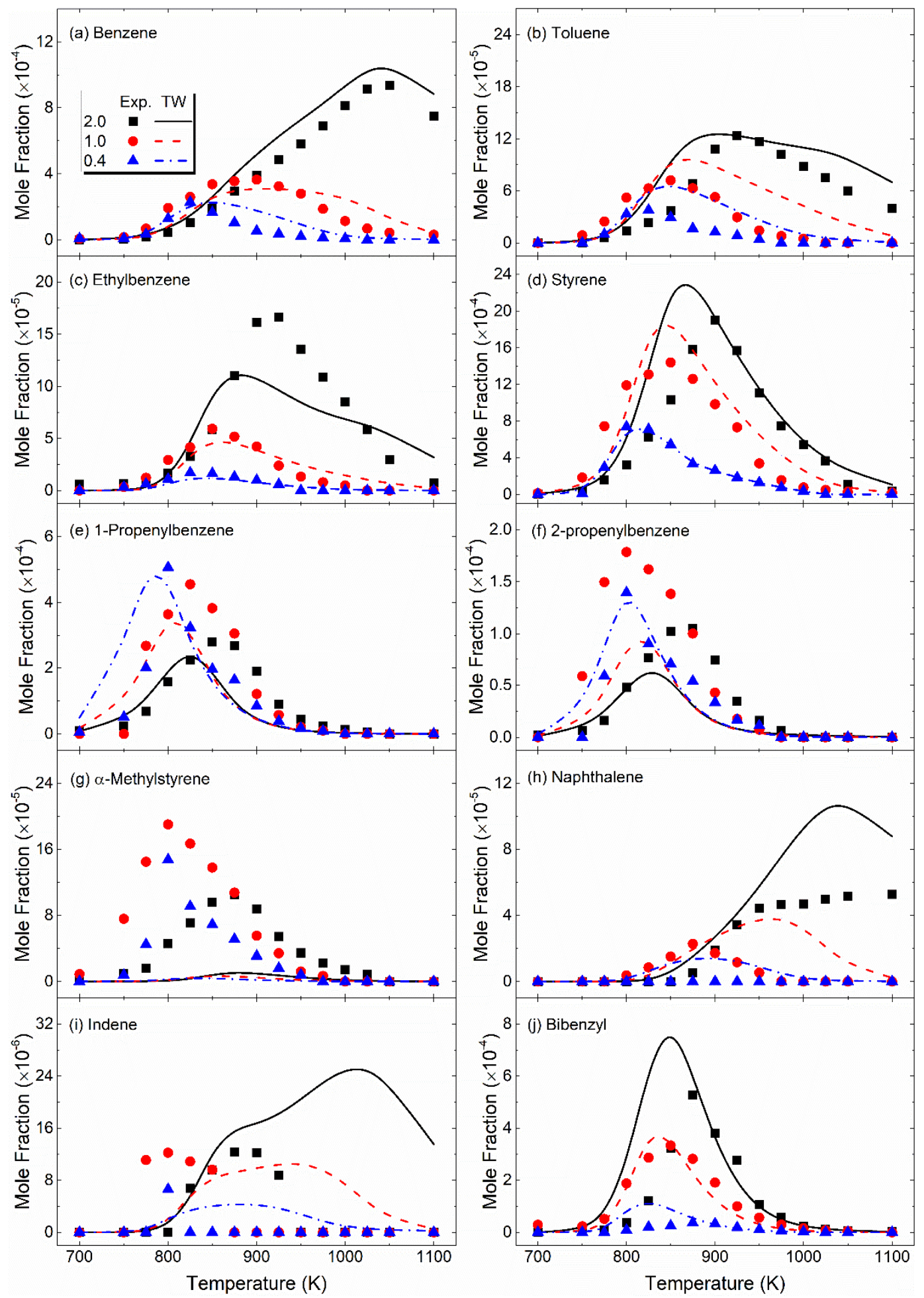

Fig. 5 Comparison between the measured (symbols) and modeling results (curves) of benzene (a), toluene (b), ethylbenzene (c), styrene (d), 1-propenylbenzene (e), 2-propenylbenzene (f), $\alpha$-methylstyrene (g), naphthalene (h), indene (i) and bibenzyl (j) using the reaction model of the present work (TW): Experimental data $-\varphi=2.0$-square, 1.0-circle, and 0.4-triangle; modeling results -2.0 -solid, 1.0-dash and 0.4-dash dotted. 
two aromatics (toluene and ethylbenzene), as all three intermediates have production channels with $\mathrm{A}_{1} \mathrm{CH}_{2}$ involved. This indicates that the peak values of toluene and ethylbenzene are smaller than that of benzene. Meanwhile, styrene is mostly formed via the decomposition of $\mathrm{A}_{1} \mathrm{CHCH}_{2} \mathrm{CH}_{3}$. The ROP analysis revealed that $28 \%$ of NPB is transformed to styrene at rich condition, which means that styrene plays an important role during the NPB oxidation. Compared to the early study of oxidation of NPB [22], six additional species, namely 1propenylbenzene, 2-propenylbenzene, $\alpha$-methylstyrene, naphthalene, benzofuran, and indene were newly detected; five of them were shown in Fig. 5. 1-Propenylbenzene, 2propenylbenzene, and $\alpha$-methylstyrene had been considered in the model proposed by Wang et al. [19] as intermediates in dynamic equilibrium, but they didn't report the experimental mole fractions of these species. The present model had been updated mostly be implementing these considerations and by recalculation of rate constant of reaction, as shown in Fig. S6 (see SM). Some additional reactions about naphthalene, benzofuran, and indene have also been updated by the latest data. As a result, the prediction of these species by the updated model presents good agreements with the experimental data shown in Fig. 5.

Under fuel rich condition $(\varphi=2)$, the peak temperatures are located at $825 \mathrm{~K}$ for both 1 propenylbenzene and 2-propenylbenzene, but at $875 \mathrm{~K}$ for $\alpha$-methylstyrene. The peak concentrations of the three $\mathrm{C}_{9} \mathrm{H}_{10}$ species were nearly $400 \mathrm{ppm}$, the same order of magnitude as for toluene, ethylbenzene and styrene. This means these species play key roles within the oxidation of NPB. All of these species exhibit similar tendencies of peak values when compared to the oxygenated intermediates which might result from the reactions of $\mathrm{A}_{1} \mathrm{C}_{3} \mathrm{H}_{6}$ with $\mathrm{O}_{2} / \mathrm{OH} / \mathrm{HO}_{2}$. The smaller $\varphi$ value supplied a higher $\mathrm{O}_{2}$ amount in the reactor, leading to the formation of more allyl benzenes, lower onset and peak temperatures, and to a higher consumption rate of allyl benzenes. 1-Propenylbenzene and 2-propenylbenzene were mainly

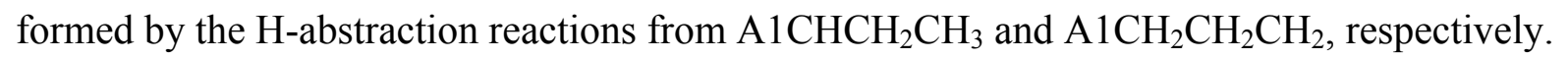
Meanwhile, most $\mathrm{A} 1 \mathrm{CH}_{2} \mathrm{CHCH}_{3}$ isomerizes to $\mathrm{A} 1 \mathrm{CH}\left(\mathrm{CH}_{3}\right) \mathrm{CH}_{2}$, since this reaction has a 
lower activation energy $\left(7.780 \mathrm{kcal} \mathrm{mol}^{-1}, 0 \mathrm{~K}\right)$ than the concurring $\beta$-scission: $\mathrm{AlCH}_{2} \mathrm{CHCH}_{3}$ $=\mathrm{A} 1 \mathrm{CHCHCH}+3\left(11.000 \mathrm{kcal} \mathrm{mol}^{-1}, 0 \mathrm{~K}\right) . \mathrm{A} 1 \mathrm{CH}\left(\mathrm{CH}_{3}\right) \mathrm{CH}_{2}$ mainly yields to $\alpha-$ methylstyrene via H-abstraction.

As an important soot precursor, naphthalene exhibits to reach a stable concentration at fuel rich condition but was hardly detected at the other two equivalence ratios (lean, stoichiometric). In early studies of benzene and butadiene flames and stirred reactors featuring ethylene and mixed aromatic/ethylene/hydrogen fuels [42], naphthalene was supposed to be formed via the pathways of: $\mathrm{C}_{5} \mathrm{H}_{5}+\mathrm{C}_{5} \mathrm{H}_{5}, \mathrm{C}_{6} \mathrm{H}_{5}+\mathrm{C}_{4} \mathrm{H}_{4}$, A1- $+\mathrm{C}_{3} \mathrm{H}_{3}$, and ethenylphenyl radical $\left(\mathrm{p}-\mathrm{C}_{8} \mathrm{H}_{7}\right)+\mathrm{C}_{2} \mathrm{H}_{2}$ reaction. This is different from the present model as according to ROP analysis most naphthalene is formed via: $\mathrm{A}_{1} \mathrm{C}_{2} \mathrm{H}_{3}+\mathrm{C}_{2} \mathrm{H}=\mathrm{A} 2+\mathrm{H}$. This difference was mainly caused by the lack of the radicals shown in previous reports $[40,42]$ such as $\mathrm{C}_{5} \mathrm{H}_{5}$ and $\mathrm{C}_{3} \mathrm{H}_{3}$. Because there was more styrene (1500 ppm of peak value at $\left.\varphi=2.0\right)$, than $\mathrm{C}_{5} \mathrm{H}_{5}$ or $\mathrm{A}_{1 \mathrm{CH}_{2}}$ radicals, and less alkene radicals compared to the present experiments. The order of concentration of indene was the smallest in all quantified intermediates. $\mathrm{A} 1 \mathrm{CHCH}_{2} \mathrm{CH}_{2}$ is the precursor of indene, which mostly transform to indene (R1906). The prediction of bibenzyl concentration is about half of the experimental data at the three fuel equivalence ratios which could be the result of the overprediction of toluene as both of these two species were produced from $\mathrm{AlCH}_{2}$. It is important to study the rate of production of these new insight species to understand in detail the fuel consumption and soot formation of NPB within its oxidation.

\subsection{Laminar burning velocity and ignition delay time}

The experimental results for the laminar burning velocity $\mathrm{S}_{\mathrm{u}}$ are presented in Fig. 6. At $p$ $=1$ bar, laminar premixed flames were stabilized in an $\varphi$-range from about 0.5 to 2.0 ; at higher pressures, this range was reduced. The maxima of the burning velocities are located at slightly rich $\varphi$-values between 1.05 and 1.1, as typical for hydrocarbon flames, and decrease with increasing pressure. In detail, $S_{\mathrm{u}}$ reaches values up to $81.1 \mathrm{~cm} \mathrm{~s}^{-1}$ at $1 \mathrm{bar}, 69.7 \mathrm{~cm} \mathrm{~s}^{-1}$ at 3 
bar, and $60.2 \mathrm{~cm} \mathrm{~s}^{-1}$ at 6 bar, respectively. The error bars of the values of $S_{\mathrm{u}}$ shown in Fig. 6 are caused by the uncertainty of the cone angle detection and the accuracy of the mass flow controllers, while those of the $\varphi$-values are caused by the accuracy of metering pump and mass flow controllers. In addition, the measurement of burning velocity may be affected by flame phenomena such as a non-ideal flow pattern and stretch including strain and curvature, depending on the heat conductivity and diffusivities of the mixture's components [27-30]. All data reported in the present work are not stretch corrected as no stretch correction methods are known for conical flames. The burning velocities measured in the present work are in good agreement with those reported by Hui et al. [9] exploiting a counterflow twin-flame with a stretch correction applied. Obviously, the stretch effects are within the reported error bars. In Fehler! Verweisquelle konnte nicht gefunden werden.6, a comparison is presented between experimental and calculated data using the newly developed mechanism as well as the one from the POLIMI group [43]. Whereas for $p=1$ bar and 3 bar, the new mechanism matches perfectly the experimental values at the fuel-rich side, the experimental values in the stoichiometric and lean region are underpredicted. Also, the calculation at $p=6$ bar is below the experimental data. Indeed, the uncertainties from the experiment at this pressure regime are likewise higher. Using the POLIMI model, a good agreement between predicted and measured data is seen at atmospheric pressure; at higher pressures, measured values are underpredicted for stoichiometric and fuel rich mixtures but matches at the lean side. So the new mechanism is especially suitable to model flame speed data for NPB in rich fuel-air mixtures. 


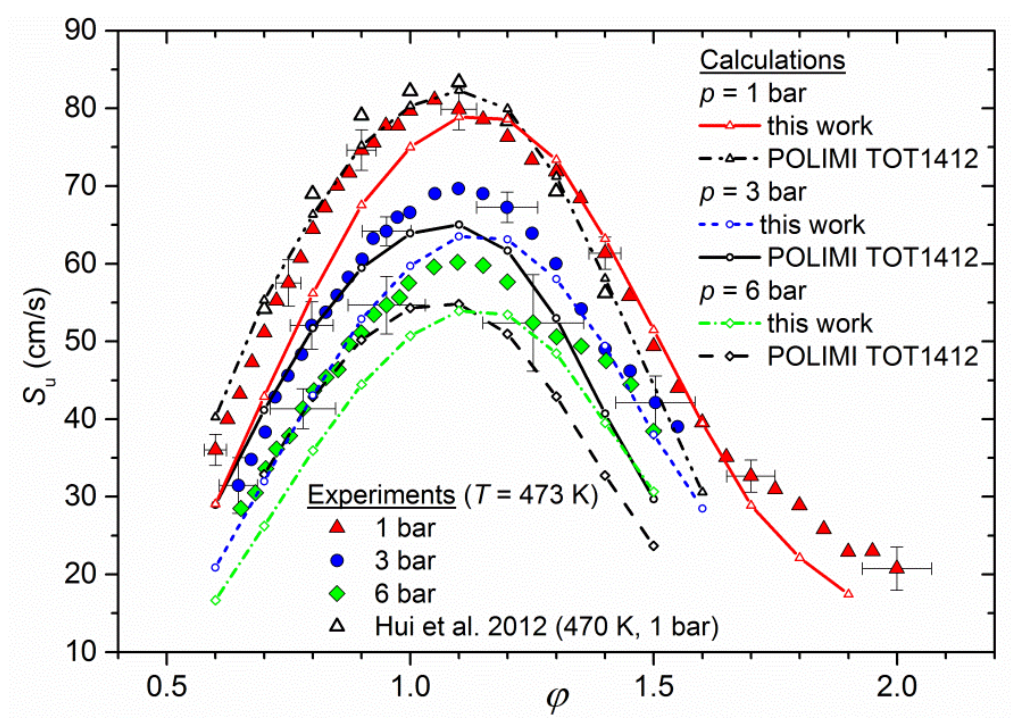

Fig. 6 Comparison between measured (symbols) and calculated (curves) laminar burning velocities of NPB at $T=473 \mathrm{~K}$ and $p=1$ bar (solid triangles), 3 bar (circles), and 6 bar (diamonds) using the reaction model of the present work (TW) - red, solid curve ( $p=1$ bar); blue, dash curve ( $p=3$ bar); green, dot dash curve ( $p=6$ bar). For comparison, experimental data from Hui et al. [9] (open triangles); calculations using the POLIMI model [43] (black curves) were added.

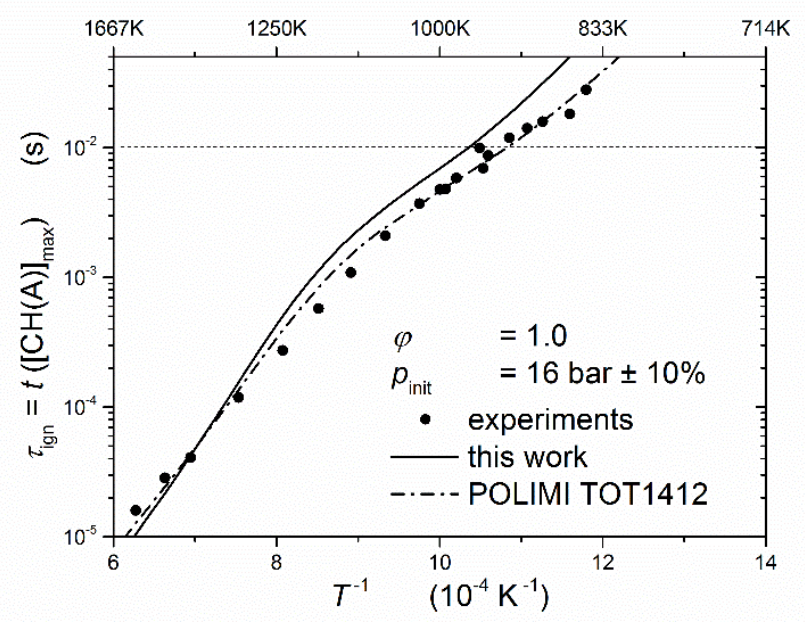

Fig. 7 Comparison between measured (symbols) and calculated (solid curve) ignition delay time data of stoichiometric NPB / synthetic air mixtures diluted 1:2 with $\mathrm{N}_{2}$ at $p_{\text {init }}=16$ bar. Simulations with $p=p(\mathrm{t})$ as derived from the experiments using the reaction model of the present work (TW) - solid curve. For comparison, calculated values using the POLIMI model [43] - dash-dotted curves.

Figure 7 compares the ignition delay time measurements with predictions of the mechanism of this work and the one of POLIMI [43]. Although measured at higher pressure 
(around $p=16$ bar) than the laminar burning velocities, the trend of the mechanism predictions with respect to ignition delay time at stoichiometric conditions reflects the trend of the laminar flame speed simulations.

\subsection{Rate of production and sensitivity analysis}

To illustrate the major reaction channels of NPB, reaction flux analysis has been performed for equivalence ratios of $\varphi=2.0(T=850 \mathrm{~K}, 52.3 \% \mathrm{NPB}$ conversion $)$ and $\varphi=0.4$ ( $T=800 \mathrm{~K}, 44.4 \%$ NPB conversion). As presented in Fig. 8, the major consumption pathways are quite similar under these two experimental conditions. H-abstraction from the side propyl

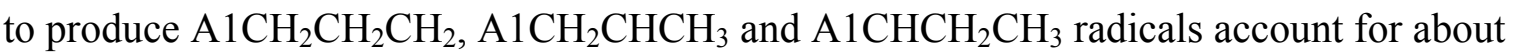
$20 \%, 30 \%$, and $50 \%$ of NPB consumption in both conditions $(20.41 \%, 27.78 \%, 49.42 \%$ in rich and $10.72 \%, 29.44 \%, 58.18 \%$ in lean condition). The differences affected by equivalence

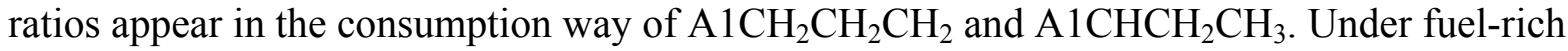
condition, $\mathrm{A} 1 \mathrm{CH}_{2} \mathrm{CH}_{2} \mathrm{CH}_{2}$ radicals tend to decompose to $\mathrm{A} 1 \mathrm{CH}_{2}$ radical $(77.58 \%)$ rather than to indane or 2-propenylbenzene (11.26\% or $11.16 \%)$. Such phenomenon comes from the fact that no sufficient oxygen is available at rich condition $(\varphi=2.0)$ for the formation of 2-

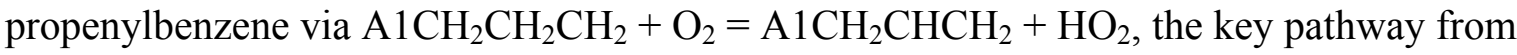

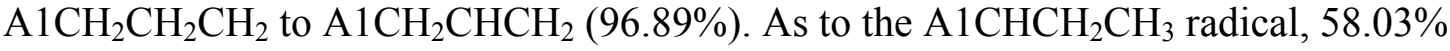
decomposes to styrene and only $23.49 \%$ leads to 1 -propenylbenzene formation at $\varphi=2.0$. These values turn to $11.42 \%$ and $56.15 \%$ as $\varphi$ decrease to 0.4 , respectively. These results explain the reason why the peak values of styrene decrease but those of propenylbenzene increase with $\varphi$ decreasing, as shown the in Fig. 5. In both rich and lean conditions, almost all the $\mathrm{A} 1 \mathrm{CH}_{2} \mathrm{CHCH}_{3}$ radicals transform to $\mathrm{A} 1 \mathrm{CH}\left(\mathrm{CH}_{3}\right) \mathrm{CH}_{2}$ radicals through the 


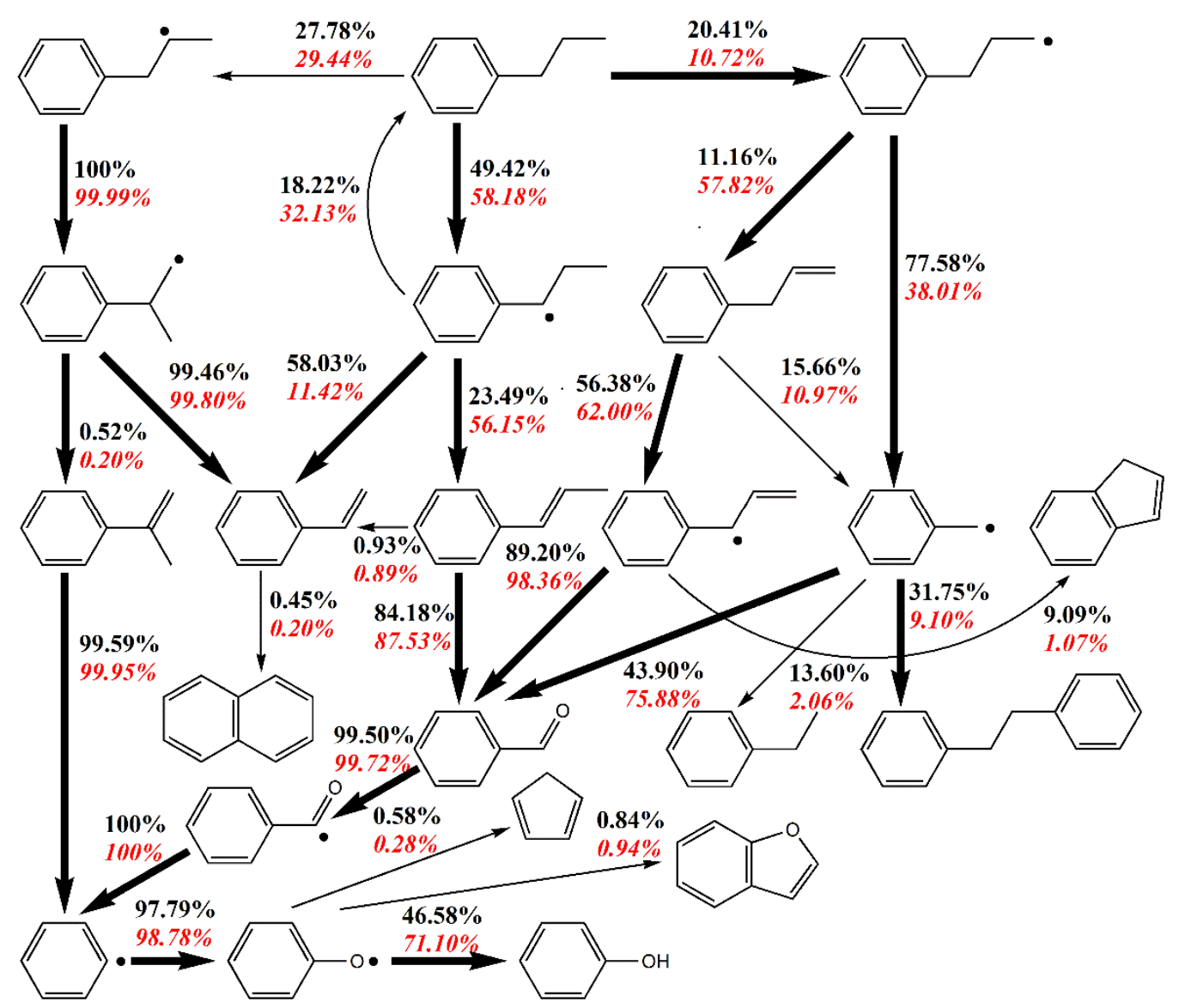

Fig. 8 Rate of production analysis of oxidation of NPB shown for a conversion ratio of about $50 \%$ : black numbers $-\varphi=2.0$ at $T=850 \mathrm{~K}$; red italic numbers $-\varphi=0.4$ at $T=800 \mathrm{~K}$. isomerization reaction $\left(\mathrm{A} 1 \mathrm{CH}_{2} \mathrm{CHCH}_{3}=\mathrm{A} 1 \mathrm{CH}\left(\mathrm{CH}_{3}\right) \mathrm{CH}_{2}\right)$, and its $\beta$-scissions to $\mathrm{A} 1-+\mathrm{C}_{3} \mathrm{H}_{6}$ and 1-propenylbenznene $+\mathrm{H}$ are quite negligible. An $\mathrm{H}$-abstraction reaction transforms $0.52 \%$ of $\mathrm{A} 1 \mathrm{CH}\left(\mathrm{CH}_{3}\right) \mathrm{CH}_{2}$ radical to $\alpha$-methylstyrene and the other radicals decompose to styrene, while such value increases to $0.20 \%$ when $\varphi=0.4$.

More than $80 \%$ of 1-propenylbenzene and $50 \%$ of 2-propenylbenzene decompose to benzaldehyde, most of which yield to $\mathrm{A} 1 \mathrm{O}$ via: $\mathrm{A} 1 \mathrm{CHO} \rightarrow \mathrm{A} 1 \mathrm{CO} \rightarrow \mathrm{A} 1-\mathrm{A} 1 \mathrm{O}$. A1O mainly converts to phenol, benzofuran and CPD. These consumption pathways explain the high concentrations of benzaldehyde and phenol, as shown in Fig. 4. Beside $\mathrm{AlCH}\left(\mathrm{CH}_{3}\right) \mathrm{CH}_{2}$ and $\mathrm{A} 1 \mathrm{CHCH}_{2} \mathrm{CH}_{3}$ radicals, styrene is also an important product in the consumption sequences of $\alpha$-methylstyrene and 1-propenylbenzene. According to this finding of the ROP analysis, styrene can be considered as a key intermediate in the NPB oxidation. Only $0.45 \%$ of styrene 
converts to naphthalene in rich condition and $0.20 \%$ under lean condition, but this route contributes to more than $90 \%$ formation of naphthalene. $31.75 \%$ of $\mathrm{A}^{1 \mathrm{CH}_{2}}$ form bibenzyl through the recombination reaction but more (43.9\%) yield to benzaldehyde in rich condition, these values change under lean condition $(9.10 \%, 75.88 \%$, respectively), since the formation of benzaldehyde needs more oxygen. Beside these two pathways, $\mathrm{A}_{1 \mathrm{CH}_{2}}$ can transform to ethylbenzene and toluene. In addition, reaction flux analyses of Dagaut's [22] and Wang's [19] model were performed, shown in Fig. S8 and S9 (see SM).

To identify the reactions that serve as key pathways in the consumption of NPB, a local sensitivity analysis has been performed for the present model under the equivalence ratios from 0.4 to 2.0. As shown in Fig. 9, $\mathrm{A} 1 \mathrm{CHCH}_{2} \mathrm{CH}_{3}+\mathrm{O}_{2}=\mathrm{A} 1 \mathrm{CHCHCH}_{3}+\mathrm{HO}_{2}$ exhibits the most promoting effect reaction of NPB consumption under both lean and stoichiometric conditions. The sensitivity

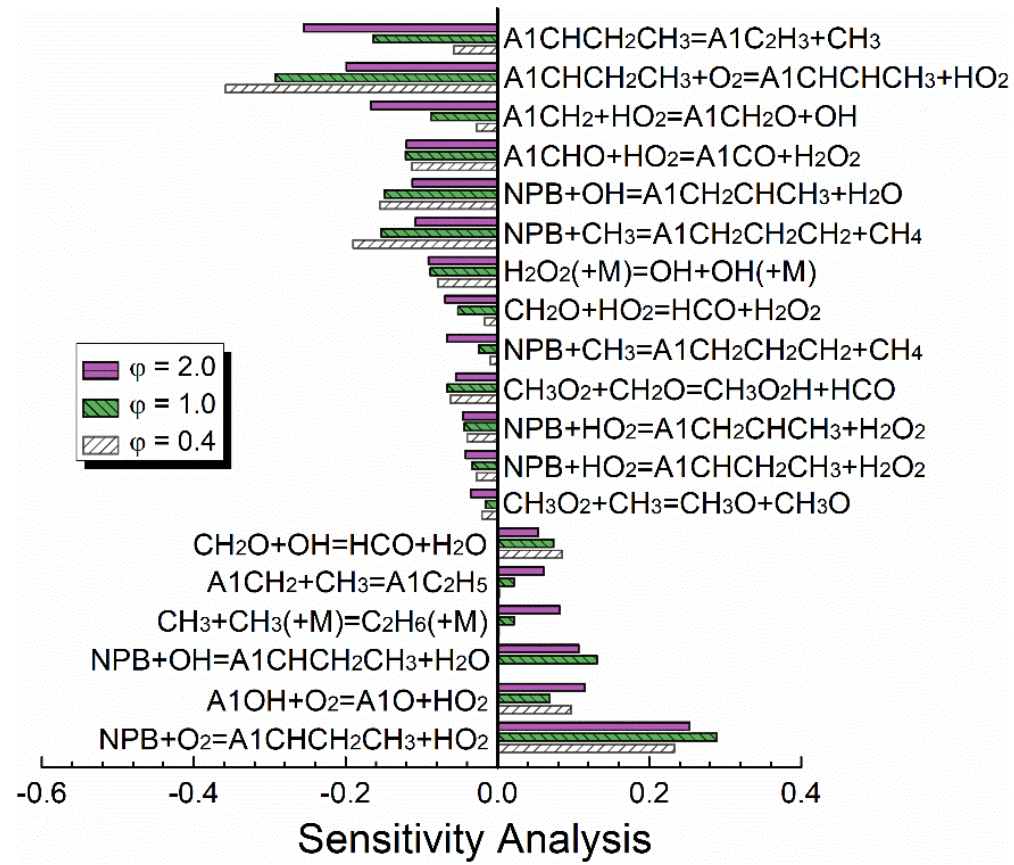

Fig. 9 Sensitivity analysis of oxidation of NPB at a conversion ratio of about 55\%. The equivalence ratios $\varphi$ are $2.0(850 \mathrm{~K}), 1.0(825 \mathrm{~K})$, and $0.4(800 \mathrm{~K})$.

analysis indicates that $\mathrm{A} 1 \mathrm{CHCH}_{2} \mathrm{CH}_{3}$ radicals play a key role in NPB oxidation in a wide range of conditions. Most of the consumption pathways of NPB have promoted effects, but two reactions of NPB yielding to $\mathrm{A} 1 \mathrm{CHCH}_{2} \mathrm{CH}_{3}$ radicals have a strong inhibiting effect on 
NPB consumption under the three equivalence ratios. Among the ROP analysis done under the same temperature at fuel-rich condition, $18.22 \%$ of $\mathrm{A}_{1 \mathrm{CHCH}} \mathrm{CH}_{3}$ radical transformed back to NPB through these two reactions. It means the higher the rates of these reactions, the more radicals react back to NPB and slow down the consumption of NPB. Since

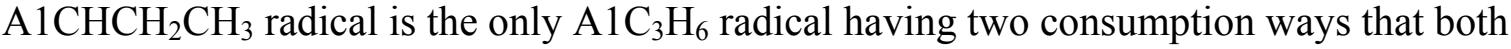
decomposes styrene and turns back to NPB, it takes part in both promoting and inhibiting reactions concerning the NPB oxidation.

The decomposition reaction of $\mathrm{A}_{1} \mathrm{CHCH}_{2} \mathrm{CH}_{3}$ radical: $\mathrm{A} 1 \mathrm{CHCH}_{2} \mathrm{CH}_{3}=\mathrm{AlC}_{2} \mathrm{H}_{3}+\mathrm{CH}_{3}$ is promoting most under rich condition $(\varphi=2.0)$ and maintain the same effect in stoichiometric condition. $\mathrm{H}_{2} \mathrm{O}_{2}(+\mathrm{M})=\mathrm{OH}+\mathrm{OH}$ is a promoting reaction in three conditions: the formation of $\mathrm{OH}$ promotes the consumption of $\mathrm{NPB}$ mostly through $(\mathrm{NPB}+\mathrm{OH}=$

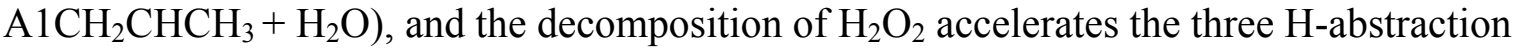
reactions of $\mathrm{NPB}\left(\mathrm{NPB}+\mathrm{HO}_{2}=\mathrm{AlC}_{3} \mathrm{H}_{6}+\mathrm{H}_{2} \mathrm{O}_{2}\right)$.

\subsection{Validation against other experimental data}

To check and to extend the validity range of the present reaction model, previous oxidation results from Dagaut et al. [22] (at $p=1.0$ atm with initial NPB concentration of $0.1 \%$ diluted in $\mathrm{N}_{2}, \varphi=0.5,1.0$, and 1.5 ) and ignition delay times measurements from Darcy et al. (at $p=1.0,10.0,30.0$ and 50.0 atm with various NPB concentrations diluted in $\mathrm{N}_{2}, \varphi=$ $0.29,0.48,0.96$ and 1.92 ) were simulated, too. Figure 10 compares the predicted profiles of NPB and of various products with the experimental results under rich condition $(\varphi=1.5)$, in symbols are measurements and lines denote 

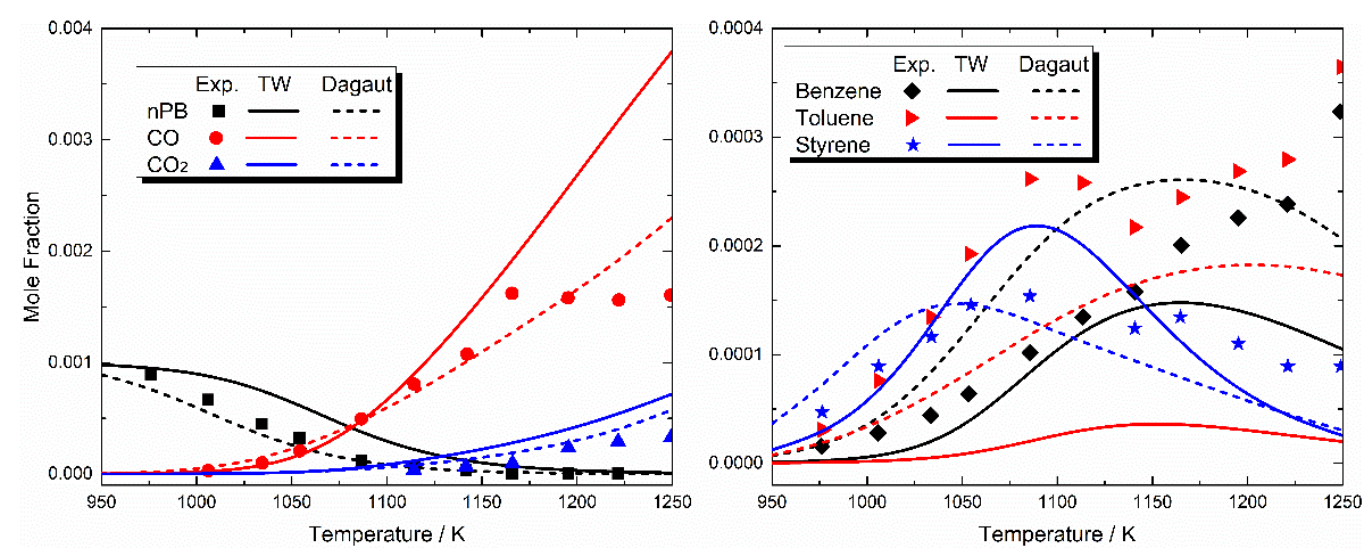

Fig. 10 Comparison between the predicted (curves) and measured (symbols) species profiles: experimental data - Dagaut et al. [22] at $\varphi=1.5$; modeling: reaction model, present work (TW - solid) and the one of Dagaut (dashed) [22].

predictions: solid lines by the current model and dashed lines by the Dagaut model.

In general, the present model gives acceptable agreement with experimental NPB data.

The prediction of fuels consumption is slightly slower than the measurements and predictions by the Dagaut model, which is attributed to the uncertainties in the estimation of experimental data and in the slower rates of the calculated reaction R1802. CO is well predicted for temperatures lower than $1150 \mathrm{~K}$, and then $\mathrm{CO}$ became overpredicted by both models. For $\mathrm{CO}_{2}$, benzene, and styrene good agreement on mole fractions and tendencies is obtained, while toluene is somewhat underpredicted by both models. Both models reach a peak in the mole fraction profiles prediction of three aromatics (benzene, toluene and styrene), for which the measured profiles do not decrease before the temperature reached about $1250 \mathrm{~K}$. As indicated from the ROP analysis, toluene is mainly formed by the reaction of $\mathrm{H}$ with $\mathrm{A}_{1} \mathrm{CH}_{2}$ radicals, which is formed through $\mathrm{A} 1 \mathrm{CH}_{2} \mathrm{CH}_{2} \mathrm{CH}_{2}$ decomposition to benzyl and ethylene at $1150 \mathrm{~K}$. Since $\mathrm{C}_{2} \mathrm{H}_{4}$ is reasonably predicted in TW model, the underprediction of toluene is caused by more $\mathrm{A}_{1} \mathrm{CH}_{2}$ consumption yielding to $\mathrm{A} 1 \mathrm{CH}_{2} \mathrm{O}$, ethylbenzene and bibenzyl rather than to toluene.

Darcy et al. [14] studied the ignition of NPB in a high-pressure shock tube and a rapid compression machine (RCM). The equivalence ratios were ranging from $\varphi=0.29$ to $\varphi=1.92$, and the pressures from $p=1$ to $p=50$ atm. Figure 11 shows comparison between the 
measured and simulated data by using the present model and Darcy's model. The ignition delay times decrease with temperature or pressure increasing, while the increasing of $\varphi$-values has an impeditive effect on ignition. The tendency of the simulated result by the present model shows a good agreement with the experimental data, while ignition delay times are slightly higher than the measurements. This overprediction is mainly caused by the low consumption speed of NPB in the present model, as shown in Fig. S8 (see SM). The rate of R1802 in Darcy's mechanism, which plays an important role in fuel's consumption, is much faster than the one in the present model, under the temperature range
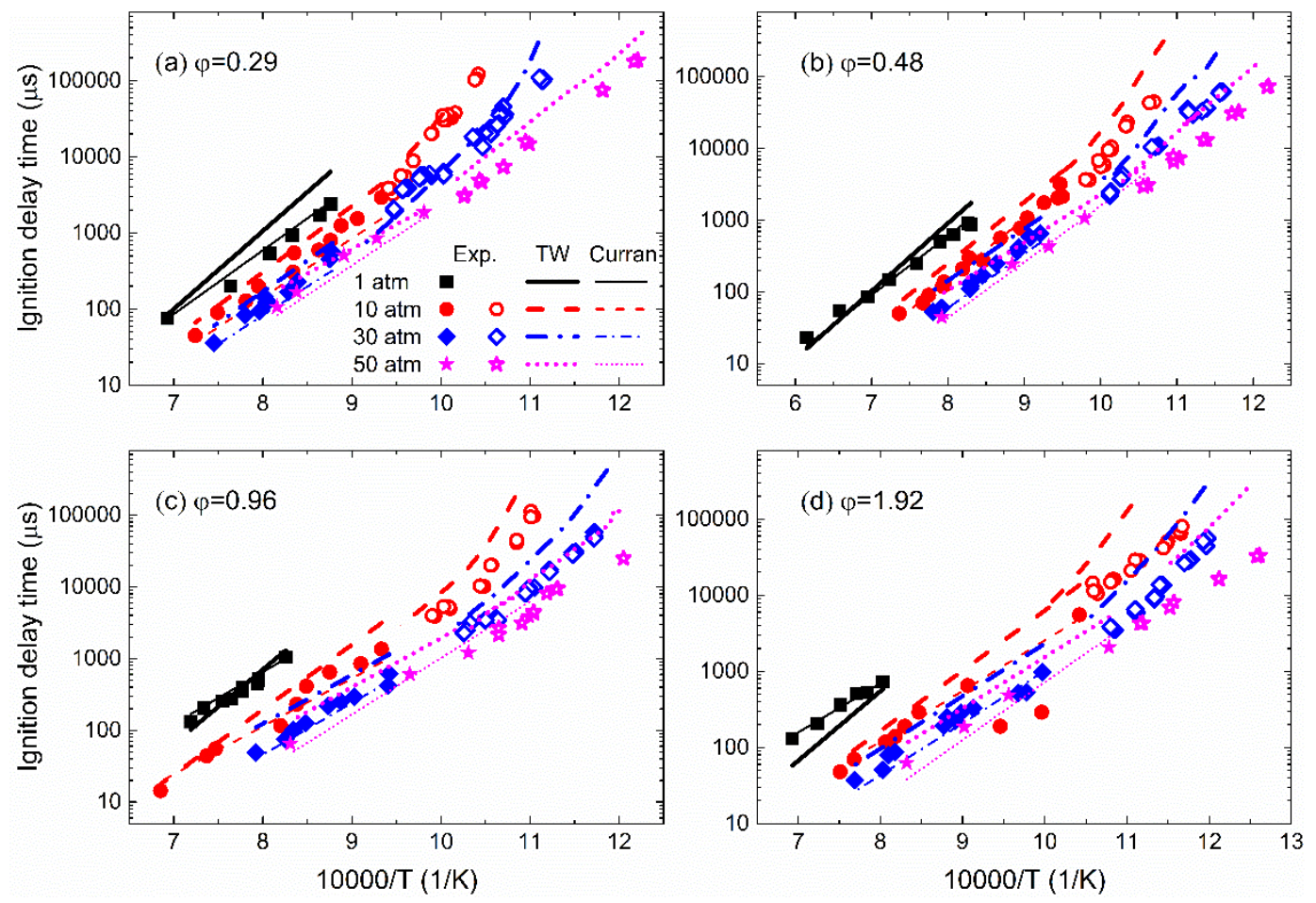

Fig. 11 Comparison between the predicted (curves) and measured (symbols) ignition delay time profiles: experimental data - Darcy et al. [14] including four equivalence ratios: (a) $\varphi=$ 0.29 , (b) $\varphi=0.48$, (c) $\varphi=0.96$ and (d) $\varphi=1.92$ (solid - shock tube data; hollow - RCM data); modeling: reaction model, present work (TW - thick) and the one of Darcy (thin) [22].

Table 1 Comparison between the maximum mole fractions of the main intermediates measured in the JSR oxidation experiments, as of 1,3,5-trimethylbenzene, 1,2,4trimethylbenzene and NPB at $\varphi=2.0$. For each fuel, the maxima mole fraction obtained among the three experiments are written in bold. 


\begin{tabular}{|c|c|c|c|}
\hline Species & $\begin{array}{l}1,3,5- \\
\text { trimethylbenzene } \\
(\mathrm{ppm})\end{array}$ & $\begin{array}{l}1,2,4- \\
\text { trimethylbenzene } \\
{[24](\mathrm{ppm})}\end{array}$ & $\begin{array}{l}\text { NPB } \\
\text { This work (ppm) }\end{array}$ \\
\hline $\begin{array}{l}\text { Fuel left at } 1100 \mathrm{~K} \\
\left(10^{6} \mathrm{ppm} \text { for initial }\right. \\
\text { concentrations })\end{array}$ & 1140.0 & 148.0 & 21.2 \\
\hline $\mathrm{CO}$ & 28000.0 & 35960.0 & 35650.0 \\
\hline $\mathrm{H}_{2}$ & 4830.0 & 4970.0 & 5690.0 \\
\hline $\mathrm{CH}_{4}$ & 3910.0 & 380.0 & 4100.0 \\
\hline $\mathrm{C}_{2} \mathrm{H}_{2}$ & - & 42.0 & 341.0 \\
\hline $\mathrm{C}_{2} \mathrm{H}_{4}$ & 175.0 & 104.0 & 2780.0 \\
\hline $\mathrm{C}_{2} \mathrm{H}_{6}$ & 25.2 & 6.0 & 171.0 \\
\hline $\mathrm{C}_{3} \mathrm{H}_{6}$ & 8.0 & - & 194.0 \\
\hline $\mathrm{CH}_{3} \mathrm{CHO}$ & 285.0 & 240.0 & 89.3 \\
\hline $\mathrm{C}_{3} \mathrm{H}_{4} \mathrm{O}$ & 16.4 & 335.0 & 155.0 \\
\hline CPD & - & - & 27.0 \\
\hline Benzene & 698.0 & 950.0 & 747.0 \\
\hline Toluene & 643.0 & 807.0 & 123.0 \\
\hline Ethylbenzene & 38.0 & 96.0 & 166.0 \\
\hline Styrene & 98.2 & 379.0 & 1900.0 \\
\hline o-Xylene & 9.3 & 429.0 & - \\
\hline m-Xylene & 458.0 & 535.0 & - \\
\hline p-Xylene & 6.4 & 352.0 & - \\
\hline 1-Propenylbenzene & - & - & 281.0 \\
\hline 2-Propenylbenzene & - & - & 105.0 \\
\hline$\alpha$-Methylstyrene & - & - & 104.0 \\
\hline Benzaldehyde & - & - & 497.0 \\
\hline Phenol & - & - & 773.0 \\
\hline Naphthalene & - & - & 52.6 \\
\hline Benzofuran & - & - & 93.9 \\
\hline Bibenzyl & - & - & 527.0 \\
\hline Indene & - & - & 12.3 \\
\hline
\end{tabular}

of 500 to $1500 \mathrm{~K}$. The faster rate causes the higher NPB consumption rate and the faster autoignition, which means short ignition delay times. The present model also predicts the measurements of rapid compression machine well. The predictions under lean conditions show good agreements with the experimental data. The tendencies are well predicted by the presented mechanism in all conditions, like shock tube experimental data. In summary, the present model has reasonable agreements on the ignition delay time measurements of NPB. 


\subsection{Comparison with 135TMB \& 124TMB}

The oxidation of three C9 aromatic fuels, namely 1,3,5-trimethylbenzene (135TMB), 1,2,4-trimethylbenzene (124TMB) [24] and NPB, have been performed in the same jet-stirred reactor. To find a component with a higher energy density (enthalpy of combustion, $273 \mathrm{~K}$ : $5264.48 \mathrm{~kJ} / \mathrm{mol}$ ) and at the same time, with a lower pollution pattern that might serve as a model component in a surrogate fuel of kerosene, a comparison is made among these three aromatic studies. Table 1 presents the peak concentrations of the intermediates and products during the oxidation of NPB and TMBs. Because the C-H bond energy in propyl of NPB is lower than the one in methyl of TMBs, the H-abstraction from NPB is much easier than the TMBs and leads to the faster consumption under the same temperature. NPB maintained the largest peaks of light hydrocarbons like $\mathrm{C}_{2} \mathrm{H}_{4}$ or $\mathrm{C}_{3} \mathrm{H}_{6}$ besides $\mathrm{CH}_{4}$ which results from the decomposition of the side propyl. Since the substitution reaction of $\mathrm{CH}_{3}$ radical is easier than the decomposition reaction of propyl of NPB, TMBs produced more $\mathrm{CH}_{4}$ than NPB and yielded to xylenes.

Figure 12 displays the comparison of the peak values of major intermediates. NPB maintained the largest peaks of ethylbenzene and styrene but not for benzene and toluene, the formation of styrene was at least five times larger when NPB is oxidized. This phenomenon can be explained by 


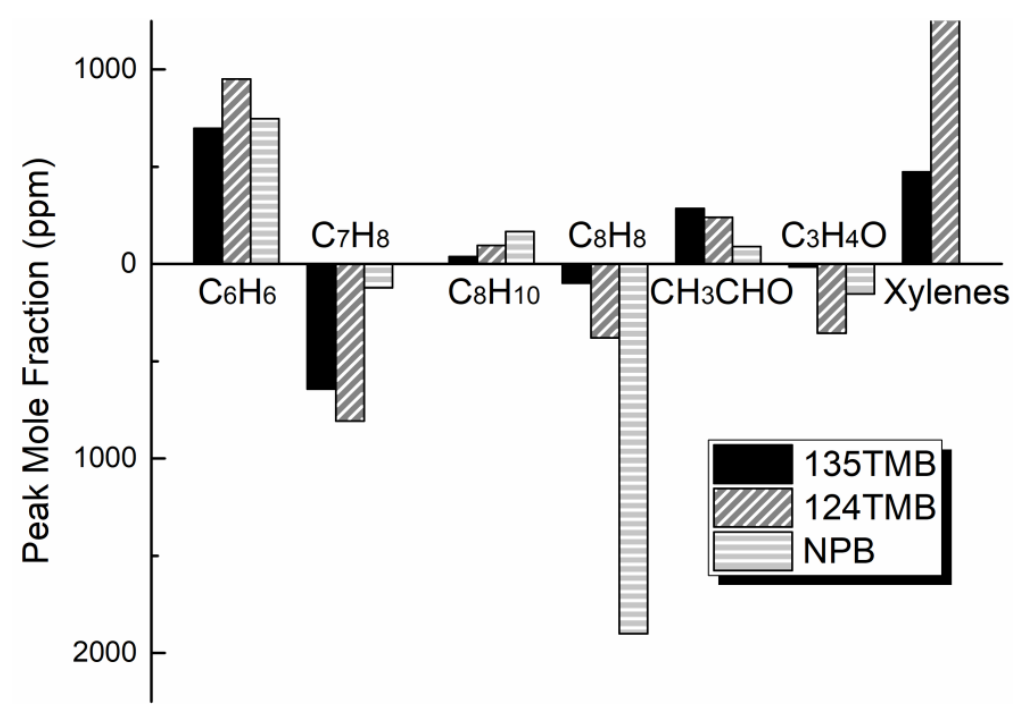

Fig. 12 Comparison of peak mole fractions of the major intermediates as measured in the oxidation of three $\mathrm{C}_{9} \mathrm{H}_{12}$ fuels, at $\varphi=2.0$. Black column - 135TMB; gray - 124TMB; light gray - NPB.

the hard addition on $\mathrm{CH}_{3}$ of TMBs and the easy decomposition of side propyl of NPB.

Benzene and toluene are the most important intermediates within 135TMB and 124TMB oxidation but not within NPB oxidation. Concerning the other aromatic intermediates, no xylenes were observed within the combustion of NPB. The formation of allyl benzenes was only observed in the oxidation of NPB. The differences species of the three C9 aromatic fuels observed in the experiments. 135TMB remained these findings in the formation of aromatics are related to the differences in reaction mechanisms. It is easy for TMBs to break the C-C bond between aromatic and $\mathrm{CH}_{3}$, while only a small part of NPB consumes through propyl abstraction. Thus, NPB prefers to form ethylbenzene and styrene rather than xylenes and toluene. This behavior also leads to the scarce formation of the light hydrocarbons, which are generated through the reactions of side propyl decomposition.

The peak values of aldehydes were quite different among the three fuels. 135TMB hold the largest peak of $\mathrm{CH}_{3} \mathrm{CHO}$ but the smallest in $\mathrm{C}_{3} \mathrm{H}_{4} \mathrm{O}$. The ROP analysis reveals that $\mathrm{CH}_{3} \mathrm{CHO}$ is mainly formed from $\mathrm{sC}_{3} \mathrm{H}_{5}$, a product of decomposition of $\mathrm{C}_{9} \mathrm{H}_{11} \mathrm{O}$ (the product resulting after $\mathrm{H}$-abstraction and $\mathrm{O}$-addition on the same $\mathrm{CH}_{3}$ of $135 \mathrm{TMB}$ ). Moreover, benzene is regarded as major precursor of $\mathrm{C}_{3} \mathrm{H}_{4} \mathrm{O}$ because the smallest benzene peak led to the 
smallest $\mathrm{C}_{3} \mathrm{H}_{4} \mathrm{O}$ peak. $124 \mathrm{TMB}$ hold the largest peaks of $\mathrm{C}_{3} \mathrm{H}_{4} \mathrm{O}$ and $\mathrm{CH}_{3} \mathrm{CHO}$, NPB produced less $\mathrm{CH}_{3} \mathrm{CHO}$ and about a factor of 2 less $\mathrm{C}_{3} \mathrm{H}_{4} \mathrm{O}$ than 124TMB. This comparison leads to the conclusion that NPB is the cleanest fuel among these three fuels with respect to pollution by aldehydes.

\section{Conclusion}

This work reports an experimental and kinetic investigation of the NPB oxidation and combustion. For obtaining a detailed information about the combustion pattern, experiments were performed in a JSR in the temperature range of 700-1100 K and under a wide range of fuel equivalence $\varphi$ from 0.4 to 2.0 . The mole fractions of 25 species including six newly observed intermediates: 1-propenylbenzene, 2-propenylbenzene, $\alpha$-methylstyrene, naphthalene, benzofuran, and indene were quantified and qualified by on-line GC and GCMS. A detailed mechanism was further developed to achieve a reasonable agreement between experimental and simulation data. The peak values of intermediates increased with the equivalence ratio decreasing; peak values of the oxygenated species decreased, respectively. The rate of production analysis indicates that NPB mainly consumed by H-abstraction from propyl produced three important $\mathrm{C}_{9} \mathrm{H}_{10}$ intermediates as mentioned above. According to sensitivity analysis, the two reactions of $\mathrm{A} 1 \mathrm{CHCH}_{2} \mathrm{CH}_{3}$ reacts back to NPB exhibit strong inhibiting effects, while the decomposition reactions of NPB and $\mathrm{C}_{9} \mathrm{H}_{11}$ radicals have the most promoting effects on NPB consumption. For a further investigation of the combustion behavior of NPB, measurements of laminar burning velocities were performed $(1,3$ and 6 bar) over a wide $\varphi$ range, and ignition delay times of stoichiometric NPB-air mixtures diluted 1:2 with $\mathrm{N}_{2}$ were experimentally determined at pressures around 16 bar behind reflected shock waves. The comparison between measured and predicted data shows the same trend, with reasonable agreement. The reaction model of the present work was further validated against other experimental data taken from literature, with the present model achieving reasonable agreements. Moreover, the comparison of oxidation experiments of three C9 fuels 
leads to the conclusion that NPB is supposed to be the most reactive fuel, with the lowest aldehydes pollution. These results are considered to be beneficial for future work on npropylbenzene and other alkylbenzenes, in order to contribute to a more comprehensive understanding of the fuel consumption and soot formation of NPB in oxidation environment.

\section{Acknowledgement}

TZY thanks for the financial support from Natural Science Foundation of China (No 51476168/91541102), the Ministry of Science and Technology of China (2017YFA0402804) and Recruitment Program of Global Youth Experts. Also, TZY and MBU acknowledge funding from the Alexander von Humboldt Research Group Linkage Programme. The assistance of N. Ackermann and J. Metzlaff in performing the shock tube experiments is gratefully acknowledged.

\section{References}

[1] D. Zheng, W.M. Yu, B.J. Zhong, RP-3 Aviation Kerosene Surrogate Fuel and the Chemical Reaction Kinetic Model, Acta Phys.-Chim. Sin. 31 (2015) 636-642.

[2] J.A. Widegren, T.J. Bruno, Thermal decomposition kinetics of the aviation turbine fuel Jet A, Ind. Eng. Chem. Res. 47 (2008) 4342-4348.

[3] M. Braun-Unkhoff, U. Riedel, Alternative fuels in aviation, CEAS Aeronautical J. 6 (2015) 83-93.

[4] M. Braun-Unkhoff, T. Kathrotia, B. Rauch, U. Riedel, About the interaction between composition and performance of alternative jet fuels, CEAS Aeronautical J. 7 (2016) 83-94.

[5] S. Riebl, M. Braun-Unkhoff, U. Riedel, A Study on the Emissions of Alternative Aviation Fuels, J. Eng. Gas Turbines Power 139 (2017) 081503.

[6] P. Dagaut, A. El Bakali, A. Ristori, The combustion of kerosene: Experimental results and kinetic modelling using 1-to 3-component surrogate model fuels, Fuel 85 (2006) 944-956.

[7] R.J. Johnston, J.T. Farrell, Laminar burning velocities and Markstein lengths of aromatics at elevated temperature and pressure, Proc. Combust. Inst. 30 (2005) 217-224.

[8] X. Hui, A.K. Das, K. Kumar, C.J. Sung, S. Dooley, F.L. Dryer, Laminar flame speeds and 
extinction stretch rates of selected aromatic hydrocarbons, Fuel 97 (2012) 695-702.

[9] X. Hui, C.J. Sung, Laminar flame speeds of transportation-relevant hydrocarbons and jet fuels at elevated temperatures and pressures, Fuel 109 (2013) 191-200.

[10] C.S. Ji, E. Dames, H. Wang, F.N. Egolfopoulos, Propagation and extinction of benzene and alkylated benzene flames, Combust. Flame 159 (2012) 1070-1081.

[11] M. Mehl, O. Herbinet, P. Dirrenberger, R. Bounaceur, P.A. Glaude, F. Battin-Leclerc, W.J. Pitz, Experimental and modeling study of burning velocities for alkyl aromatic components relevant to diesel fuels, Proc. Combust. Inst. 35 (2015) 341-348.

[12] A. Roubaud, R. Minetti, L.R. Sochet, Oxidation and combustion of low alkylbenzenes at high pressure: Comparative reactivity and auto-ignition, Combust. Flame 121 (2000) 535-541.

[13] D. Darcy, M. Mehl, J.M. Simmie, J. Wurmel, W.K. Metcalfe, C.K. Westbrook, W.J. Pitz, H.J. Curran, An experimental and modeling study of the shock tube ignition of a mixture of nheptane and n-propylbenzene as a surrogate for a large alkyl benzene, Proc. Combust. Inst. 34 (2013) 411-418.

[14] D. Darcy, H. Nakamura, C.J. Tobin, M. Mehl, W.K. Metcalfe, W.J. Pitz, C.K. Westbrook, H.J. Curran, A high-pressure rapid compression machine study of npropylbenzene ignition, Combust. Flame 161 (2014) 65-74.

[15] D. Darcy, H. Nakamura, C.J. Tobin, M. Mehl, W.K. Metcalfe, W.J. Pitz, C.K. Westbrook, H.J. Curran, An experimental and modeling study of surrogate mixtures of npropyl- and n-butylbenzene in $\mathrm{n}$-heptane to simulate $\mathrm{n}$-decylbenzene ignition, Combust. Flame 161 (2014) 1460-1473.

[16] S. Gudiyella, K. Brezinsky, High pressure study of n-propylbenzene oxidation, Combust. Flame 159 (2012) 940-958.

[17] S. Gudiyella, K. Brezinsky, The high pressure study of n-propylbenzene pyrolysis, Proc. Combust. Inst. 34 (2013) 1767-1774.

[18] H. Anderson, C.S. McEnally, L.D. Pfefferle, Experimental study of naphthalene formation pathways in non-premixed methane flames doped with alkylbenzenes, Proc. Combust. Inst. 28 (2000) 2577-2583.

[19] Z.D. Wang, Y.Y. Li, F. Zhang, L.D. Zhang, W.H. Yuan, Y.Z. Wang, F. Qi, An 
experimental and kinetic modeling investigation on a rich premixed n-propylbenzene flame at low pressure, Proc. Combust. Inst. 34 (2013) 1785-1793.

[20] F. Qi, R. Yang, B. Yang, C.Q. Huang, L.X. Wei, J. Wang, L.S. Sheng, Y.W. Zhang, Isomeric identification of polycyclic aromatic hydrocarbons formed in combustion with tunable vacuum ultraviolet photoionization, Rev. Sci. Instrum. 77 (2006) 5.

[21] F. Qi, Combustion chemistry probed by synchrotron VUV photoionization mass spectrometry, Proc. Combust. Inst. 34 (2013) 33-63.

[22] P. Dagaut, A. Ristori, A. El Bakali, M. Cathonnet, Experimental and kinetic modeling study of the oxidation of n-propylbenzene, Fuel 81 (2002) 173-184.

[23] B.Y. Wang, Y.X. Liu, J.J. Weng, P. Glarborg, Z.Y. Tian, New insights in the lowtemperature oxidation of acetylene, Proc. Combust. Inst. 36 (2017) 355-363.

[24] J.J. Weng, Y.X. Liu, B.Y. Wang, L.L. Xing, L.D. Zhang, Z.Y. Tian, Experimental and kinetic investigation of 1,2,4-trimethylbenzene oxidation at low temperature, Proc. Combust. Inst. 36 (2017) 909-917.

[25] G. Andrews, D. Bradley, Determination of burning velocities: a critical review, Combust. Flame 18 (1972) 133-153.

[26] H. Eberius, T. Kick, Stabilization of premixed, conical methane flames at high pressure, Ber. Bunsenges. Phys. Chem. 96 (1992) 1416-1419.

[27] T. Kick, T. Kathrotia, M. Braun-Unkhoff, U. Riedel, An experimental and modeling study of laminar flame speeds of alternative aviation fuels, ASME 2011 Turbo Expo: Turbine Technical Conference and Exposition, American Society of Mechanical Engineers, 2011, pp. 579-589.

[28] T. Kick, J. Herbst, T. Kathrotia, J. Marquetand, M. Braun-Unkhoff, C. Naumann, U. Riedel, An experimental and modeling study of burning velocities of possible future synthetic jet fuels, Energy 43 (2012) 111-123.

[29] A. Mzé-Ahmed, P. Dagaut, K. Hadj-Ali, G. Dayma, T. Kick, J. Herbst, T. Kathrotia, M. Braun-Unkhoff, J. Herzler, C. Naumann, U. Riedel, Oxidation of a coal-to-liquid synthetic jet fuel: experimental and chemical kinetic modeling study, Energy Fuels 26 (2012) 6070-6079.

[30] P. Dagaut, F. Karsenty, G. Dayma, P. Diévart, K. Hadj-Ali, A. Mzé-Ahmed, M. Braun- 
Unkhoff, J. Herzler, T. Kathrotia, T. Kick, C. Naumann, U. Riedel, L. Thomas, Experimental and detailed kinetic model for the oxidation of a Gas to Liquid (GtL) jet fuel, Combust. Flame 161 (2014) 835-847.

[31] T. Kathrotia, C. Naumann, P. Oßwald, M. Köhler, U. Riedel, Kinetics of Ethylene Glycol: The first validated reaction scheme and first measurements of ignition delay times and speciation data, Combust. Flame 179 (2017) 172-184.

[32] P. Glarborg, R.J. Kee, J.F. Grcar, J.A. Miller, A Fortran Program for Modelling Well Stirred Reactors, Report No. SAND86-8209, Sandia National Laboratories, 1986.

[33] D.G. Goodwin, H.K. Moffat, R.L. Speth, "Cantera: An object- oriented software toolkit for chemical kinetics, thermodynamics, and transport processes", http://www.cantera.org, Version 2.2.1., 2016

[34] R.J. Kee, G. Dixon-Lewis, J. Warnatz, M.E. Coltrin, J.A. Miller, "The Chemkin Transport Database. Report SAND86-8246", Sandia National Laboratories, Livermore (CA), USA., (1986).

[35] R.J. Kee, F.M. Rupley, J.A. Miller, "CHEMKIN: The Chemkin Thermodynamic Database. Rep. SAND87-8215", Sandia National Laboratories, Livermore (CA), USA., (1987).

[36] E. Goos, A. Burcat, B. Ruscic, Extended Third Millennium Ideal Gas and Condensed Phase Thermochemical Database for Combustion with updates from Active Thermochemical Tables, http://burcat.technion.ac.il/dir/.

[37] J.A. Montgomery, M.J. Frisch, J.W. Ochterski, G.A. Petersson, A complete basis set model chemistry. VI. Use of density functional geometries and frequencies, J. Chem. Phys. 110 (1999) 2822-2827.

[38] P. Diévart, P. Dagaut, The oxidation of n-butylbenzene: Experimental study in a JSR at 10atm and detailed chemical kinetic modeling, Proc. Combust. Inst. 33 (2011) 209-216.

[39] S.M. Burke, W. Metcalfe, O. Herbinet, F. Battin-Leclerc, F.M. Haas, J. Santner, F.L. Dryer, H.J. Curran, An experimental and modeling study of propene oxidation. Part 1: Speciation measurements in jet-stirred and flow reactors, Combust. Flame 161 (2014) 27652784.

[40] Z.Y. Tian, W.J. Pitz, R. Fournet, P.A. Glaude, F. Battin-Leclerc, A detailed kinetic 
modeling study of toluene oxidation in a premixed laminar flame, Proc. Combust. Inst. 33 (2011) 233-261.

[41] B.Y. Wang, Dan Yu, Y.X. Liu, J.J. Weng, G.F. Pan, Z.Y. Tian, An experimental and modeling study on the low temperature oxidation of surrogate for JP-8 part I: neat 1,3,5trimethylbenzene, Combust. Flame, under review, 2017.

[42] P. Lindstedt, L. Maurice, M. Meyer, Thermodynamic and kinetic issues in the formation and oxidation of aromatic species, Faraday Discuss. 119 (2001) 409-432.

[43] The CRECK Modeling Group, Politecnico di Milano: POLIMI_TOT1212NOx and references therein (2016);

URL:http://creckmodeling.chem.polimi.it/index.php/menukinetics/menu-kinetics- detailedmechanisms/menukinetics-complete-mechanism (accessed 2017/01/01). 


\section{SUPPLEMENTAL MATERIAL}

\section{TO}

A wide-range experimental and modeling study of oxidation and combustion of n-propylbenzene

Yue-Xi Liu ${ }^{1,2}$, Bing-Yin Wang ${ }^{1,2}$, Jun-Jie Weng ${ }^{1}$, Dan $\mathrm{Yu}^{1}$, Sandra Richter ${ }^{3}$, Thomas Kick ${ }^{3}$, Clemens Naumann ${ }^{3}$, Marina Braun-Unkhoff ${ }^{3}, Z^{2}$ hen-Yu $\operatorname{Tian}^{1,2, *}$

${ }^{1}$ Institute of Engineering Thermophysics, Chinese Academy of Sciences, Beisihuanxi 11, Beijing 100190, China

${ }^{2}$ University of Chinese Academy of Sciences, 19 A Yuquan Rd., Beijing 100049, China

${ }^{3}$ Institute of Combustion Technology, German Aerospace Center (DLR), 70569 Stuttgart, Germany

List of Supplemental Material

A "supplemental material" is included in this paper. It consists of the following sections:

Section 1: The estimate of the heat release

Section 2: Experimental conditions and analysis methods

Section 3: The original experimental data

Section 4: The Gaussian calculation results

Section 5: Primary and secondary mechanism of NPB

Section 6: The species and their corresponding structure

Section 7: Comparison of the predictions of different models

Section 8: The ROP analysis results of the other models 
Section 1: The estimate of the heat release

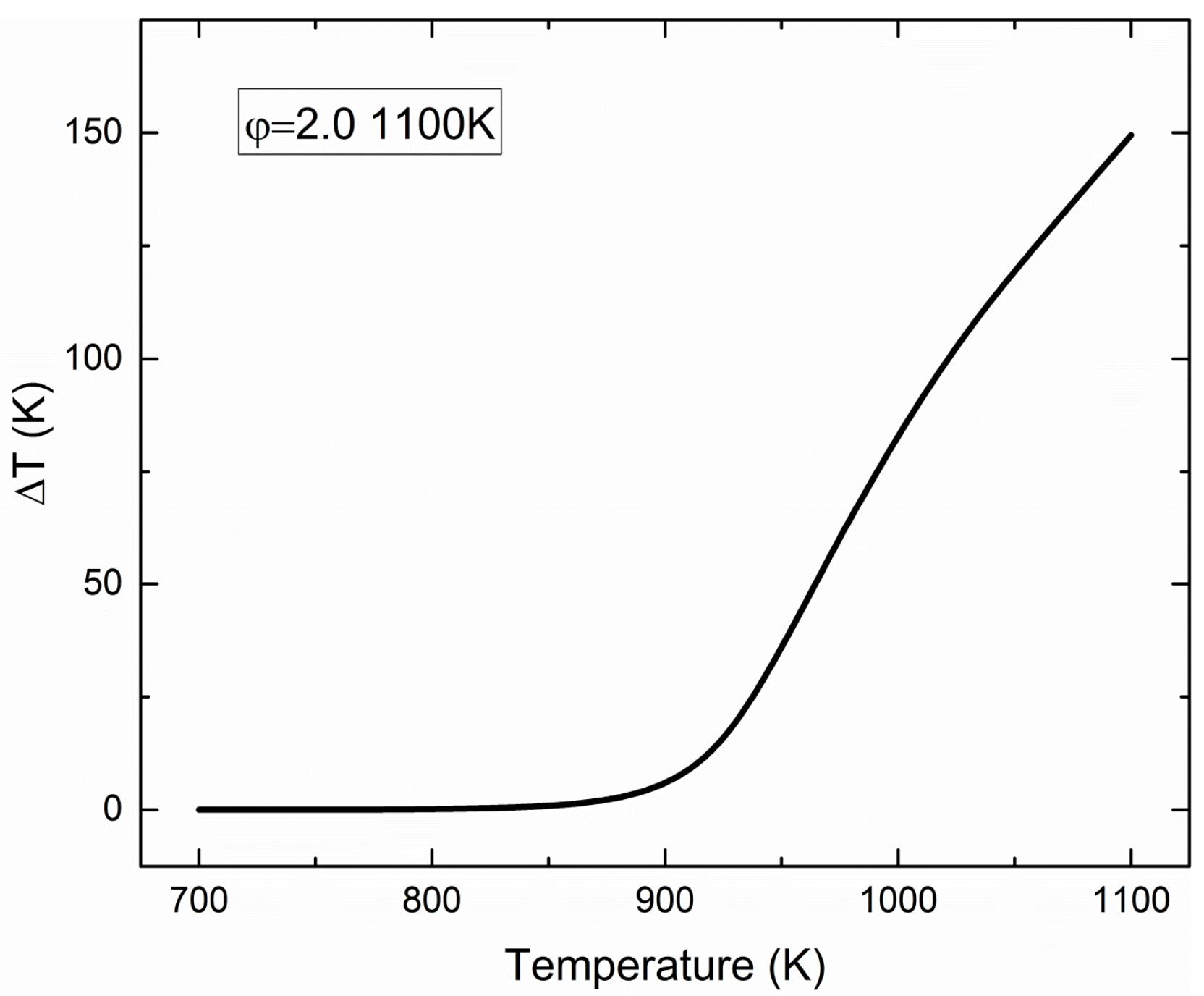

Fig. $\mathbf{S 1}$ The estimate of heat release under the adiabatic condition. The estimated $\Delta \mathrm{T}$ was $150 \mathrm{~K}$ around in the condition of $\varphi=2.0$ at $1100 \mathrm{~K}$. 


\section{Section 2: Experimental conditions and analysis methods}

Table S1 JSR reactor - Initial concentrations

\begin{tabular}{cccc}
\hline$\varphi$ & $\mathrm{NPB}$ & $\mathrm{O}_{2}$ & $\mathrm{Ar}$ \\
\hline 0.4 & 0.01 & 0.30 & 0.69 \\
1.0 & 0.01 & 0.12 & 0.87 \\
2.0 & 0.01 & 0.06 & 0.93 \\
\hline
\end{tabular}

Note: the total flow rate and mass flow rate of NPB are $1000.00 \mathrm{sccm}$ and $0.062 \mathrm{ml} / \mathrm{min}$, respectively.

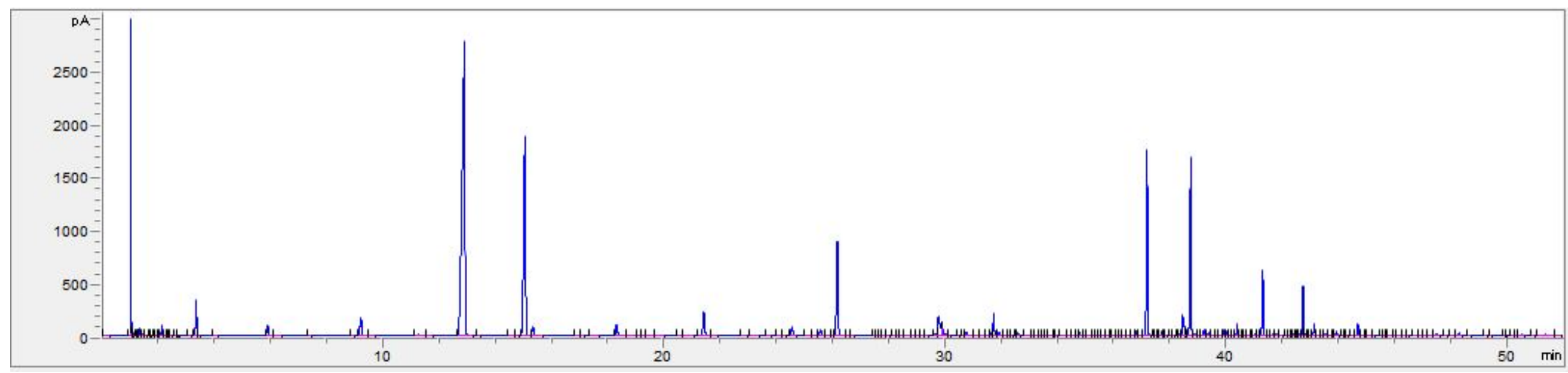

Figs. S2 The sample chromatogram of aromatics species. The column used to analyze the aromatic species was HP-INNOWAX (Aglient Technologies, Inc), with length of $30 \mathrm{~m}$ and diameter of $0.32 \mathrm{~mm}$.

The efficiency carbon number method was reported in 2012 and mainly used on aromatics quantification for gas-chromatograph [1]. In gaschromatograph, response factor is very important and influences the mole fraction results directly. The efficiency carbon number method shows a relationship between two response factors of two aromatics. There is an equation: 


$$
\frac{k(x)}{k(s)}=\frac{E(s)}{E(x)}
$$

$k(x)$; response factor of unknown specles

$k(s)$ : response factor of standard specles

$E(x)_{i}$ efficlency carbon number of unknown specles

$E(s)$, effledency carbon number of standard specles

The standard species means the response factor of which is already known. Table S2 shows the efficiency carbon number used in this work.

Table S2 The efficiency carbon number used in this work

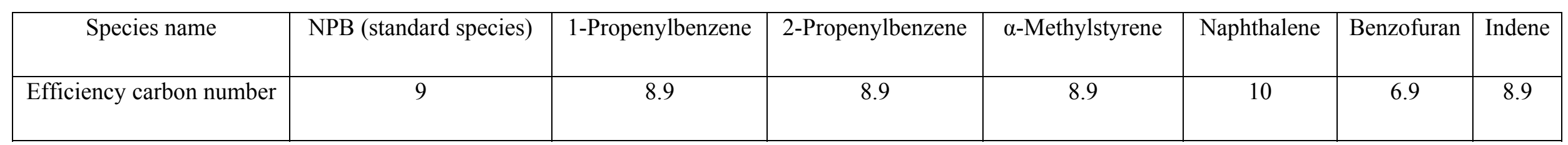




\section{Section 3: The original experimental data}

Table S3 The original experimental data of all species measured in the oxidation of NPB at low temperature $(\varphi=2.0)$

\begin{tabular}{|c|c|c|c|c|c|c|c|c|c|c|c|c|c|c|c|}
\hline \multirow{2}{*}{ Species } & \multirow{2}{*}{ Names } & \multicolumn{14}{|c|}{ Mole fractions (ppm) at different temperature $(\mathrm{K})$} \\
\hline & & 700 & 750 & 800 & 825 & 850 & 875 & 900 & 925 & 950 & 975 & 1000 & 1025 & 1050 & 1100 \\
\hline $\mathrm{nPB}$ & n-Propylbenzene & 10000.0 & 9910.0 & 9360.0 & 8250.0 & 7200.0 & 5580.0 & 3630.0 & 1890.0 & 1050.0 & 54.3 & 24.1 & 7.8 & 5.0 & 2.1 \\
\hline $\mathrm{CO}$ & Carbon oxide & 0.0 & 0.0 & 154.5 & 3180.0 & 7550.0 & 11240.0 & 13650.0 & 17300.0 & 22380.0 & 26000.0 & 28430.0 & 30970.0 & 32770.0 & 35650.0 \\
\hline $\mathrm{CO} 2$ & Carbon dioxide & 0.0 & 0.0 & 134.9 & 399.6 & 1240.0 & 1870.0 & 2220.0 & 3020.0 & 4420.0 & 6230.0 & 7730.0 & 8770.0 & 9830.0 & 11110.0 \\
\hline $\mathrm{H} 2$ & Hydrogen & 0.0 & 0.0 & 0.0 & 0.0 & 0.0 & 0.0 & 0.0 & 0.0 & 0.0 & 1840.0 & 2390.0 & 3310.0 & 3900.0 & 5690.0 \\
\hline $\mathrm{CH} 4$ & Methane & 0.0 & 0.0 & 0.0 & 276.0 & 759.3 & 1120.0 & 1540.0 & 1950.0 & 2510.0 & 2750.0 & 3000.0 & 3400.0 & 3650.0 & 4100.0 \\
\hline $\mathrm{C} 2 \mathrm{H} 2$ & Acetylene & 0.0 & 0.0 & 1.1 & 37.7 & 88.7 & 129.2 & 169.9 & 201.0 & 219.1 & 232.1 & 254.8 & 281.9 & 310.0 & 341.5 \\
\hline $\mathrm{C} 2 \mathrm{H} 4$ & Ethylene & 0.0 & 0.0 & 412.4 & 851.4 & 1230.0 & 1690.0 & 2390.0 & 2650.0 & 2780.0 & 2650.0 & 2520.0 & 2410.0 & 2250.0 & 2010.0 \\
\hline $\mathrm{C} 2 \mathrm{H} 6$ & Ethane & 0.0 & 0.0 & 0.0 & 20.3 & 54.4 & 68.9 & 87.7 & 114.6 & 139.9 & 151.7 & 163.8 & 167.6 & 171.0 & 156.3 \\
\hline C3H6 & Propylene & 0.0 & 0.0 & 16.9 & 35.2 & 65.1 & 113.1 & 146.4 & 194.6 & 171.9 & 139.8 & 104.2 & 78.3 & 65.6 & 57.1 \\
\hline CPD & Cyclopentadiene & 0.0 & 0.0 & 0.0 & 0.0 & 0.0 & 7.8 & 14.3 & 19.6 & 22.7 & 24.3 & 25.3 & 26.3 & 26.8 & 27.0 \\
\hline CH3CHO & Acetaldehyde & 0.0 & 0.0 & 3.5 & 8.9 & 17.4 & 36.6 & 66.7 & 88.5 & 89.3 & 75.5 & 64.5 & 58.5 & 51.9 & 46.1 \\
\hline $\mathrm{C} 3 \mathrm{H} 4 \mathrm{O}$ & Acrolein & 0.0 & 0.0 & 0.0 & 16.5 & 30.1 & 66.4 & 126.1 & 155.3 & 138.3 & 95.0 & 69.2 & 54.4 & 34.2 & 13.2 \\
\hline A1 & Benzene & 6.7 & 7.7 & 25.8 & 46.9 & 75.1 & 137.5 & 257.2 & 404.2 & 544.6 & 653.1 & 694.1 & 737.2 & 747.0 & 746.9 \\
\hline $\mathrm{A} 1 \mathrm{CH} 3$ & Toluene & 0.0 & 0.0 & 13.9 & 23.2 & 37.5 & 68.0 & 108.0 & 123.5 & 116.4 & 101.9 & 88.4 & 75.5 & 60.1 & 39.6 \\
\hline
\end{tabular}




\begin{tabular}{|c|c|c|c|c|c|c|c|c|c|c|c|c|c|c|c|}
\hline $\mathrm{A} 1 \mathrm{C} 2 \mathrm{H} 5$ & Ethylbenzene & 0.0 & 6.4 & 16.4 & 32.8 & 58.5 & 110.4 & 161.7 & 166.5 & 135.8 & 109.1 & 85.3 & 58.5 & 29.6 & 7.6 \\
\hline $\mathrm{A} 1 \mathrm{C} 2 \mathrm{H} 3$ & Styrene & 0.0 & 32.6 & 321.8 & 623.4 & 1030.0 & 1580.0 & 1900.0 & 1570.0 & 1110.0 & 750.4 & 545.4 & 367.2 & 108.2 & 37.8 \\
\hline $\mathrm{A} 1 \mathrm{CHCHCH} 3$ & 1-Propenylbenzene & 0.0 & 24.1 & 157.3 & 223.4 & 280.5 & 269.4 & 189.6 & 88.8 & 43.3 & 23.8 & 13.5 & 5.8 & 0.0 & 0.0 \\
\hline $\mathrm{A} 1 \mathrm{CH} 2 \mathrm{CHCH} 2$ & 2-Propenylbenzene & 0.0 & 6.7 & 47.9 & 76.5 & 102.4 & 105.3 & 74.2 & 34.6 & 16.2 & 6.4 & 0.0 & 0.0 & 0.0 & 0.0 \\
\hline $\mathrm{A} 1 \mathrm{C}(\mathrm{CH} 3) \mathrm{CH} 2$ & $\alpha$-Methylstyrenen & 0.0 & 9.7 & 45.5 & 70.8 & 95.7 & 104.6 & 88.0 & 54.5 & 34.5 & 22.0 & 14.5 & 8.5 & 0.0 & 0.0 \\
\hline $\mathrm{C} 9 \mathrm{H} 8$ & Indene & 0.0 & 0.0 & 0.0 & 6.8 & 9.6 & 12.3 & 12.2 & 8.8 & 0.0 & 0.0 & 0.0 & 0.0 & 0.0 & 0.0 \\
\hline A2 & Naphhthalene & 0.0 & 0.0 & 0.0 & 0.0 & 0.0 & 5.5 & 19.0 & 34.2 & 44.5 & 46.5 & 46.8 & 49.8 & 51.4 & 52.7 \\
\hline C14H14 & Bibenzyl & 0.0 & 3.2 & 36.5 & 121.2 & 322.8 & 526.8 & 381.0 & 275.9 & 107.2 & 58.8 & 23.4 & 13.3 & 6.7 & 2.7 \\
\hline $\mathrm{A} 1 \mathrm{OH}$ & Phenol & 0.0 & 0.0 & 4.8 & 20.3 & 79.9 & 206.2 & 476.7 & 686.7 & 773.3 & 703.3 & 590.0 & 510.0 & 340.0 & 98.1 \\
\hline $\mathrm{A} 1 \mathrm{CHO}$ & Benzaldehyde & 0.0 & 6.9 & 53.8 & 115.7 & 219.4 & 357.4 & 496.7 & 462.1 & 354.4 & 238.1 & 164.4 & 104.3 & 49.9 & 17.7 \\
\hline $\mathrm{C} 8 \mathrm{H} 6 \mathrm{O}$ & Benzofuran & 0.0 & 0.0 & 0.0 & 0.0 & 8.5 & 27.8 & 65.2 & 93.2 & 94.0 & 77.5 & 65.7 & 50.9 & 38.2 & 15.6 \\
\hline
\end{tabular}

Table S4 The original experimental data of all species measured in the oxidation of NPB at low temperature $(\varphi=1.0)$.

\begin{tabular}{|c|c|c|c|c|c|c|c|c|c|c|c|c|c|c|c|}
\hline \multirow{2}{*}{ Species } & \multirow{2}{*}{ Names } & \multicolumn{14}{|c|}{ Mole fractions (ppm) at different temperature (K) } \\
\hline & & 700 & 750 & 800 & 825 & 850 & 875 & 900 & 925 & 950 & 975 & 1000 & 1025 & 1050 & 1100 \\
\hline $\mathrm{nPB}$ & n-Propylbenzene & 10000.0 & 9900.0 & 7540.0 & 3850.0 & 2780.0 & 2070.0 & 1080.0 & 702.3 & 276.8 & 70.6 & 39.0 & 10.6 & 3.6 & 0.0 \\
\hline $\mathrm{CO}$ & Carbon oxide & 0.0 & 0.0 & 165.8 & 1980.0 & 4240.0 & 10890.0 & 18400.0 & 23880.0 & 29720.0 & 32240.0 & 34800.0 & 31300.0 & 25890.0 & 19230.0 \\
\hline $\mathrm{CO} 2$ & Carbon dioxide & 0.0 & 41.6 & 99.6 & 351.5 & 1340.0 & 2660.0 & 3570.0 & 4660.0 & 5080.0 & 27380.0 & 40590.0 & 48660.0 & 58160.0 & 61730.0 \\
\hline $\mathrm{H} 2$ & Hydrogen & 0.0 & 0.0 & 0.0 & 0.0 & 0.0 & 0.0 & 0.0 & 0.0 & 2350.0 & 2790.0 & 0.0 & 0.0 & 0.0 & 0.0 \\
\hline
\end{tabular}




\begin{tabular}{|c|c|c|c|c|c|c|c|c|c|c|c|c|c|c|c|}
\hline $\mathrm{CH} 4$ & Methane & 0.0 & 0.0 & 0.0 & 124.9 & 519.7 & 964.6 & 1250.0 & 1580.0 & 1720.0 & 1550.0 & 999.5 & 521.7 & 290.5 & 135.7 \\
\hline $\mathrm{C} 2 \mathrm{H} 2$ & Acetylene & 0.0 & 0.0 & 0.0 & 0.0 & 40.0 & 119.2 & 151.4 & 181.6 & 205.2 & 218.2 & 190.2 & 125.7 & 56.1 & 13.6 \\
\hline $\mathrm{C} 2 \mathrm{H} 4$ & Ethylene & 0.0 & 0.0 & 90.8 & 622.6 & 1200.0 & 1660.0 & 1720.0 & 1750.0 & 1650.0 & 1350.0 & 1070.0 & 701.6 & 219.9 & 76.5 \\
\hline $\mathrm{C} 2 \mathrm{H} 6$ & Ethane & 0.0 & 0.0 & 0.0 & 0.0 & 0.0 & 33.3 & 47.0 & 61.1 & 76.2 & 69.5 & 49.8 & 28.6 & 10.1 & 2.6 \\
\hline $\mathrm{C} 3 \mathrm{H} 6$ & Propylene & 0.0 & 0.0 & 0.0 & 23.7 & 46.4 & 109.3 & 108.4 & 100.3 & 86.6 & 48.0 & 24.4 & 0.0 & 0.0 & 0.0 \\
\hline CPD & Cyclopentadiene & 0.0 & 0.0 & 5.8 & 8.8 & 10.3 & 11.8 & 11.0 & 8.0 & 4.0 & 0.0 & 0.0 & 0.0 & 0.0 & 0.0 \\
\hline $\mathrm{CH} 3 \mathrm{CHO}$ & Acetaldehyde & 0.0 & 1.7 & 36.6 & 103.0 & 113.4 & 98.3 & 80.2 & 50.3 & 33.0 & 22.0 & 14.7 & 10.0 & 7.8 & 0.0 \\
\hline $\mathrm{C} 3 \mathrm{H} 4 \mathrm{O}$ & Acrolein & 0.0 & 0.0 & 45.9 & 124.7 & 146.8 & 165.5 & 140.7 & 122.6 & 68.6 & 43.4 & 30.0 & 18.3 & 10.2 & 0.0 \\
\hline A1 & Benzene & 5.7 & 15.1 & 192.8 & 259.6 & 336.5 & 355.1 & 364.3 & 324.3 & 278.8 & 187.8 & 113.3 & 68.8 & 42.8 & 30.1 \\
\hline $\mathrm{A} 1 \mathrm{CH} 3$ & Toluene & 0.0 & 8.9 & 52.20 & 62.8 & 72.2 & 63.1 & 52.9 & 29.6 & 14.4 & 7.9 & 5.0 & 0.0 & 0.0 & 0.0 \\
\hline $\mathrm{A} 1 \mathrm{C} 2 \mathrm{H} 5$ & Ethylbenzene & 0.0 & 3.4 & 29.44 & 41.6 & 59.3 & 51.7 & 42.3 & 24.0 & 13.4 & 7.9 & 5.0 & 0.0 & 0.0 & 0.0 \\
\hline A1CHCHCH3 & 1-Propenylbenzene & 0.0 & 0.0 & 364.5 & 455.3 & 383.0 & 306.1 & 120.9 & 57.1 & 21.1 & 10.0 & 0.0 & 0.0 & 0.0 & 0.0 \\
\hline $\mathrm{A} 1 \mathrm{CH} 2 \mathrm{CHCH} 2$ & 2-Propenylbenzene & 0.0 & 58.8 & 178.5 & 161.9 & 138.4 & 100.3 & 43.0 & 17.7 & 7.3 & 0.0 & 0.0 & 0.0 & 0.0 & 0.0 \\
\hline $\mathrm{A} 1 \mathrm{C}(\mathrm{CH} 3) \mathrm{CH} 2$ & $\alpha$-Methylstyrenen & 8.9 & 75.7 & 190.3 & 166.9 & 137.8 & 107.5 & 55.4 & 34.1 & 12.1 & 6.6 & 0.0 & 0.0 & 0.0 & 0.0 \\
\hline C9H8 & Indene & 0.0 & 0.0 & 12.23 & 10.9 & 9.6 & 0.0 & 0.0 & 0.0 & 0.0 & 0.0 & 0.0 & 0.0 & 0.0 & 0.0 \\
\hline A2 & Naphhthalene & 0.0 & 0.0 & 3.71 & 8.6 & 15.0 & 22.7 & 17.1 & 11.6 & 5.4 & 0.0 & 0.0 & 0.0 & 0.0 & 0.0 \\
\hline C14H14 & Bibenzyl & 29.4 & 23.1 & 187.8 & 286.7 & 333.8 & 282.1 & 191.4 & 100.1 & 56.6 & 29.9 & 15.9 & 8.5 & 5.0 & 0.0 \\
\hline $\mathrm{A} 1 \mathrm{OH}$ & Phenol & 9.6 & 10.1 & 220.9 & 505.0 & 900.0 & 700.0 & 462.0 & 300.0 & 150.2 & 84.0 & 50.7 & 20.4 & 0.0 & 0.0 \\
\hline
\end{tabular}




\begin{tabular}{|c|c|c|c|c|c|c|c|c|c|c|c|c|c|c|c|}
\hline $\mathrm{A} 1 \mathrm{CHO}$ & Benzaldehyde & 0.0 & 66.5 & 500.0 & 602.5 & 610.0 & 495.0 & 280.0 & 144.7 & 79.0 & 56.3 & 36.2 & 23.4 & 12.1 & 3.6 \\
\hline C8H6O & Benzofuran & 0.0 & 0.0 & 36.67 & 57.3 & 112.4 & 90.6 & 68.6 & 37.40 & 23.0 & 14.4 & 8.5 & 5.2 & 0.0 & 0.0 \\
\hline
\end{tabular}

Table S5 The original experimental data of all species measured in the oxidation of NPB at low temperature $(\varphi=0.4)$.

\begin{tabular}{|c|c|c|c|c|c|c|c|c|c|c|c|c|c|c|c|}
\hline \multirow{2}{*}{ Species } & \multirow{2}{*}{ Names } & \multicolumn{14}{|c|}{ Mole fractions $\left(\times 10^{-4}\right)$ at different temperature $(\mathrm{K})$} \\
\hline & & 700 & 750 & 800 & 825 & 850 & 875 & 900 & 925 & 950 & 975 & 1000 & 1025 & 1050 & 1100 \\
\hline nPB & n-Propylbenzene & 9830.0 & 9320.0 & 3530.0 & 1720.0 & 1130.0 & 616.6 & 388.0 & 121.0 & 69.9 & 29.6 & 5.6 & 0.0 & 0.0 & 0.0 \\
\hline $\mathrm{CO}$ & Carbon oxide & 0.0 & 0.0 & 0.0 & 0.0 & 106.1 & 2880.0 & 8770.0 & 18790.0 & 22930.0 & 21780.0 & 14890.0 & 6450.0 & 2140.0 & 874.4 \\
\hline $\mathrm{CO} 2$ & Carbon dioxide & 0.0 & 36.6 & 73.3 & 1850.0 & 494 & 17610.0 & 34230.0 & 55720.0 & 63570.0 & 74710.0 & 77070.0 & 78110.0 & 78630.0 & 78900.0 \\
\hline $\mathrm{H} 2$ & Hydrogen & 0.0 & 0.0 & 0.0 & 0.0 & 0.0 & 0.0 & 0.0 & 0.0 & 0.0 & 0.0 & 0.0 & 0.0 & 0.0 & 0.0 \\
\hline $\mathrm{CH} 4$ & Methane & 0.0 & 0.0 & 0.0 & 147.3 & 372.1 & 461.0 & 726.5 & 964.5 & 764.9 & 305.6 & 169.9 & 84.6 & 50.3 & 9.5 \\
\hline $\mathrm{C} 2 \mathrm{H} 2$ & Acetylene & 0.0 & 0.0 & 0.0 & 52.9 & 140.4 & 171.1 & 159.3 & 120.5 & 48.1 & 19.4 & 6.9 & 0.0 & 0.0 & 0.0 \\
\hline $\mathrm{C} 2 \mathrm{H} 4$ & Ethylene & 0.0 & 0.0 & 97.4 & 791.5 & 1190.0 & 1120.0 & 954.7 & 619.1 & 355.8 & 100.1 & 70.7 & 30.1 & 9.6 & 0.0 \\
\hline $\mathrm{C} 2 \mathrm{H} 6$ & Ethane & 0.0 & 0.0 & 0.0 & 0.0 & 0.0 & 0.0 & 0.0 & 0.0 & 0.0 & 0.0 & 0.0 & 0.0 & 0.0 & 0.0 \\
\hline C3H6 & Propylene & 0.0 & 0.0 & 0.0 & 52.5 & 64.5 & 54.6 & 0.0 & 0.0 & 0.0 & 0.0 & 0.0 & 0.0 & 0.0 & 0.0 \\
\hline CPD & Cyclopentadiene & 0.0 & 0.0 & 6.3 & 7.2 & 0.0 & 0.0 & 0.0 & 0.0 & 0.0 & 0.0 & 0.0 & 0.0 & 0.0 & 0.0 \\
\hline CH3CHO & Acetaldehyde & 0.0 & 0.0 & 85.0 & 98.0 & 79.9 & 55.0 & 39.5 & 24.1 & 15.3 & 11.3 & 8.1 & 5.5 & 0.0 & 0.0 \\
\hline $\mathrm{C} 3 \mathrm{H} 4 \mathrm{O}$ & Acrolein & 0.0 & 0.0 & 111.1 & 135.7 & 83.2 & 47.1 & 31.3 & 19.7 & 12.2 & 8.2 & 4.9 & 0.0 & 0.0 & 0.0 \\
\hline A1 & Benzene & 7.3 & 7.3 & 128.4 & 228.4 & 165.4 & 105.0 & 53.4 & 36.2 & 20.1 & 14.0 & 7.8 & 0.0 & 0.0 & 0.0 \\
\hline
\end{tabular}




\begin{tabular}{|c|c|c|c|c|c|c|c|c|c|c|c|c|c|c|c|}
\hline $\mathrm{A} 1 \mathrm{CH} 3$ & Toluene & 0.0 & 0.0 & 33.2 & 38.0 & 29.4 & 16.6 & 12.7 & 8.37 & 4.1 & 0.0 & 0.0 & 0.0 & 0.0 & 0.0 \\
\hline $\mathrm{A} 1 \mathrm{C} 2 \mathrm{H} 5$ & Ethylbenzene & 0.0 & 3.3 & 11.1 & 17.1 & 16.4 & 13.1 & 9.8 & 5.9 & 0.0 & 0.0 & 0.0 & 0.0 & 0.0 & 0.0 \\
\hline $\mathrm{A} 1 \mathrm{C} 2 \mathrm{H} 3$ & Styrene & 0.0 & 9.3 & 737.4 & 710.0 & 543.1 & 333.2 & 260.8 & 184.6 & 128.0 & 74.9 & 35.0 & 0.0 & 0.0 & 0.0 \\
\hline $\mathrm{A} 1 \mathrm{CHCHCH3}$ & 1-Propenylbenzene & 4.8 & 50.4 & 506.4 & 324.5 & 196.1 & 163.5 & 84.5 & 38.1 & 17.4 & 8.7 & 0.0 & 0.0 & 0.0 & 0.0 \\
\hline $\mathrm{A} 1 \mathrm{CH} 2 \mathrm{CHCH} 2$ & 2-Propenylbenzene & 0.0 & 0.0 & 139.5 & 90.4 & 70.6 & 54.0 & 33.5 & 16.9 & 11.2 & 0.0 & 0.0 & 0.0 & 0.0 & 0.0 \\
\hline $\mathrm{A} 1 \mathrm{C}(\mathrm{CH} 3 \mathrm{CH} 2$ & a-Methylstyrenen & 0.0 & 7.8 & 147.5 & 91.0 & 68.8 & 51.1 & 30.8 & 16.2 & 8.1 & 0.0 & 0.0 & 0.0 & 0.0 & 0.0 \\
\hline $\mathrm{C} 9 \mathrm{H} 8$ & Indene & 0.0 & 0.0 & 6.6 & 0.0 & 0.0 & 0.0 & 0.0 & 0.0 & 0.0 & 0.0 & 0.0 & 0.0 & 0.0 & 0.0 \\
\hline $\mathrm{A} 2$ & Naphhthalene & 0.0 & 0.0 & 0.0 & 0.0 & 0.0 & 0.0 & 0.0 & 0.0 & 0.0 & 0.0 & 0.0 & 0.0 & 0.0 & 0.0 \\
\hline $\mathrm{C} 14 \mathrm{H} 14$ & Bibenzyl & 0.0 & 0.0 & 8.8 & 20.4 & 25.6 & 37.3 & 33.2 & 18.6 & 11.1 & 6.8 & 2.6 & 0.0 & 0.0 & 0.0 \\
\hline $\mathrm{A} 1 \mathrm{OH}$ & Phenol & 0.0 & 6.6 & 626.6 & 1150.0 & 864.6 & 530.9 & 306.4 & 159.5 & 85.0 & 39.3 & 0.0 & 0.0 & 0.0 & 0.0 \\
\hline $\mathrm{A} 1 \mathrm{CHO}$ & Benzaldehyde & 8.6 & 56.0 & 687.0 & 901.3 & 577.6 & 454.6 & 300.6 & 215.1 & 149.7 & 124.7 & 88.1 & 57.4 & 31.0 & 14.1 \\
\hline $\mathrm{C} 8 \mathrm{H} 6 \mathrm{O}$ & Benzofuran & 0.0 & 0.0 & 12.9 & 29.7 & 17.7 & 11.7 & 7.7 & 4.2 & 0.0 & 0.0 & 0.0 & 0.0 & 0.0 & 0.0 \\
\hline
\end{tabular}


Table S6 Experimental results for the laminar burning velocity of NPB at a constant preheat temperature of $473 \mathrm{~K}$

\begin{tabular}{|c|c|c|c|c|c|}
\hline \multicolumn{6}{|c|}{$p=1$ bar } \\
\hline$\varphi$ & $\Delta \varphi$ & $\Delta \varphi / \varphi(\%)$ & $S_{\mathrm{u}} / \mathrm{cm} \mathrm{s}^{-1}$ & $\Delta S_{\mathrm{u}} / \mathrm{cm} \mathrm{s}^{-1}$ & $\Delta S_{\mathrm{u}} / S_{\mathrm{u}}(\%)$ \\
\hline 0.600 & 0.023 & 3.78 & 36.02 & 2.00 & 5.54 \\
\hline 0.625 & 0.023 & 3.68 & 39.98 & 3.35 & 8.38 \\
\hline 0.650 & 0.023 & 3.60 & 43.23 & 1.99 & 4.61 \\
\hline 0.675 & 0.024 & 3.54 & 47.32 & 2.15 & 4.55 \\
\hline 0.700 & 0.024 & 3.49 & 51.17 & 1.82 & 3.56 \\
\hline 0.725 & 0.025 & 3.45 & 55.26 & 2.10 & 3.80 \\
\hline 0.750 & 0.026 & 3.41 & 57.52 & 2.99 & 5.20 \\
\hline 0.775 & 0.026 & 3.39 & 60.76 & 2.98 & 4.90 \\
\hline 0.800 & 0.027 & 3.37 & 64.47 & 2.97 & 4.61 \\
\hline 0.825 & 0.028 & 3.36 & 67.22 & 2.98 & 4.43 \\
\hline 0.850 & 0.028 & 3.35 & 70.05 & 3.00 & 4.28 \\
\hline 0.875 & 0.029 & 3.33 & 71.71 & 2.63 & 3.67 \\
\hline 0.900 & 0.030 & 3.33 & 74.62 & 2.60 & 3.49 \\
\hline 0.925 & 0.031 & 3.32 & 75.59 & 2.74 & 3.62 \\
\hline 0.950 & 0.031 & 3.31 & 77.79 & 2.85 & 3.66 \\
\hline 0.975 & 0.032 & 3.31 & 77.79 & 2.73 & 3.51 \\
\hline 1.000 & 0.033 & 3.31 & 79.70 & 2.69 & 3.38 \\
\hline 1.050 & 0.035 & 3.31 & 81.11 & 2.50 & 3.08 \\
\hline 1.100 & 0.036 & 3.31 & 79.90 & 2.68 & 3.36 \\
\hline 1.150 & 0.038 & 3.31 & 78.59 & 2.51 & 3.20 \\
\hline 1.200 & 0.040 & 3.32 & 76.33 & 2.77 & 3.63 \\
\hline 1.250 & 0.042 & 3.33 & 72.24 & 2.62 & 3.63 \\
\hline 1.300 & 0.026 & 1.98 & 71.85 & 1.78 & 2.47 \\
\hline 1.350 & 0.031 & 2.27 & 68.41 & 1.71 & 2.49 \\
\hline 1.400 & 0.033 & 2.34 & 61.36 & 2.08 & 3.38 \\
\hline 1.450 & 0.035 & 2.41 & 55.85 & 2.81 & 5.03 \\
\hline
\end{tabular}




\begin{tabular}{|c|c|c|c|c|c|}
\hline 1.500 & 0.037 & 2.48 & 49.39 & 3.01 & 6.09 \\
\hline 1.550 & 0.039 & 2.53 & 44.02 & 2.68 & 6.09 \\
\hline 1.599 & 0.042 & 2.63 & 39.56 & 3.47 & 8.77 \\
\hline 1.649 & 0.046 & 2.77 & 35.10 & 3.36 & 9.57 \\
\hline 1.699 & 0.050 & 2.92 & 32.65 & 2.08 & 6.36 \\
\hline 1.749 & 0.053 & 3.04 & 30.97 & 2.55 & 8.25 \\
\hline 1.799 & 0.057 & 3.16 & 28.90 & 3.78 & 13.07 \\
\hline 1.849 & 0.060 & 3.26 & 25.84 & 2.43 & 9.42 \\
\hline 1.899 & 0.064 & 3.35 & 22.91 & 2.45 & 10.68 \\
\hline 1.949 & 0.067 & 3.46 & 23.01 & 2.81 & 12.19 \\
\hline 1.999 & 0.071 & 3.55 & 20.76 & 2.78 & 13.39 \\
\hline \multicolumn{6}{|c|}{$p=3$ bar } \\
\hline$\varphi$ & $\Delta \varphi$ & $\Delta \varphi / \varphi(\%)$ & $S_{\mathrm{u}} / \mathrm{cm} \mathrm{s}^{-1}$ & $\Delta S_{\mathrm{u}} / \mathrm{cm} \mathrm{s}^{-1}$ & $\Delta S_{\mathrm{u}} / S_{\mathrm{u}}(\%)$ \\
\hline 0.647 & 0.039 & 6.049 & 31.449 & 3.580 & 11.382 \\
\hline 0.673 & 0.040 & 5.947 & 34.801 & 3.369 & 9.682 \\
\hline 0.702 & 0.041 & 5.836 & 38.300 & 2.420 & 6.320 \\
\hline 0.723 & 0.042 & 5.751 & 42.828 & 3.662 & 8.551 \\
\hline 0.749 & 0.042 & 5.647 & 45.636 & 2.270 & 4.974 \\
\hline 0.777 & 0.043 & 5.550 & 48.333 & 1.696 & 3.508 \\
\hline 0.798 & 0.044 & 5.502 & 52.078 & 3.051 & 5.858 \\
\hline 0.826 & 0.045 & 5.435 & 53.734 & 2.376 & 4.422 \\
\hline 0.850 & 0.046 & 5.398 & 55.917 & 1.922 & 3.436 \\
\hline 0.873 & 0.047 & 5.366 & 58.226 & 1.838 & 3.156 \\
\hline 0.901 & 0.048 & 5.324 & 60.584 & 2.135 & 3.525 \\
\hline 0.924 & 0.049 & 5.302 & 63.273 & 1.721 & 2.721 \\
\hline 0.951 & 0.050 & 5.270 & 64.181 & 1.869 & 2.913 \\
\hline 0.974 & 0.051 & 5.256 & 65.976 & 1.844 & 2.794 \\
\hline 0.999 & 0.052 & 5.241 & 66.598 & 1.683 & 2.527 \\
\hline 1.050 & 0.055 & 5.229 & 69.017 & 1.716 & 2.487 \\
\hline 1.099 & 0.057 & 5.225 & 69.672 & 1.672 & 2.399 \\
\hline
\end{tabular}




\begin{tabular}{|c|c|c|c|c|c|}
\hline 1.149 & 0.060 & 5.233 & 69.024 & 1.887 & 2.734 \\
\hline 1.199 & 0.063 & 5.244 & 67.257 & 1.948 & 2.896 \\
\hline 1.250 & 0.066 & 5.261 & 63.911 & 1.744 & 2.729 \\
\hline 1.299 & 0.069 & 5.284 & 59.982 & 1.972 & 3.287 \\
\hline 1.351 & 0.072 & 5.304 & 53.918 & 1.368 & 2.537 \\
\hline 1.400 & 0.075 & 5.322 & 53.181 & 2.653 & 4.988 \\
\hline 1.452 & 0.078 & 5.373 & 50.549 & 3.408 & 6.743 \\
\hline 1.503 & 0.081 & 5.415 & 44.800 & 3.464 & 7.733 \\
\hline 1.549 & 0.084 & 5.455 & 38.985 & 2.354 & 6.039 \\
\hline \multicolumn{6}{|c|}{$p=6$ bar } \\
\hline$\varphi$ & $\Delta \varphi$ & $\Delta \varphi / \varphi(\%)$ & $S_{\mathrm{u}} / \mathrm{cm} \mathrm{s}^{-1}$ & $\Delta S_{\mathrm{u}} / \mathrm{cm} \mathrm{s}^{-1}$ & $\Delta S_{\mathrm{u}} / S_{\mathrm{u}}(\%)$ \\
\hline 0.652 & 0.059 & 9.00 & 28.48 & 4.16 & 14.60 \\
\hline 0.682 & 0.060 & 8.87 & 30.49 & 3.41 & 11.19 \\
\hline 0.703 & 0.062 & 8.81 & 33.60 & 3.59 & 10.70 \\
\hline 0.725 & 0.064 & 8.80 & 36.14 & 2.92 & 8.07 \\
\hline 0.752 & 0.065 & 8.70 & 37.86 & 3.63 & 9.60 \\
\hline 0.779 & 0.067 & 8.60 & 41.34 & 2.57 & 6.21 \\
\hline 0.802 & 0.069 & 8.57 & 43.66 & 3.09 & 7.08 \\
\hline 0.827 & 0.070 & 8.50 & 45.38 & 4.30 & 9.48 \\
\hline 0.852 & 0.072 & 8.47 & 46.40 & 3.09 & 6.67 \\
\hline 0.874 & 0.074 & 8.48 & 49.66 & 2.99 & 6.03 \\
\hline 0.899 & 0.076 & 8.44 & 51.11 & 6.08 & 11.89 \\
\hline 0.925 & 0.077 & 8.37 & 53.49 & 4.73 & 8.85 \\
\hline 0.951 & 0.079 & 8.33 & 54.67 & 3.71 & 6.78 \\
\hline 0.978 & 0.081 & 8.30 & 55.68 & 4.68 & 8.41 \\
\hline 0.997 & 0.083 & 8.30 & 57.54 & 6.53 & 11.35 \\
\hline 1.049 & 0.087 & 8.27 & 59.60 & 5.64 & 9.46 \\
\hline 1.097 & 0.091 & 8.27 & 60.21 & 7.24 & 12.03 \\
\hline 1.150 & 0.095 & 8.26 & 59.78 & 5.51 & 9.23 \\
\hline 1.200 & 0.099 & 8.25 & 57.68 & 5.68 & 9.84 \\
\hline
\end{tabular}




\begin{tabular}{|c|c|c|c|c|c|}
\hline 1.252 & 0.103 & 8.25 & 52.16 & 6.22 & 11.93 \\
\hline 1.301 & 0.108 & 8.27 & 52.31 & 6.25 & 11.95 \\
\hline 1.351 & 0.112 & 8.30 & 51.77 & 3.47 & 6.70 \\
\hline 1.402 & 0.117 & 8.33 & 49.02 & 5.26 & 10.74 \\
\hline 1.453 & 0.122 & 8.38 & 45.51 & 4.19 & 9.21 \\
\hline 1.500 & 0.127 & 8.46 & 38.44 & 2.43 & 6.31 \\
\hline
\end{tabular}

Table S7 Experimental results for the ignition delay time measurements of NPB / synthetic air mixtures at $\phi=1$ and at a dilution of 1:2 with nitrogen

\begin{tabular}{|c|c|c|c|c|c|}
\hline Reference \# & $\mathrm{M}_{1}$ & $\mathrm{p}_{1} / \mathrm{bar}$ & $\mathrm{T}_{5 \mathrm{~s}} / \mathrm{K}$ & $\mathrm{P}_{5 \mathrm{~s}} / \mathrm{bar}$ & $\mathrm{t}\left([\mathrm{CH}(\mathrm{A})]_{\max }\right) / \mathrm{s}$ \\
\hline 3679 & 2.022 & 1.077 & 1000 & 17.00 & 0.004745 \\
\hline 3680 & 2.012 & 0.994 & 993 & 15.43 & 0.004799 \\
\hline 3681 & 2.063 & 0.911 & 1026 & 15.38 & 0.003711 \\
\hline 3682 & 2.136 & 0.828 & 1071 & 15.68 & 0.002089 \\
\hline 3683 & 2.212 & 0.745 & 1122 & 15.85 & 0.001089 \\
\hline 3684 & 2.29 & 0.663 & 1174 & 15.77 & 0.000575 \\
\hline 3685 & 2.382 & 0.58 & 1238 & 15.68 & 0.000272 \\
\hline 3686 & 2.507 & 0.498 & 1327 & 15.82 & 0.000118 \\
\hline 3687 & 2.659 & 0.415 & 1440 & 15.81 & 0.000041 \\
\hline 3688 & 1.948 & 1.242 & 953 & 17.26 & 0.009948 \\
\hline 3689 & 1.796 & 1.45 & 862 & 15.19 & 0.018182 \\
\hline 3690 & 1.771 & 1.657 & 848 & 16.53 & 0.027821 \\
\hline 3691 & 1.684 & 1.863 & 798 & 15.52 & -- \\
\hline 3692 & 1.895 & 1.242 & 921 & 15.71 & 0.011886 \\
\hline 3693 & 1.865 & 1.346 & 903 & 16.10 & 0.014108 \\
\hline 3694 & 1.839 & 1.408 & 888 & 16.05 & 0.015864 \\
\hline 3695 & 1.941 & 1.16 & 949 & 15.94 & 0.006954 \\
\hline 3696 & 1.99 & 1.118 & 980 & 16.72 & 0.005842 \\
\hline 3697 & 1.933 & 1.201 & 944 & 16.25 & 0.008688 \\
\hline 3698 & 2.748 & 0.373 & 1508 & 15.73 & 0.000028 \\
\hline 3699 & 2.857 & 0.332 & 1594 & 15.75 & 0.000016 \\
\hline
\end{tabular}




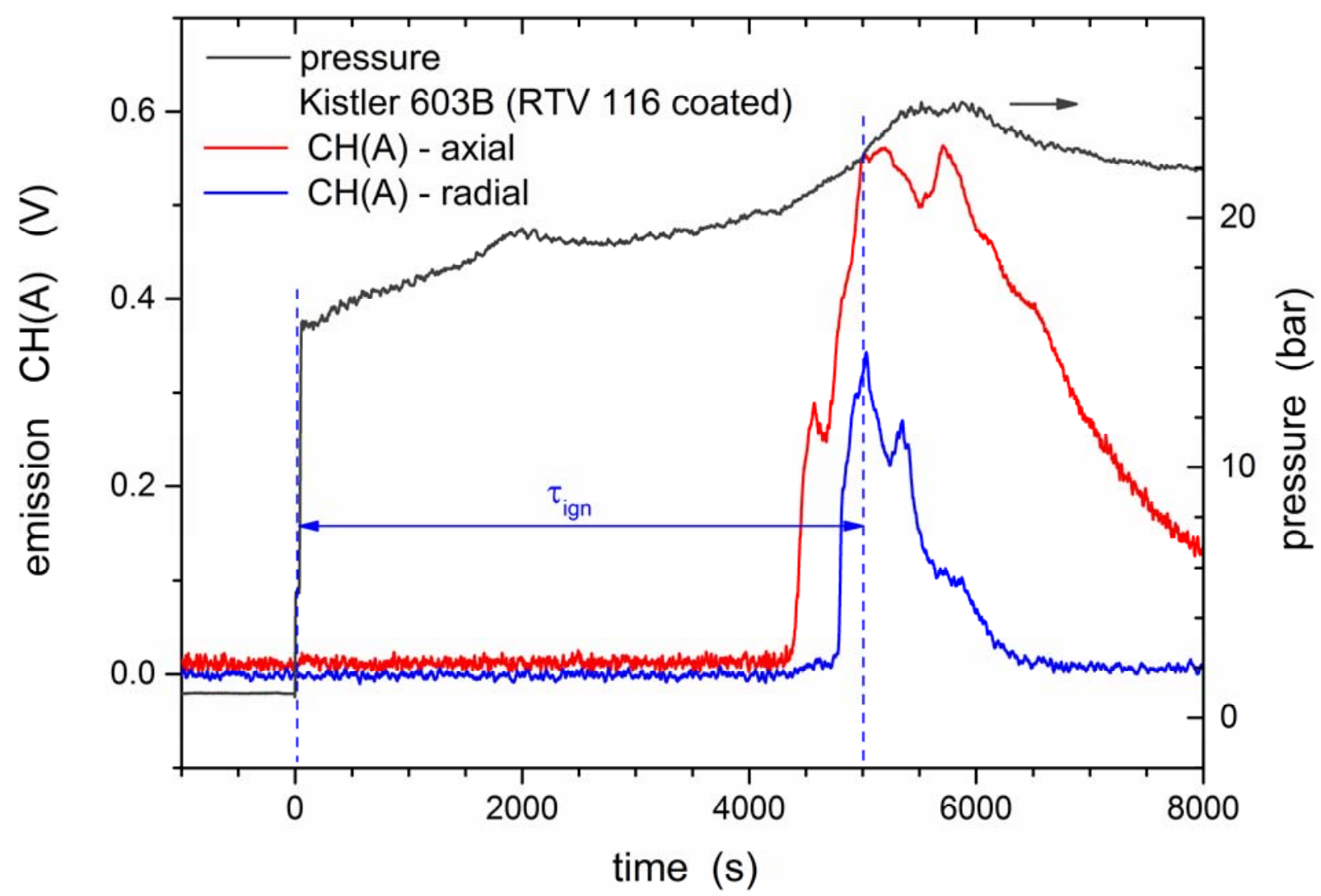

Fig. S3 Ignition delay time measurements of NPB / synthetic air mixture at $\phi=1$ and at a dilution of 1:2 with nitrogen at initial conditions behind the reflected shock wave of $\mathrm{T}=990$ $\mathrm{K}$ and $\mathrm{p}=15.4$ bar; ignition delay time is defined as the time difference between the initiation of the reactive system at the end plate and the occurrence of maximum $\mathrm{CH}(\mathrm{A})$-emission (amplified by FEMTO's logarithmic amplifiers HLVA-100) taking blast wave propagation into account. 
Section 4: The Gaussian calculation results
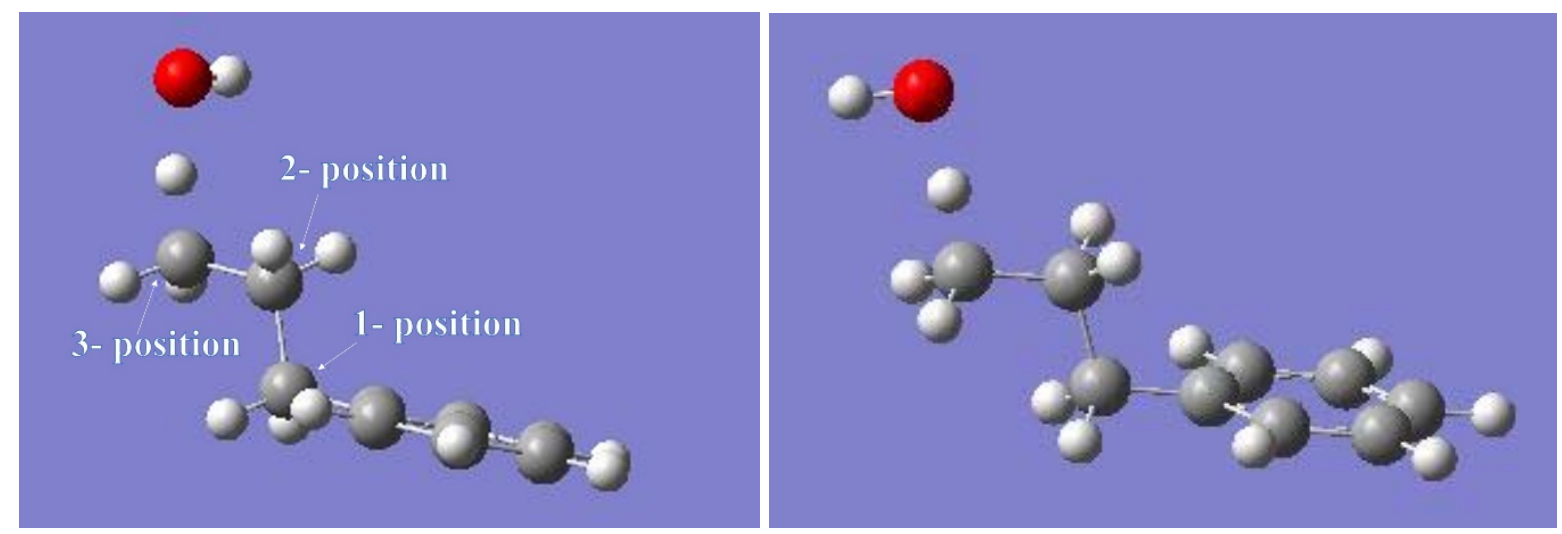

Figs. S4 and S5 The initial and final structure of the transient state of H-abstraction from 3position attack by $\mathrm{OH}$ radical.

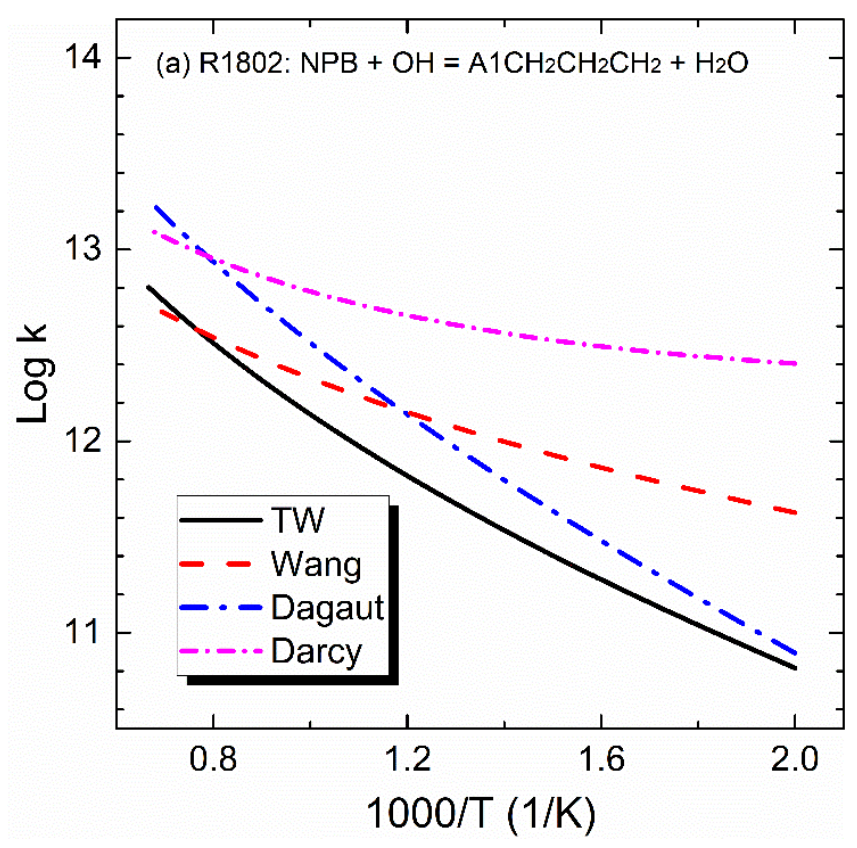

Fig. S6 Comparison of rate constant in four different reaction models: this work (TW), Dagaut [2], Darcy [3] and Wang [4]. 


\section{Section 5: Primary and secondary mechanism of NPB}

Table S8 The primary and secondary mechanism of NPB. $k=A \cdot T^{n} \cdot \exp \left(-E_{a} / R \cdot T\right)$, units are mol, $\mathrm{s}, \mathrm{cm}^{3}$ and kcal.

\begin{tabular}{|c|c|c|c|c|}
\hline Reactions & A & $n$ & $\mathrm{E}_{\mathrm{a}}$ & Ref. \\
\hline \multicolumn{5}{|l|}{ Unimolecular initiations } \\
\hline 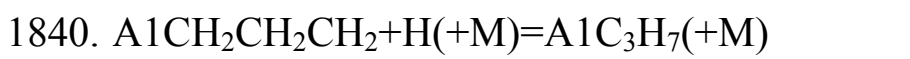 & $1.80 \mathrm{E}+13$ & 0.0 & 0 & $\mathrm{a}$ \\
\hline 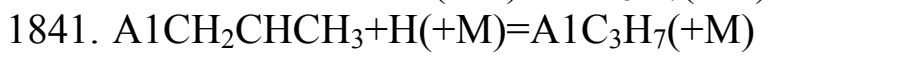 & $2.40 \mathrm{E}+13$ & 0.0 & 0 & $\mathrm{a}$ \\
\hline 1842. $\mathrm{A}_{1} \mathrm{CHCH}_{2} \mathrm{CH}_{3}+\mathrm{H}(+\mathrm{M})=\mathrm{AlC}_{3} \mathrm{H}_{7}(+\mathrm{M})$ & $2.00 \mathrm{E}+14$ & 0.0 & 0 & $\mathrm{a}$ \\
\hline 1836. $\mathrm{A}_{1} \mathrm{C}_{3} \mathrm{H}_{7}+\mathrm{H}=\mathrm{nC}_{3} \mathrm{H}_{7}+\mathrm{A} 1$ & $2.40 \mathrm{E}+13$ & 0.0 & 5123.0 & $\mathrm{a}$ \\
\hline 1839. $\mathrm{A} 1-+\mathrm{nC}_{3} \mathrm{H}_{7}(+\mathrm{M})=\mathrm{A}_{1} \mathrm{C}_{3} \mathrm{H}_{7}(+\mathrm{M})$ & $2.33 \mathrm{E}+14$ & -0.3 & -191.0 & $\mathrm{a}$ \\
\hline 1837. $\mathrm{A}_{1} \mathrm{C}_{3} \mathrm{H}_{7}=\mathrm{A} 1 \mathrm{CH}_{2}+\mathrm{C}_{2} \mathrm{H}_{5}$ & $6.11 \mathrm{E}+16$ & -23.8 & 118160.0 & $b$ \\
\hline 1838. $\mathrm{A}_{1} \mathrm{C}_{3} \mathrm{H}_{7}=\mathrm{A} 1 \mathrm{CH}_{2} \mathrm{CH}_{2}+\mathrm{CH}_{3}$ & $5.00 \mathrm{E}+16$ & 0.0 & 78500.0 & $\mathrm{a}$ \\
\hline \multicolumn{5}{|l|}{ Bimolecular initiations } \\
\hline 1804. $\mathrm{A}_{1 \mathrm{C}} \mathrm{H}_{7}+\mathrm{O}_{2}=\mathrm{A} 1 \mathrm{CH}_{2} \mathrm{CH}_{2} \mathrm{CH}_{2}+\mathrm{HO}_{2}$ & $6.00 \mathrm{E}+13$ & 0.0 & 52290.0 & $d$ \\
\hline 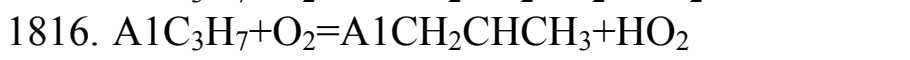 & $2.00 \mathrm{E}+13$ & 0.0 & 49640.0 & $\mathrm{~d}$ \\
\hline 1828. $\mathrm{A}_{1} \mathrm{C}_{3} \mathrm{H}_{7}+\mathrm{O}_{2}=\mathrm{A} 1 \mathrm{CHCH}_{2} \mathrm{CH}_{3}+\mathrm{HO}_{2}$ & $4.00 \mathrm{E}+13$ & 0.0 & 35800.0 & $\mathrm{a}$ \\
\hline \multicolumn{5}{|l|}{ Metatheses } \\
\hline 1800. $\mathrm{A}_{1} \mathrm{C}_{3} \mathrm{H}_{7}+\mathrm{H}=\mathrm{A} 1 \mathrm{CH}_{2} \mathrm{CH}_{2} \mathrm{CH}_{2}+\mathrm{H}_{2}$ & $6.31 \mathrm{E}+07$ & 2.2 & 8640.7 & $\mathrm{~b}$ \\
\hline 1801. $\mathrm{A}_{1} \mathrm{C}_{3} \mathrm{H}_{7}+\mathrm{O}=\mathrm{A} 1 \mathrm{CH}_{2} \mathrm{CH}_{2} \mathrm{CH}_{2}+\mathrm{OH}$ & $1.93 \mathrm{E}+05$ & 2.7 & 3716.0 & a \\
\hline 1802. $\mathrm{A}_{1} \mathrm{C}_{3} \mathrm{H}_{7}+\mathrm{OH}=\mathrm{A} 1 \mathrm{CH}_{2} \mathrm{CH}_{2} \mathrm{CH}_{2}+\mathrm{H}_{2} \mathrm{O}$ & $5.67 \mathrm{E}+03$ & 2.9 & 2001.5 & $\mathrm{c}$ \\
\hline 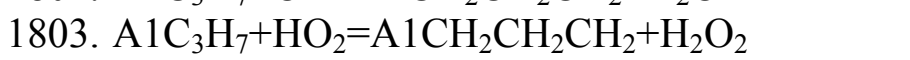 & $4.08 \mathrm{E}+01$ & 3.6 & 17160.0 & $\mathrm{~d}$ \\
\hline 1805. $\mathrm{A}_{1} \mathrm{C}_{3} \mathrm{H}_{7}+\mathrm{CH}_{3}=\mathrm{A} 1 \mathrm{CH}_{2} \mathrm{CH}_{2} \mathrm{CH}_{2}+\mathrm{CH}_{4}$ & $5.00 \mathrm{E}+12$ & 0.0 & 11710.0 & $\mathrm{a}$ \\
\hline 1806. $\mathrm{A}_{1} \mathrm{C}_{3} \mathrm{H}_{7}+\mathrm{C}_{2} \mathrm{H}_{3}=\mathrm{A} 1 \mathrm{CH}_{2} \mathrm{CH}_{2} \mathrm{CH}_{2}+\mathrm{C}_{2} \mathrm{H}$ & $6.00 \mathrm{E}+02$ & 3.3 & 10502.0 & $\mathrm{a}$ \\
\hline 1807. $\mathrm{A}_{1} \mathrm{C}_{3} \mathrm{H}_{7}+\mathrm{C}_{2} \mathrm{H}_{5}=\mathrm{A} 1 \mathrm{CH}_{2} \mathrm{CH}_{2} \mathrm{CH}_{2}+\mathrm{C}_{2} \mathrm{H}_{6}$ & $3.16 \mathrm{E}+11$ & 0.0 & 12300.0 & $\mathrm{a}$ \\
\hline 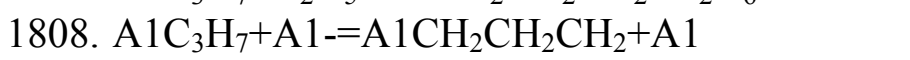 & $7.94 \mathrm{E}+11$ & 0.0 & 20500.0 & $\mathrm{a}$ \\
\hline 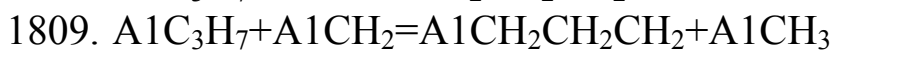 & $7.94 \mathrm{E}+11$ & 0.0 & 20500.0 & $\mathrm{a}$ \\
\hline 1810. $\mathrm{A}_{1} \mathrm{C}_{3} \mathrm{H}_{7}+\mathrm{A} 1 \mathrm{CHCH}_{3}=\mathrm{A} 1 \mathrm{CH}_{2} \mathrm{CH}_{2} \mathrm{CH}_{2}+\mathrm{A} 1 \mathrm{C}_{2} \mathrm{H}_{5}$ & $7.94 \mathrm{E}+11$ & 0.0 & 20500.0 & a \\
\hline 1811. $\mathrm{A}_{1} \mathrm{C}_{3} \mathrm{H}_{7}+\mathrm{CH}_{3} \mathrm{O}=\mathrm{A} 1 \mathrm{CH}_{2} \mathrm{CH}_{2} \mathrm{CH}_{2}+\mathrm{CH}_{3} \mathrm{OH}$ & $3.18 \mathrm{E}+11$ & 0.0 & 7050.0 & $\mathrm{a}$ \\
\hline 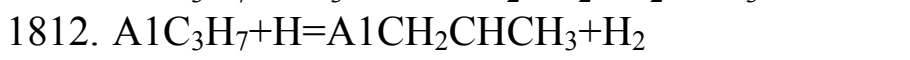 & $7.97 \mathrm{E}+07$ & 1.9 & 6819.3 & $\mathrm{~b}$ \\
\hline 1813. $\mathrm{A}_{1 \mathrm{C}} \mathrm{H}_{7}+\mathrm{O}=\mathrm{A} 1 \mathrm{CH}_{2} \mathrm{CHCH}_{3}+\mathrm{OH}$ & $4.77 \mathrm{E}+04$ & 2.7 & 2106.0 & $\mathrm{a}$ \\
\hline 1814. $\mathrm{A}_{1} \mathrm{C}_{3} \mathrm{H}_{7}+\mathrm{OH}=\mathrm{A} 1 \mathrm{CH}_{2} \mathrm{CHCH}_{3}+\mathrm{H}_{2} \mathrm{O}$ & $7.08 \mathrm{E}+06$ & 1.9 & -159.0 & a \\
\hline 1815. $\mathrm{A}_{1} \mathrm{C}_{3} \mathrm{H}_{7}+\mathrm{HO}_{2}=\mathrm{A} 1 \mathrm{CH}_{2} \mathrm{CHCH}_{3}+\mathrm{H}_{2} \mathrm{O}_{2}$ & $9.64 \mathrm{E}+03$ & 2.6 & 13910.0 & a \\
\hline 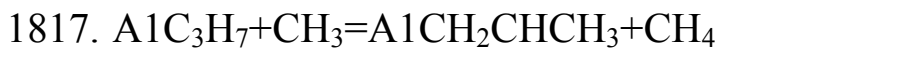 & $6.00 \mathrm{E}+11$ & 0.0 & 10120.0 & $\mathrm{~d}$ \\
\hline 1818. $\mathrm{A}_{1} \mathrm{C}_{3} \mathrm{H}_{7}+\mathrm{C}_{2} \mathrm{H}_{3}=\mathrm{A} 1 \mathrm{CH}_{2} \mathrm{CHCH}_{3}+\mathrm{C}_{2} \mathrm{H}_{4}$ & $1.00 \mathrm{E}+03$ & 3.1 & 8829.0 & a \\
\hline 1819. $\mathrm{A}_{1} \mathrm{C}_{3} \mathrm{H}_{7}+\mathrm{C}_{2} \mathrm{H}_{5}=\mathrm{A} 1 \mathrm{CH}_{2} \mathrm{CHCH}_{3}+\mathrm{C}_{2} \mathrm{H}_{6}$ & $5.01 \mathrm{E}+10$ & 0.0 & 10400.0 & $\mathrm{a}$ \\
\hline 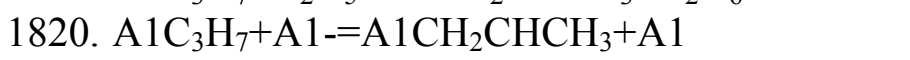 & $7.94 \mathrm{E}+11$ & 0.0 & 16200.0 & a \\
\hline 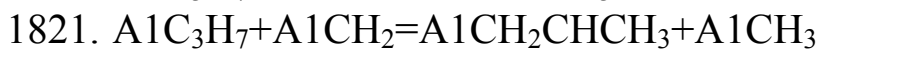 & $7.94 \mathrm{E}+11$ & 0.0 & 16200.0 & $\mathrm{a}$ \\
\hline 1822. $\mathrm{A}_{1} \mathrm{C}_{3} \mathrm{H}_{7}+\mathrm{A} 1 \mathrm{CHCH}_{3}=\mathrm{A} 1 \mathrm{CH}_{2} \mathrm{CHCH}_{3}+\mathrm{A} 1 \mathrm{C}_{2} \mathrm{H}_{5}$ & $7.94 \mathrm{E}+11$ & 0.0 & 16200.0 & $\mathrm{a}$ \\
\hline 1823. $\mathrm{A}_{1} \mathrm{C}_{3} \mathrm{H}_{7}+\mathrm{CH}_{3} \mathrm{O}=\mathrm{A} 1 \mathrm{CH}_{2} \mathrm{CHCH}_{3}+\mathrm{CH}_{3} \mathrm{OH}$ & $7.20 \mathrm{E}+10$ & 0.0 & 4470.0 & a \\
\hline 1824. $\mathrm{A}_{1} \mathrm{C}_{3} \mathrm{H}_{7}+\mathrm{H}=\mathrm{A} 1 \mathrm{CHCH}_{2} \mathrm{CH}_{3}+\mathrm{H}_{2}$ & $5.75 \mathrm{E}+07$ & 1.9 & 5599.2 & $\mathrm{~b}$ \\
\hline 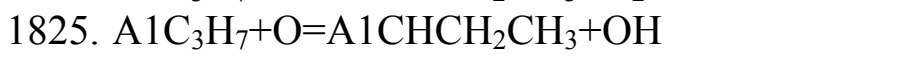 & $4.77 \mathrm{E}+04$ & 2.7 & 1106.0 & $\mathrm{a}$ \\
\hline 1826. $\mathrm{A}_{1} \mathrm{C}_{3} \mathrm{H}_{7}+\mathrm{OH}=\mathrm{A} 1 \mathrm{CHCH}_{2} \mathrm{CH}_{3}+\mathrm{H}_{2} \mathrm{O}$ & $3.00 \mathrm{E}+06$ & 2.0 & -1520.0 & $\mathrm{~b}$ \\
\hline 1827. $\mathrm{A}_{1} \mathrm{C}_{3} \mathrm{H}_{7}+\mathrm{HO}_{2}=\mathrm{A} 1 \mathrm{CHCH}_{2} \mathrm{CH}_{3}+\mathrm{H}_{2} \mathrm{O}_{2}$ & $6.32 \mathrm{E}+01$ & 3.4 & 13720.0 & $\mathrm{~d}$ \\
\hline 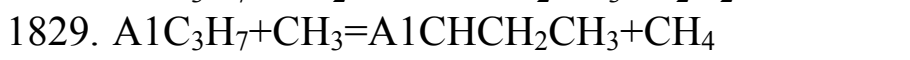 & $6.00 \mathrm{E}+11$ & 0.0 & 10120.0 & $\mathrm{a}$ \\
\hline 1830. $\mathrm{A}_{1} \mathrm{C}_{3} \mathrm{H}_{7}+\mathrm{C}_{2} \mathrm{H}_{3}=\mathrm{A} 1 \mathrm{CHCH}_{2} \mathrm{CH}_{3}+\mathrm{C}_{2} \mathrm{H}_{4}$ & $1.00 \mathrm{E}+03$ & 3.1 & 8829.0 & $\mathrm{a}$ \\
\hline 1831. $\mathrm{A}_{1} \mathrm{C}_{3} \mathrm{H}_{7}+\mathrm{C}_{2} \mathrm{H}_{5}=\mathrm{A} 1 \mathrm{CHCH}_{2} \mathrm{CH}_{3}+\mathrm{C}_{2} \mathrm{H}_{6}$ & $5.01 \mathrm{E}+10$ & 0.0 & 10400.0 & $\mathrm{a}$ \\
\hline 1832. $\mathrm{A}_{1} \mathrm{C}_{3} \mathrm{H}_{7}+\mathrm{A} 1-=\mathrm{A} 1 \mathrm{CHCH}_{2} \mathrm{CH}_{3}+\mathrm{A} 1$ & $7.94 \mathrm{E}+11$ & 0.0 & 16200.0 & $\mathrm{a}$ \\
\hline
\end{tabular}




\begin{tabular}{|c|c|c|c|c|}
\hline 1833. $\mathrm{A} 1 \mathrm{C}_{3} \mathrm{H}_{7}+\mathrm{A} 1 \mathrm{CH}_{2}=\mathrm{A} 1 \mathrm{CHCH}_{2} \mathrm{CH}_{3}+\mathrm{A}_{1 \mathrm{CH}}$ & $7.94 \mathrm{E}+11$ & 0.0 & 16200.0 & a \\
\hline 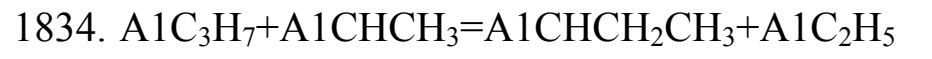 & $7.94 \mathrm{E}+11$ & 0.0 & 16200.0 & a \\
\hline 1835. $\mathrm{A}_{1} \mathrm{C}_{3} \mathrm{H}_{7}+\mathrm{CH}_{3} \mathrm{O}=\mathrm{A} 1 \mathrm{CHCH}_{2} \mathrm{CH}_{3}+\mathrm{CH}_{3} \mathrm{OH}$ & $7.20 \mathrm{E}+10$ & 0.0 & 4470.0 & a \\
\hline \multicolumn{5}{|l|}{ Reactions of $\mathrm{C}_{9} \mathrm{H}_{11}$} \\
\hline 1843. $\mathrm{A}_{1 \mathrm{CH}_{2}} \mathrm{CH}_{2} \mathrm{CH}_{2}=\mathrm{A} 1 \mathrm{CH}_{2}+\mathrm{C}_{2} \mathrm{H}_{4}$ & $2.00 \mathrm{E}+13$ & 0.0 & 28700.0 & $\mathrm{~b}$ \\
\hline 1844. $\mathrm{A} 1 \mathrm{CH}_{2} \mathrm{CHCH}_{2}+\mathrm{H}=\mathrm{A} 1 \mathrm{CH}_{2} \mathrm{CH}_{2} \mathrm{CH}_{2}$ & $2.50 \mathrm{E}+11$ & 0.5 & 2620.0 & $\mathrm{~b}$ \\
\hline 1845. $\mathrm{A}_{1} \mathrm{CH}_{2} \mathrm{CH}_{2} \mathrm{CH}_{2}+\mathrm{O}_{2}=\mathrm{A} 1 \mathrm{CH}_{2} \mathrm{CHCH}_{2}+\mathrm{HO}_{2}$ & $5.00 \mathrm{E}+13$ & 0.0 & 11000.0 & e \\
\hline 1846. $\mathrm{A} 1 \mathrm{CHCH}_{2} \mathrm{CH}_{3}+\mathrm{O}_{2}=\mathrm{A} 1 \mathrm{CHCHCH}_{3}+\mathrm{HO}_{2}$ & $1.58 \mathrm{E}+13$ & 0.0 & 15200.0 & e \\
\hline 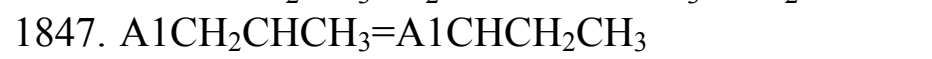 & $2.00 \mathrm{E}-15$ & 6.6 & 13502.0 & $\mathrm{~b}$ \\
\hline 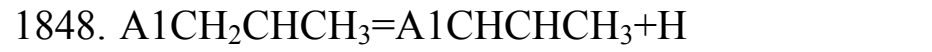 & $1.50 \mathrm{E}-17$ & 7.1 & 13119.0 & $\mathrm{~b}$ \\
\hline 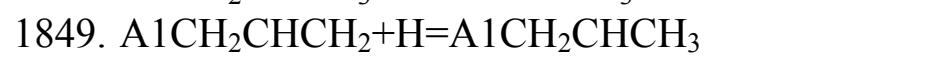 & $2.50 \mathrm{E}+11$ & 0.5 & 2620.0 & $\mathrm{~b}$ \\
\hline 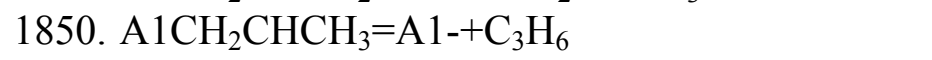 & $5.00 \mathrm{E}-21$ & 8.2 & 15514.0 & $\mathrm{~b}$ \\
\hline 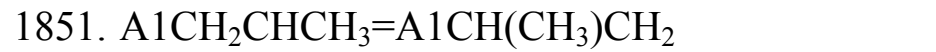 & $5.56 \mathrm{E}+06$ & 0.7 & 7780.0 & $\mathrm{~b}$ \\
\hline 1852. $\mathrm{A}_{1} \mathrm{CH}_{2} \mathrm{CHCH}_{3}+\mathrm{O}=\mathrm{A} 1 \mathrm{CH}_{2}+\mathrm{CH}_{3} \mathrm{CHO}$ & $2.00 \mathrm{E}+13$ & 0.0 & 4000.0 & $\mathrm{~b}$ \\
\hline 1853. $\mathrm{A}_{1} \mathrm{CH}_{2} \mathrm{CHCH}_{3}+\mathrm{OH}=\mathrm{A} 1 \mathrm{CH}_{3}+\mathrm{CH}_{3} \mathrm{CHO}$ & $2.00 \mathrm{E}+13$ & 0.0 & 4000.0 & $\mathrm{~b}$ \\
\hline 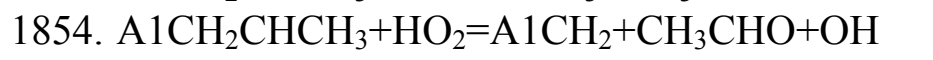 & $2.00 \mathrm{E}+13$ & 0.0 & 4000.0 & $\mathrm{~b}$ \\
\hline 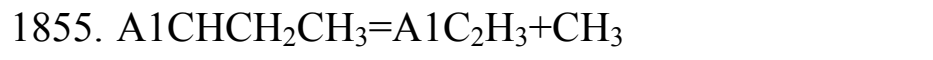 & $1.30 \mathrm{E}+13$ & 0.0 & 35900.0 & $\mathrm{~b}$ \\
\hline 1856. $\mathrm{A} 1 \mathrm{CHCH}_{2} \mathrm{CH}_{3}=\mathrm{A} 1 \mathrm{CHCHCH}{ }_{3}+\mathrm{H}$ & $3.00 \mathrm{E}+13$ & 0.0 & 50500.0 & $\mathrm{~b}$ \\
\hline 1857. $\mathrm{A} 1 \mathrm{CHCH}_{2} \mathrm{CH}_{3}+\mathrm{O}=\mathrm{A} 1 \mathrm{CHO}+\mathrm{C}_{2} \mathrm{H}_{5}$ & $1.60 \mathrm{E}+13$ & 0.0 & 0.0 & $\mathrm{~b}$ \\
\hline 1858. $\mathrm{A} 1 \mathrm{CHCH}_{2} \mathrm{CH}_{3}+\mathrm{OH}=\mathrm{A} 1 \mathrm{CHO}+\mathrm{C}_{2} \mathrm{H}_{6}$ & $1.60 \mathrm{E}+13$ & 0.0 & 0.0 & $\mathrm{~b}$ \\
\hline 1859. $\mathrm{A} 1 \mathrm{CHCH}_{2} \mathrm{CH}_{3}+\mathrm{HO}_{2}=\mathrm{A} 1 \mathrm{CHO}+\mathrm{C}_{2} \mathrm{H}_{5}+\mathrm{OH}$ & $5.00 \mathrm{E}+12$ & 0.0 & 4000.0 & $\mathrm{~b}$ \\
\hline 1860. $\mathrm{A} 1 \mathrm{CH}\left(\mathrm{CH}_{3}\right) \mathrm{CH}_{2}=\mathrm{A} 1 \mathrm{C}_{2} \mathrm{H}_{3}+\mathrm{CH}_{3}$ & $1.00 \mathrm{E}+14$ & 0.0 & 24000.0 & $\mathrm{f}$ \\
\hline 1861. $\mathrm{A} 1 \mathrm{CH}\left(\mathrm{CH}_{3}\right) \mathrm{CH}_{2}=\mathrm{A} 1-+\mathrm{C}_{3} \mathrm{H}_{6}$ & $2.00 \mathrm{E}+13$ & 0.0 & 38500.0 & $\mathrm{~b}$ \\
\hline 1862. $\mathrm{A} 1 \mathrm{C}\left(\mathrm{CH}_{3}\right) \mathrm{CH}_{2}+\mathrm{H}=\mathrm{A} 1 \mathrm{CH}\left(\mathrm{CH}_{3}\right) \mathrm{CH}_{2}$ & $3.26 \mathrm{E}+61$ & -14.9 & 20161.0 & $\mathrm{~d}$ \\
\hline \multicolumn{5}{|l|}{ Reactions of $\mathrm{C}_{9} \mathrm{H}_{10}$} \\
\hline 1863. $\mathrm{A} 1 \mathrm{CH}_{2} \mathrm{CHCH}_{2}+\mathrm{O}_{2}=\mathrm{A} 1 \mathrm{CHCHCH}_{2}+\mathrm{HO}_{2}$ & $1.40 \mathrm{E}+11$ & 0.0 & 26310.0 & $\mathrm{~b}$ \\
\hline 1864. $\mathrm{A} 1 \mathrm{CH}_{2} \mathrm{CHCH}_{2}+\mathrm{O}=\mathrm{A} 1 \mathrm{CH}_{2}+\mathrm{CH}_{2} \mathrm{CHO}$ & $6.40 \mathrm{E}+04$ & 2.6 & -1130.0 & $\mathrm{~b}$ \\
\hline 1865. $\mathrm{A}_{1} \mathrm{CH}_{2} \mathrm{CHCH}_{2}+\mathrm{H}=\mathrm{A} 1-+\mathrm{C}_{3} \mathrm{H}_{6}$ & $1.32 \mathrm{E}+13$ & 0.0 & 1560.0 & $\mathrm{~b}$ \\
\hline 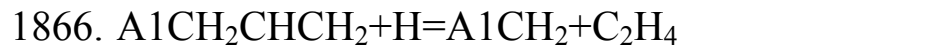 & $1.60 \mathrm{E}+22$ & -2.4 & 11180.0 & $b$ \\
\hline 1867. $\mathrm{A} 1 \mathrm{CH}_{2} \mathrm{CHCH}_{2}+\mathrm{H}=\mathrm{AlC}_{2} \mathrm{H}_{3}+\mathrm{CH}_{3}$ & $2.00 \mathrm{E}+12$ & 0.0 & 7000.0 & $\mathrm{~b}$ \\
\hline 1867. $\mathrm{A} 1 \mathrm{CH}_{2} \mathrm{CHCH}_{2}+\mathrm{OH}=\mathrm{A} 1 \mathrm{CH}_{2} \mathrm{CH}_{2}+\mathrm{CH}_{2} \mathrm{O}$ & $1.37 \mathrm{E}+12$ & 0.0 & -1040.0 & $\mathrm{~b}$ \\
\hline 1869. $\mathrm{A} 1 \mathrm{CH}_{2} \mathrm{CHCH}_{2}+\mathrm{CH}_{3}=\mathrm{A} 1 \mathrm{CH}_{2}+\mathrm{C}_{3} \mathrm{H}_{6}$ & $1.69 \mathrm{E}+11$ & 0.0 & 7400.0 & $\mathrm{~b}$ \\
\hline 1870. $\mathrm{A}_{1 C \mathrm{CH}_{2}} \mathrm{CHCH}_{2}+\mathrm{CH}_{3}=\mathrm{A} 1 \mathrm{CH}_{3}+\mathrm{aC}_{3} \mathrm{H}_{5}$ & $1.20 \mathrm{E}+12$ & 0.0 & 15900.0 & $\mathrm{~b}$ \\
\hline 1871. $\mathrm{A} 1 \mathrm{CH}_{2} \mathrm{CHCH}_{2}+\mathrm{H}=\mathrm{A} 1+\mathrm{aC}_{3} \mathrm{H}_{5}$ & $5.80 \mathrm{E}+13$ & 0.0 & 8100.0 & $\mathrm{~b}$ \\
\hline 1872. $\mathrm{A}_{1} \mathrm{CH}_{2} \mathrm{CHCH}_{2}+\mathrm{O}=\mathrm{A} 1 \mathrm{CHCHCH}_{2}+\mathrm{OH}$ & $8.80 \mathrm{E}+10$ & 0.7 & 3250.0 & $\mathrm{~b}$ \\
\hline 1873. $\mathrm{A}_{1 \mathrm{CH}} \mathrm{CHCH}_{2}+\mathrm{H}=\mathrm{A} 1 \mathrm{CHCHCH}_{2}+\mathrm{H}_{2}$ & $5.40 \mathrm{E}+04$ & 2.5 & -1900.0 & $\mathrm{~b}$ \\
\hline 1874. $\mathrm{A} 1 \mathrm{CH}_{2} \mathrm{CHCH}_{2}+\mathrm{OH}=\mathrm{A} 1 \mathrm{CHCHCH}_{2}+\mathrm{H}_{2} \mathrm{O}$ & $3.00 \mathrm{E}+06$ & 2.0 & -1520.0 & $\mathrm{~b}$ \\
\hline 1875. $\mathrm{A} 1 \mathrm{CH}_{2} \mathrm{CHCH}_{2}+\mathrm{HO}_{2}=\mathrm{A} 1 \mathrm{CHCHCH}_{2}+\mathrm{H}_{2} \mathrm{O}_{2}$ & $6.40 \mathrm{E}+03$ & 2.6 & 12400.0 & $\mathrm{~b}$ \\
\hline 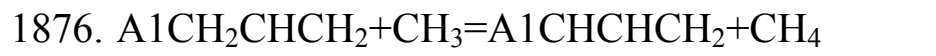 & $1.00 \mathrm{E}+11$ & 0.0 & 7300.0 & $\mathrm{~b}$ \\
\hline 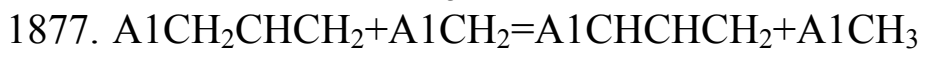 & $1.00 \mathrm{E}+12$ & 0.0 & 15100.0 & $\mathrm{~b}$ \\
\hline 1878. $\mathrm{A} 1 \mathrm{CHCHCH}+\mathrm{H}=\mathrm{A} 1 \mathrm{CH}_{2} \mathrm{CHCH}_{2}$ & $1.00 \mathrm{E}+14$ & 0.0 & 0.0 & $\mathrm{~b}$ \\
\hline 1879. $\mathrm{A} 1 \mathrm{CHCHCH}+\mathrm{H}(+\mathrm{M})=\mathrm{A} 1 \mathrm{CHCHCH}_{3}(+\mathrm{M})$ & $2.00 \mathrm{E}+14$ & 0.0 & 0.0 & $\mathrm{~b}$ \\
\hline 1880. $\mathrm{A} 1 \mathrm{CHCH}+\mathrm{CH}_{3}(+\mathrm{M})=\mathrm{A} 1 \mathrm{CHCHCH}_{3}(+\mathrm{M})$ & $2.50 \mathrm{E}+13$ & 0.0 & 0.0 & $\mathrm{~b}$ \\
\hline 1881. $\mathrm{A} 1 \mathrm{CHCHCH}{ }_{3}=\mathrm{H}_{2}+\mathrm{A} 1 \mathrm{CCCH}_{3}$ & $1.18 \mathrm{E}+95$ & -23.6 & 125649.0 & $\mathrm{~b}$ \\
\hline 1882. $\mathrm{A} 1 \mathrm{CHCHCH}+\mathrm{H}=\mathrm{AlC}_{2} \mathrm{H}_{3}+\mathrm{CH}_{3}$ & $8.80 \mathrm{E}+16$ & -1.1 & 6461.0 & $\mathrm{~b}$ \\
\hline 1883. $\mathrm{A} 1 \mathrm{CHCHCH} 3+\mathrm{H}=\mathrm{A} 1 \mathrm{CHCHCH}{ }_{2}+\mathrm{H}_{2}$ & $1.73 \mathrm{E}+05$ & 2.5 & 2490.0 & $\mathrm{~b}$ \\
\hline 1884. $\mathrm{A} 1 \mathrm{CHCHCH}{ }_{3}+\mathrm{CH}_{3}=\mathrm{A} 1 \mathrm{CHCHCH}_{2}+\mathrm{CH}_{4}$ & $2.20 \mathrm{E}+00$ & 3.5 & 5675.0 & $\mathrm{~b}$ \\
\hline 1885. $\mathrm{A} 1 \mathrm{CHCHCH}+\mathrm{O}=\mathrm{A} 1 \mathrm{CHCHCH}+\mathrm{OH}$ & $1.80 \mathrm{E}+11$ & 0.7 & 5880.0 & $\mathrm{~b}$ \\
\hline 1886. $\mathrm{A} 1 \mathrm{CHCHCH}+\mathrm{OH}=\mathrm{A} 1 \mathrm{CHCHCH}_{2}+\mathrm{H}_{2} \mathrm{O}$ & $3.10 \mathrm{E}+06$ & 2.0 & -298.0 & $\mathrm{~b}$ \\
\hline 1887. $\mathrm{A} 1 \mathrm{CHCHCH}+\mathrm{HO}_{2}=\mathrm{A} 1 \mathrm{CHCHCH}+\mathrm{H}_{2} \mathrm{O}_{2}$ & $7.13 \mathrm{E}+03$ & 2.8 & 14913.0 & $\mathrm{~b}$ \\
\hline 1888. $\mathrm{A} 1 \mathrm{CHCHCH}_{3}+\mathrm{H}=\mathrm{A} 1+\mathrm{aC}_{3} \mathrm{H}_{5}$ & $4.80 \mathrm{E}+13$ & 0.0 & 5123.0 & $\mathrm{~b}$ \\
\hline
\end{tabular}




\begin{tabular}{|c|c|c|c|c|}
\hline 1889. $\mathrm{A} 1 \mathrm{CHCHCH}+\mathrm{OH}=\mathrm{A} 1 \mathrm{CHO}+\mathrm{C}_{2} \mathrm{H}_{5}$ & $2.60 \mathrm{E}+13$ & 0.0 & 0.0 & $\mathrm{~b}$ \\
\hline 1890. $\mathrm{A} 1 \mathrm{CCH}_{2}+\mathrm{CH}_{3}=\mathrm{A} 1 \mathrm{C}\left(\mathrm{CH}_{3}\right) \mathrm{CH}_{2}$ & $1.50 \mathrm{E}+13$ & 0.0 & 0.0 & $\mathrm{~b}$ \\
\hline 1891. $\mathrm{A} 1 \mathrm{C}\left(\mathrm{CH}_{3}\right) \mathrm{CH}_{2}+\mathrm{H}=\mathrm{A}_{1} \mathrm{C}_{2} \mathrm{H}_{3}+\mathrm{CH}_{3}$ & $5.80 \mathrm{E}+13$ & 0.0 & 8100.0 & $\mathrm{~b}$ \\
\hline 1892. $\mathrm{A} 1 \mathrm{C}\left(\mathrm{CH}_{3}\right) \mathrm{CH}_{2}+\mathrm{O}_{2}=\mathrm{aC}_{3} \mathrm{H}_{4}+\mathrm{A} 1-+\mathrm{HO}_{2}$ & $1.20 \mathrm{E}+13$ & 0.0 & 49000.0 & $\mathrm{~b}$ \\
\hline 1893. $\mathrm{A} 1 \mathrm{C}\left(\mathrm{CH}_{3}\right) \mathrm{CH}_{2}+\mathrm{O}=\mathrm{aC}_{3} \mathrm{H}_{4}+\mathrm{A} 1-+\mathrm{OH}$ & $5.10 \mathrm{E}+13$ & 0.0 & 7850.0 & $\mathrm{~b}$ \\
\hline 1894. $\mathrm{A} 1 \mathrm{C}\left(\mathrm{CH}_{3}\right) \mathrm{CH}_{2}+\mathrm{H}=\mathrm{aC}_{3} \mathrm{H}_{4}+\mathrm{A} 1-+\mathrm{H}_{2}$ & $2.85 \mathrm{E}+07$ & 2.0 & 7700.0 & $\mathrm{~b}$ \\
\hline 1895. $\mathrm{A} 1 \mathrm{C}\left(\mathrm{CH}_{3}\right) \mathrm{CH}_{2}+\mathrm{OH}=\mathrm{aC}_{3} \mathrm{H}_{4}+\mathrm{A} 1-+\mathrm{H}_{2} \mathrm{O}$ & $2.67 \mathrm{E}+06$ & 2.0 & 450.0 & $\mathrm{~b}$ \\
\hline 1896. $\mathrm{A} 1 \mathrm{C}\left(\mathrm{CH}_{3}\right) \mathrm{CH}_{2}+\mathrm{HO}_{2}=\mathrm{aC}_{3} \mathrm{H}_{4}+\mathrm{A} 1-+\mathrm{H}_{2} \mathrm{O}_{2}$ & $6.00 \mathrm{E}+11$ & 0.0 & 17000.0 & $\mathrm{~b}$ \\
\hline 1897. $\mathrm{A} 1 \mathrm{C}\left(\mathrm{CH}_{3}\right) \mathrm{CH}_{2}+\mathrm{CH}_{3}=\mathrm{aC}_{3} \mathrm{H}_{4}+\mathrm{A} 1-+\mathrm{CH}_{4}$ & $3.00 \mathrm{E}-01$ & 4.0 & 8200.0 & $\mathrm{~b}$ \\
\hline \multicolumn{5}{|l|}{ Reactions of $\mathrm{C}_{9} \mathrm{H}_{9}$} \\
\hline 1898. $\mathrm{A} 1 \mathrm{CHCCH}_{2}+\mathrm{H}=\mathrm{A} 1 \mathrm{CHCHCH}_{2}$ & $4.80 \mathrm{E}+61$ & -14.7 & 26000.0 & $\mathrm{~b}$ \\
\hline 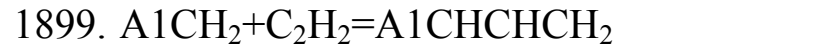 & $4.10 \mathrm{E}+53$ & -13.3 & 33200.0 & $\mathrm{~b}$ \\
\hline 1900. $\mathrm{A} 1 \mathrm{CHCHCH}_{2}+\mathrm{H}=\mathrm{A} 1 \mathrm{CHCCH}_{2}+\mathrm{H}_{2}$ & $3.45 \mathrm{E}+06$ & 2.1 & 4955.0 & $\mathrm{~b}$ \\
\hline 1901. $\mathrm{A} 1 \mathrm{CHCHCH}_{2}+\mathrm{CH}_{3}=\mathrm{A} 1 \mathrm{CHCCH}_{2}+\mathrm{CH}_{4}$ & $3.01 \mathrm{E}+12$ & -0.3 & -130.0 & $\mathrm{~b}$ \\
\hline 1902. $\mathrm{A}_{1} \mathrm{CH}_{2}+\mathrm{C}_{2} \mathrm{H}_{3}=\mathrm{A} 1 \mathrm{CHCHCH}_{2}+\mathrm{H}$ & $1.50 \mathrm{E}+24$ & -2.8 & 18618.0 & $\mathrm{~b}$ \\
\hline 1903. $\mathrm{A} 1 \mathrm{CHCHCH}_{2}+\mathrm{OH}=\mathrm{A} 1 \mathrm{CHCCH}_{2}+\mathrm{H}_{2} \mathrm{O}$ & $6.00 \mathrm{E}+12$ & 0.0 & 0.0 & $\mathrm{~b}$ \\
\hline 1904. $\mathrm{A} 1 \mathrm{CHCHCH}{ }_{2}+\mathrm{O}_{2}=\mathrm{A} 1 \mathrm{CHCCH}_{2}+\mathrm{HO}_{2}$ & $4.99 \mathrm{E}+15$ & -1.4 & 22428.0 & $\mathrm{~b}$ \\
\hline 1905. $\mathrm{A} 1 \mathrm{CHCHCH} \mathrm{H}_{2}+\mathrm{HO}_{2}=\mathrm{OH}+\mathrm{C}_{2} \mathrm{H}_{3}+\mathrm{A} 1 \mathrm{CHO}$ & $5.00 \mathrm{E}+12$ & 0.0 & 0.0 & $\mathrm{~b}$ \\
\hline 1906. $\mathrm{C}_{9} \mathrm{H}_{8}+\mathrm{H}=\mathrm{A} 1 \mathrm{CHCHCH}{ }_{2}$ & $5.80 \mathrm{E}+13$ & 0.0 & 8100.0 & $\mathrm{~g}$ \\
\hline \multicolumn{5}{|l|}{ Reactions of $\mathrm{C}_{9} \mathrm{H}_{8}$} \\
\hline 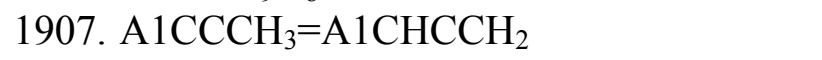 & $3.20 \mathrm{E}+61$ & -14.6 & 88200.0 & $\mathrm{~b}$ \\
\hline 1908. $\mathrm{H}+\mathrm{A} 1 \mathrm{CHCCH}_{2}=\mathrm{H}+\mathrm{A} 1 \mathrm{CCCH}_{3}$ & $1.47 \mathrm{E}+13$ & 0.3 & 4103.0 & $\mathrm{~b}$ \\
\hline 1909. $\mathrm{A} 1 \mathrm{CCCH}_{3}+\mathrm{C}_{3} \mathrm{H}_{3}=\mathrm{A} 1 \mathrm{CHCCH}_{2}+\mathrm{C}_{3} \mathrm{H}_{3}$ & $6.14 \mathrm{E}+06$ & 1.7 & 10450.0 & $\mathrm{~b}$ \\
\hline 1910. $\mathrm{A} 1 \mathrm{CHCCH}_{2}=\mathrm{C}_{3} \mathrm{H}_{3}+\mathrm{A} 1-$ & $1.02 \mathrm{E}+51$ & -11.0 & 102317.0 & $\mathrm{~b}$ \\
\hline 1911. $\mathrm{A}_{1} \mathrm{CCCH}_{3}=\mathrm{C}_{3} \mathrm{H}_{3}+\mathrm{A} 1-$ & $3.70 \mathrm{E}+44$ & -9.1 & 100390.0 & $\mathrm{~b}$ \\
\hline 1912. $\mathrm{A} 1 \mathrm{CCCH}_{3}+\mathrm{H}=\mathrm{C}_{3} \mathrm{H}_{3}+\mathrm{A} 1$ & $3.57 \mathrm{E}+04$ & 2.8 & 4821.0 & $\mathrm{~b}$ \\
\hline 1913. $\mathrm{A} 1 \mathrm{CCCH}_{3}+\mathrm{CH}_{3}=\mathrm{C}_{3} \mathrm{H}_{3}+\mathrm{A} 1 \mathrm{CH}_{3}$ & $2.20 \mathrm{E}-04$ & 5.0 & 8300.0 & $\mathrm{~b}$ \\
\hline 1914. $\mathrm{A} 1 \mathrm{CHCCH}_{2}+\mathrm{H}=\mathrm{C}_{3} \mathrm{H}_{3}+\mathrm{A} 1$ & $6.60 \mathrm{E}+03$ & 3.1 & 5522.0 & $\mathrm{~b}$ \\
\hline 1915. $\mathrm{A} 1 \mathrm{CHCCH}_{2}+\mathrm{CH}_{3}=\mathrm{C}_{3} \mathrm{H}_{3}+\mathrm{A}_{1} \mathrm{CH}_{3}$ & $6.60 \mathrm{E}-04$ & 5.0 & 8300.0 & $\mathrm{~b}$ \\
\hline 1916. $\mathrm{H}+\mathrm{A} 1 \mathrm{CHCCH}_{2}=\mathrm{A} 1 \mathrm{CH}_{2}+\mathrm{C}_{2} \mathrm{H}_{2}$ & $2.72 \mathrm{E}+09$ & 1.2 & 6834.0 & $\mathrm{~b}$ \\
\hline 1917. $\mathrm{H}+\mathrm{A} 1 \mathrm{CCCH}_{3}=\mathrm{C}_{2} \mathrm{H}_{2}+\mathrm{A} 1 \mathrm{CH}_{2}$ & $3.89 \mathrm{E}+10$ & 1.0 & 4114.0 & $\mathrm{~b}$ \\
\hline 1918. $\mathrm{A} 1 \mathrm{CCCH}_{3}+\mathrm{OH}=\mathrm{C}_{3} \mathrm{H}_{3}+\mathrm{A} 1 \mathrm{OH}$ & $1.00 \mathrm{E}+06$ & 2.0 & 100.0 & $\mathrm{~b}$ \\
\hline 1919. $\mathrm{A} 1 \mathrm{CHCCH}_{2}+\mathrm{OH}=\mathrm{C}_{3} \mathrm{H}_{3}+\mathrm{A} 1 \mathrm{OH}$ & $5.30 \mathrm{E}+06$ & 2.0 & 2000.0 & $\mathrm{~b}$ \\
\hline \multicolumn{5}{|l|}{ Indene productions } \\
\hline 595. $\mathrm{H}+\mathrm{C}_{9} \mathrm{H}_{8}=\mathrm{H}_{2}+\mathrm{C}_{9} \mathrm{H}_{7}$ & $1.08 \mathrm{E}+05$ & 2.5 & -1900 & $\mathrm{~g}$ \\
\hline 596. $\mathrm{C}_{9} \mathrm{H}_{8}+\mathrm{O}=\mathrm{C}_{9} \mathrm{H}_{7}+\mathrm{OH}$ & $1.76 \mathrm{E}+11$ & 0.7 & 3250 & $\mathrm{~g}$ \\
\hline 597. $\mathrm{C}_{9} \mathrm{H}_{8}+\mathrm{OH}=\mathrm{C}_{9} \mathrm{H}_{7}+\mathrm{H}_{2} \mathrm{O}$ & $6.00 \mathrm{E}+6$ & 2.0 & 1520 & $\mathrm{~g}$ \\
\hline 601. $\mathrm{C}_{9} \mathrm{H}_{8}+\mathrm{O}_{2}=\mathrm{C}_{9} \mathrm{H}_{7}+\mathrm{HO}_{2}$ & $1.40 \mathrm{E}+12$ & 0.0 & 28080.0 & $\mathrm{~g}$ \\
\hline \multicolumn{5}{|l|}{ Bibenzyl productions } \\
\hline 864. $\mathrm{A} 1 \mathrm{CH}_{2}+\mathrm{A}_{1 \mathrm{CH}}=\mathrm{C}_{14} \mathrm{H}_{14}$ & $1.00 \mathrm{E}+13$ & 0.0 & 454.0 & $\mathrm{~h}$ \\
\hline
\end{tabular}

Note:

a Rate constant taken equal to the values proposed by Dagaut et al. [2] for the primary reactions of NPB.

b Rate constant taken equal to the values proposed by Wang et al. [4] for the primary and secondary reactions of NPB.

c Rate constant calculated in this work.

d Rate constant by analogy with values proposed by Burke et al. [5] for the reactions of $\mathrm{C}_{3} \mathrm{H}_{8}$. e Rate constant taken equal to the values proposed by Diévart et al. [6] for the reactions of $\mathrm{A}_{1} \mathrm{C}_{3} \mathrm{H}_{5}$ production.

f Rate constant taken equal to the values proposed by Dagaut et al. [7] for the same reaction. 
g Rate constant taken equal to the values proposed by Tian et al. [8] for the reactions of indane and indene.

$\mathrm{h}$ Rate constant taken equal to the values proposed by Dagaut et al. [2] for the same reaction. 


\section{Section 6: The species and their corresponding structure}

Table S9 Names and structures of species mentioned in this work

\begin{tabular}{|c|c|c|c|}
\hline Name & Structure & Name & Structure \\
\hline 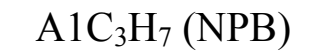 & & 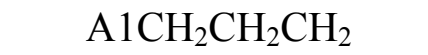 & \\
\hline $\mathrm{A} 1 C H_{2} \mathrm{CHCH}_{3}$ & & $\mathrm{~A} 1 \mathrm{CHCH}_{2} \mathrm{CH}_{3}$ & \\
\hline $\begin{array}{l}\mathrm{A} 1 \mathrm{CHCHCH}_{3}(1- \\
\text { propenylbenznen) }\end{array}$ & & $\begin{array}{l}{\mathrm{A} 1 \mathrm{CH}_{2} \mathrm{CHCH}_{2}(2-}_{\text {propenylbenznen) }}\end{array}$ & \\
\hline $\begin{array}{c}\mathrm{A} 1 \mathrm{C}\left(\mathrm{CH}_{3}\right) \mathrm{CH}_{2}(\alpha- \\
\text { methylstyrene })\end{array}$ & & A2 (naphthalene) & \\
\hline C9H8 (indene) & & C8H6O (benzofuran) & \\
\hline A1C2H3 (styrene) & & A1CHO (benzaldehyde) & \\
\hline $\mathrm{A} 1 C H_{2} \mathrm{O}$ & & $\mathrm{A} 1 \mathrm{CO}$ & \\
\hline $\mathrm{A} 1 C H_{2}$ (benzyl) & & A1O & \\
\hline A1OH (phenol) & & A1- (phenyl) & \\
\hline $\mathrm{C}_{3} \mathrm{H}_{4} \mathrm{O}$ & & $\mathrm{C}_{3} \mathrm{H}_{5} \mathrm{O}$ & \\
\hline $\mathrm{aC}_{3} \mathrm{H}_{5}$ & & & \\
\hline
\end{tabular}


Section 7: Comparison of the predictions of different models
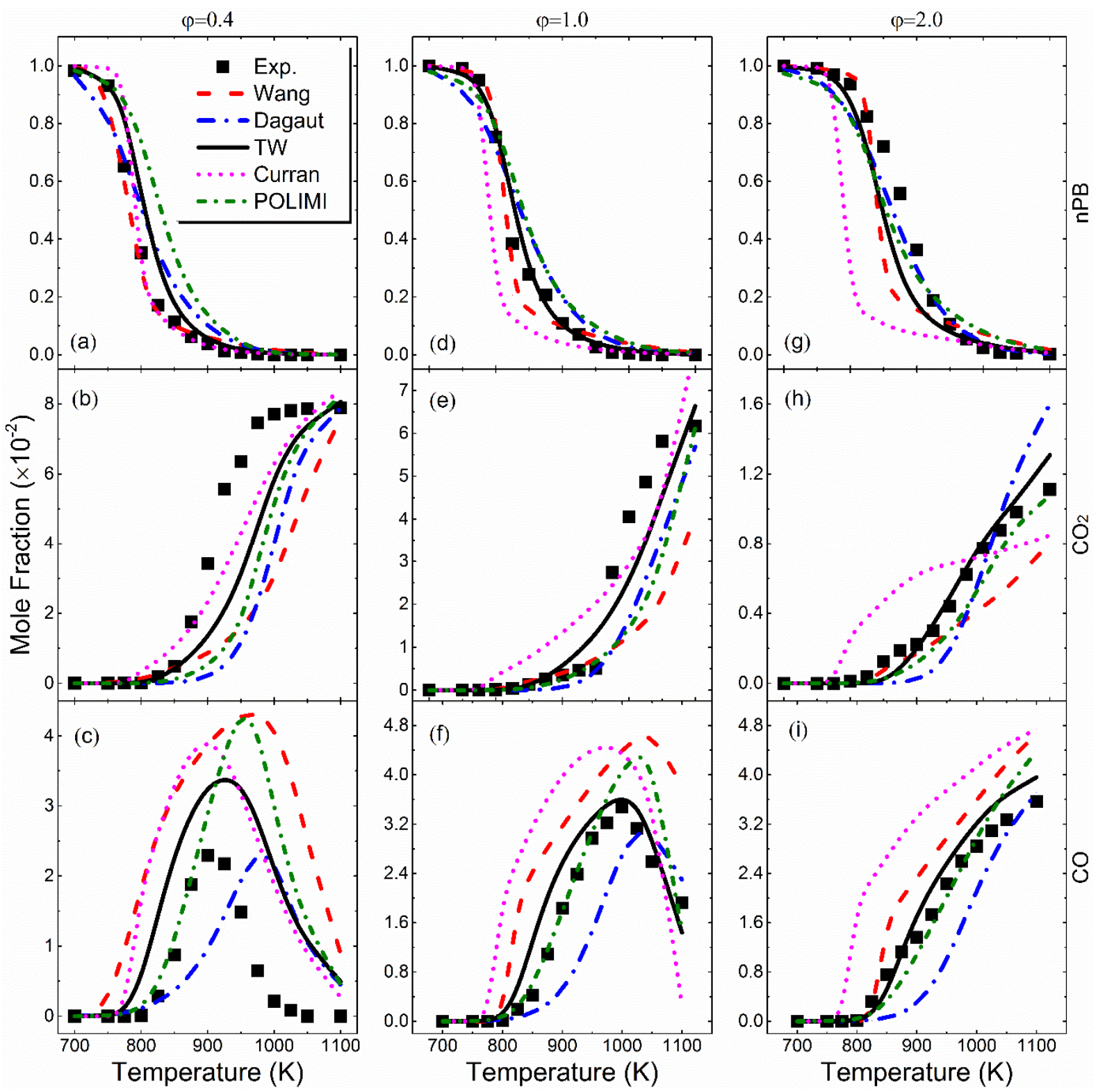

Fig. S7 Comparison between the measured (symbols) and modeling results (curves) of the fuel (NPB - top) and two major products $\left(\mathrm{CO}_{2}-\right.$ medium and $\mathrm{CO}$ - bottom) using three reaction models: Wang et al. [4]- dashed; Dagaut et al. [2] - dash-dotted; this work (TW) solid. Equivalence ratios $\varphi$ from 0.4 (a-c), $1.0(\mathrm{~d}-\mathrm{f})$ and $2.0(\mathrm{~g}-\mathrm{i})$. 


\section{Section 8: The ROP analysis results of the other models}

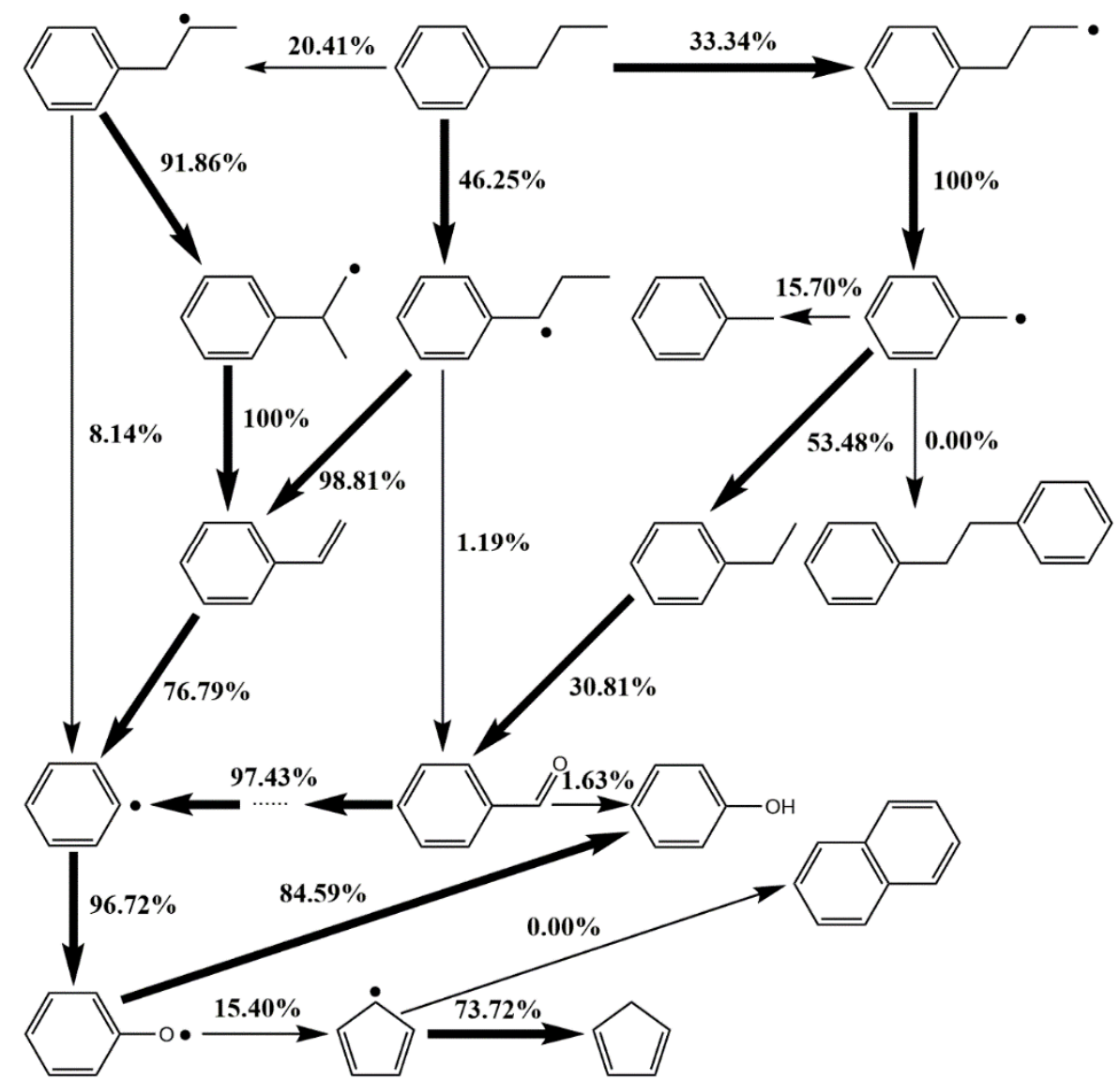

Fig. S8 The ROP analysis from Dagaut's model [2] under $\varphi=2.0$ and temperature of $850 \mathrm{~K}$.

In this ROP analysis, all of bibenzyl was produced from $\mathrm{A}_{1 \mathrm{CH}_{2}}$ and all of naphthalene was produced from $\mathrm{C}_{5} \mathrm{H}_{5}$. Under this condition, only $15.7 \%$ benzyl radical transforms to toluene, as $53.48 \%$ of benzyl transforms to ethylbenzene. This lead the underprediction of toluene. Compared to the ROP of the present model, less radical transforms to toluene and lead more underprediction, shown in Fig. 10. 


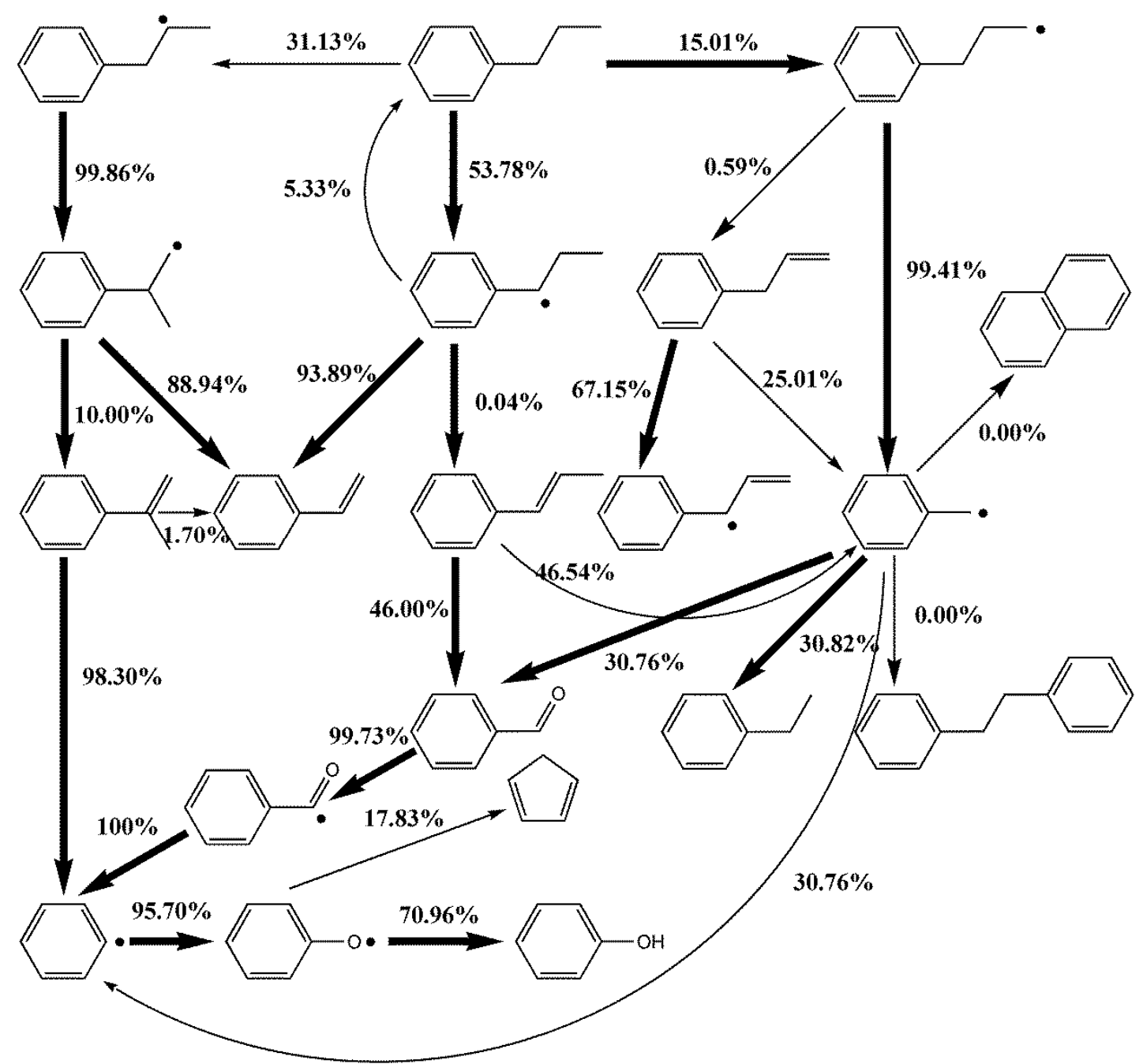

Fig. S9 The ROP analysis from Wang's model [4] under $\varphi=2.0$ and temperature of $850 \mathrm{~K}$.

Considering about the other two models mentioned in previous part, some differences are revealed by ROP analysises. NPB mainly consume by $\mathrm{H}$-abstraction on 1- and 3-position in Dagaut's model, which is similar to the present model. Since the propenylbenzenes have not been considered, the main consumption pathways of NPB yield to ethylbenzene, toluene and benzene. $72.5 \%$ of NPB is consumed via three reactions: $\mathrm{NPB}+\mathrm{OH}=\mathrm{A}_{1} \mathrm{C}_{3} \mathrm{H}_{6}+\mathrm{H}_{2} \mathrm{O}$ in Wang's mechanism, the difference is that 2- position $\mathrm{H}$-abstraction becomes more active than 3- position. The account of the formation of propenylbenzenes is less than $1 \%$. 


\section{References}

[1] American Society for Testing and Meterial, ASTM D7504-2012, Standard test method for trace impurities in monocyclic aromatic hydrocarbon by gas chromatography and effective carbon number [S], West Conshohocken, ASTM International, 2012.

[2] P. Dagaut, A. Ristori, A. El Bakali, M. Cathonnet, Experimental and kinetic modeling study of the oxidation of n-propylbenzene, Fuel 81 (2002) 173-184.

[3] D. Darcy, H. Nakamura, C.J. Tobin, M. Mehl, W.K. Metcalfe, W.J. Pitz, C.K. Westbrook, H.J. Curran, A high-pressure rapid compression machine study of n-propylbenzene ignition, Combust. Flame 161 (2014) 65-74.

[4] Z.D. Wang, Y.Y. Li, F. Zhang, L.D. Zhang, W.H. Yuan, Y.Z. Wang, F. Qi, An experimental and kinetic modeling investigation on a rich premixed n-propylbenzene flame at low pressure, Proc. Combust. Inst. 34 (2013) 1785-1793.

[5] S.M. Burke, W. Metcalfe, O. Herbinet, F. Battin-Leclerc, F.M. Haas, J. Santner, F.L. Dryer, H.J. Curran, An experimental and modeling study of propene oxidation. Part 1: Speciation measurements in jet-stirred and flow reactors, Combust. Flame 161 (2014) 27652784.

[6] P. Diévart, P. Dagaut, The oxidation of n-butylbenzene: Experimental study in a JSR at 10atm and detailed chemical kinetic modeling, Proc. Combust. Inst. 33 (2011) 209-216.

[7] P. Dagaut, F. Karsenty, G. Dayma, P. Diévart, K. Hadj-Ali, A. Mzé-Ahmed, M. BraunUnkhoff, J. Herzler, T. Kathrotia, T. Kick, C. Naumann, U. Riedel, L. Thomas, Experimental and detailed kinetic model for the oxidation of a Gas to Liquid (GtL) jet fuel, Combust. Flame 161 (2014) 835-847.

[8] Z.Y. Tian, W.J. Pitz, R. Fournet, P.A. Glaude, F. Battin-Leclerc, A detailed kinetic modeling study of toluene oxidation in a premixed laminar flame, Proc. Combust. Inst. 33 (2011) 233-261. 